\title{
Title: Therapeutic reversal of prenatal pontine ID1 signaling in DIPG
}

Authors: Viveka Nand Yadav ${ }^{1 *}$, Micah K. Harris ${ }^{1}$, Dana Messinger ${ }^{1}$, Chase Thomas ${ }^{1}$, Jessica

Stallard $^{1}$,Tingting Qin ${ }^{7}$, Brendan Mullan ${ }^{1}$, Ruby Siada ${ }^{1}$, Ramya Ravindran ${ }^{1}$, Michael Niculcea ${ }^{1}$, Kevin F. Ginn ${ }^{8}$, Melissa A.H. Gener ${ }^{9}$, Kathleen Dorris ${ }^{10}$, Nicholas A. Vitanza ${ }^{11}$, Susanne V. Schmidt $^{12}$, Jasper Spitzer ${ }^{12}$, Jiang Li ${ }^{13}$, Mariella G. Filbin ${ }^{13}$, Xuhong Cao ${ }^{14}$, Maria G. Castro ${ }^{15}$, Pedro R. Lowenstein ${ }^{14}$, Rajen Mody ${ }^{1}$, Arul Chinnaiyan ${ }^{13}$, Pierre-Yves Desprez ${ }^{3}$, Sean McAllister ${ }^{3}$, Cynthia Hawkins ${ }^{4}$, Sebastian M. Waszak ${ }^{5,6}$, Sriram Venneti ${ }^{1,14}$, and Carl Koschmann $^{1 *}$

\section{Affiliations:}

${ }^{1}$ Department of Pediatrics, Division of Pediatric Hematology-Oncology, University of Michigan Medical School; Ann Arbor, USA.

${ }^{2}$ Department of Neurology, University of Michigan Medical School; Ann Arbor, USA.

${ }^{3}$ Cancer Research, California Pacific Medical Center Research Institute; San Francisco, USA.

${ }^{4}$ Arthur and Sonia Labatt Brain Tumour Research Centre, Hospital for Sick Children, University of Toronto; Toronto, Canada.

${ }^{5}$ Centre for Molecular Medicine Norway (NCMM), Nordic EMBL Partnership, University of Oslo and Oslo University Hospital; Oslo, Norway.

${ }^{6}$ Department of Pediatric Research, Division of Pediatric and Adolescent Medicine,

Rikshospitalet, Oslo University Hospital; Oslo, Norway.

${ }^{7}$ Department of Computational Medicine and Bioinformatics, University of Michigan Medical School; Ann Arbor, USA.

${ }^{8}$ Department of Pediatrics, Children's Mercy Kansas City; Kansas City, USA.

${ }^{9}$ Department of Pathology and Laboratory Medicine, Children's Mercy Kansas City; Kansas City, USA.

${ }^{10}$ Department of Pediatrics, University of Colorado School of Medicine; Aurora, USA.

${ }^{11}$ Department of Pediatrics, Seattle Children's; Seattle, USA.

${ }^{12}$ Institute of Innate Immunity, AG Immunogenomics, University Bonn; Bonn, Germany.

${ }^{13}$ Department of Pediatric Oncology, Dana-Farber Boston Children's Cancer and Blood Disorders Center; Boston, USA.

${ }^{14}$ Department of Pathology, University of Michigan Medical School; Ann Arbor, USA.

${ }^{15}$ Departments of Neurosurgery and Cell and Developmental Biology, University of Michigan Medical School; Ann Arbor, USA.

*Corresponding author. Viveka Nand Yadav ${ }^{1}, \mathrm{PhD}$ (vyadav@med.umich.edu) and Carl J. Koschmann ${ }^{1}$, MD (ckoschma@med.umich.edu). ${ }^{1}$ Department of Pediatrics, Division of Pediatric Hematology-Oncology, University of Michigan Medical School, 1540 E Hospital Dr., Ann Arbor, Michigan 48109, USA (Tel: 734-936-9814; Fax: 734-232-8740

One Sentence Summary: The transcription factor ID1 is upregulated in a subset of DIPG tumor 
44 Abstract: Diffuse intrinsic pontine glioma (DIPG) is a highly aggressive brain tumor with rare survival beyond two years. This poor prognosis is largely due to the tumor's highly infiltrative and invasive nature. Previous reports demonstrate upregulation of the transcription factor ID1 with $\mathrm{H} 3 \mathrm{~K} 27 \mathrm{M}$ and $A C V R 1$ mutations, but this has not been confirmed in human tumors or therapeutically targeted. We developed an in utero electroporation (IUE) murine H3K27Mdriven tumor model, which demonstrates increased ID1 expression in H3K27M- and ACVR 1mutated tumor cells. In human tumors, elevated ID1 expression is associated with $\mathrm{H} 3 \mathrm{~K} 27 \mathrm{M} / A C V R$ 1-mutation, brainstem location, and reduced survival. The ID1 promoter demonstrates a similar active epigenetic state in H3K27M tumor cells and murine prenatal

53 hindbrain cells. In the developing human brain, ID1 is expressed highest in oligo/astrocyte-

54 precursor cells (OAPCs). These $\mathrm{ID}^{+} / \mathrm{SPARCL1}^{+}$cells share a transcriptional program with astrocyte-like (AC-like) DIPG cells, and demonstrate upregulation of gene sets involved with regulation of cell migration. Both genetic and pharmacologic [cannabidiol (CBD)] suppression of ID1 results in decreased DIPG cell invasion/migration in vitro and invasion/tumor growth in multiple in vivo models. CBD reduces proliferation through reactive oxygen species (ROS) production at low micromolar concentrations, which we found to be achievable in the murine brainstem. Further, pediatric high-grade glioma patients treated off-trial with $\mathrm{CBD}(\mathrm{n}=15)$

61 demonstrate tumor ID1 reduction and improved overall survival compared to historical controls.

62 Our study identifies that IDI is upregulated in DIPG through reactivation of a developmental

63 OAPC transcriptional state, and ID1-driven invasiveness of DIPG is therapeutically targetable with CBD. 
INTRODUCTION pons (1). With a median survival of 10-11 months, DIPG remains the most aggressive primary brain tumor in children (2). Standard of care consists of palliative radiation, and experimental

71 chemotherapies have yet to demonstrate benefit beyond radiation (2). Even with the advent of

72 precision-based medicine, clinical trials targeting specific molecular targets are lacking,

73 highlighting the need to identify novel therapeutic targets in DIPG.

As many as $80 \%$ of DIPGs harbor mutations in histone H3, which leads to a lysine-tomethionine substitution (H3K27M) in H3.3A (H3F3A) and H3C2 (HIST1H3B) $(1,3)$. H3K27M is now understood to define a distinct clinical and biological subgroup in DIPG, and is associated with a worse prognosis (4). The H3K27M mutation represses the polycomb repressive complex 2 (PRC2), resulting in global reduction of $\mathrm{H} 3 \mathrm{~K} 27 \mathrm{me} 3$ (with focal gains) (5) and global increases in acetylation of $\mathrm{H} 3 \mathrm{~K} 27$ (H3K27ac), associated with upregulation of tumor-driving genes $(6,7)$. specific gene expression, and constitutive expression of Inhibitor of DNA binding (ID) proteins have been shown to inhibit the differentiation of multiple tissues (8). ID proteins dimerize with bHLH transcription factors, preventing DNA binding (9). Overexpression of the Inhibitor of

84 DNA binding 1 (IDI) gene has been tied to the pathogenesis of multiple human cancers (10-12). receptor type 1 (ACVR1) signaling, which is recurrently mutated/activated in $25 \%$ of human 
turn increases ID1 expression (16). Prior studies have shown K27M and ACVR1 to upregulate

91 ID1 in cultured human astrocytes and murine models of DIPG $(13,14)$. ID1 has been shown to

92 drive an invasive tumor phenotype in multiple solid tumors $(10,11)$. Invasion into normal

93 pontine tissue is a pathognomonic feature of DIPG, but its regulation remains poorly understood.

94 Further, analysis of ID1 in human DIPG, and its regulation and targetability, have not been

95 previously investigated.

96 In the present study, we show that human DIPGs demonstrate epigenetic activation and

97 increased expression of ID1, influenced by H3K27M and ACVR1 mutational status and brain

98 location. This epigenetic activation mimics ID1 regulation in the developing human and murine

99 prenatal pons. Genetic knockdown and pharmacologic [cannabidiol (CBD)] inhibition of ID1

100 decreases invasion and migration and improves survival in multiple preclinical DIPG models and

101 human patients. These findings represent an exciting new direction for understanding the

102 regulation and targetability of invasion in DIPG, with broad implications for therapeutic

103 targeting of solid tumors with ID1 up-regulation.

105 RESULTS

106 Increased ID1 expression with H3K27M and ACVR1 mutations in murine DIPG tumor

107 model

108 We first sought to confirm whether ID1 expression is affected by the presence of

$109 \mathrm{H} 3 \mathrm{~K} 27 \mathrm{M}$ and $A C V R 1$ mutations. We adopted an in utero electroporation (IUE) model of

110 pediatric high-grade glioma (pHGG), as previously described by our group (17). Mice developed

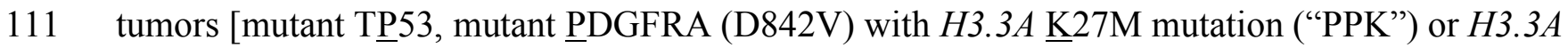

112 wildtype ("PPW”)] via plasmid injection into the lateral ventricles of E13.5 embryonic CD1 
113 mice (Fig. 1A-B). Transfection efficiency and tumor growth/size were monitored using in vivo

114 bioluminescence imaging, and primary neurosphere cell cultures were generated for each group

115 by tumor dissociation (Fig. 1B). Survival analysis revealed that PPK mice $(\mathrm{n}=15)$ had

116 significantly reduced survival compared to their H3 $3^{\text {Wildtype (WT) }}$ counterparts (PPW; n=10) (Fig.

117 1C). Additionally, immunohistochemistry (IHC) and western blot analyses of murine tumors

118 showed tumor-specific expression of H3K27M and global loss of H3K27me3 expression, a

119 salient feature expected in H3K27M-mutant DIPG tumors (Fig. 1D-E) (18). Importantly, ID1

120 expression was elevated in PPK tumors compared to PPW (Fig. 1E). In order to determine the

121 impact of $A C V R 1$ mutation on ID1 expression in DIPG, we introduced $A C V R 1$ mutation via

122 lentiviral (LV) transduction into PPK tumor cells and primary $H 3.3 A \mathrm{~K} 27 \mathrm{M} / A C V R 1^{\mathrm{WT}}$ human

123 DIPG cells (DIPGXIIIp). Western blot analysis revealed increased ID1 expression and SMAD

124 activation with the introduction of $A C V R 1$ mutation in both PPK and DIPGXIIIp tumor cells

125 (Fig. 1F), consistent with previous reports $(13,14)$.

127 ID1 expression increased in human DIPG and associated with lower overall survival

We next assessed the impact of $\mathrm{H} 3 \mathrm{~K} 27 \mathrm{M}(H 3.3 A$ or $H 3 C 2)$ and $A C V R 1$ mutations on

129 IDI expression in DIPG and non-brainstem pHGG. Whole transcriptome sequencing was

130 performed on 34 DIPG and 18 normal post-mortem brain tissue specimens taken from a single

131 institutional cohort (Sick Kids, Toronto). Compared to normal brain (cortex), DIPG tissue

132 showed significantly higher IDI expression (Fig. 1G). Single cell RNA-sequencing (scRNA-seq)

133 data from H3K27M-mutant DIPG tumors [Dana-Farber Cancer Institute (DFCI) cohort (19)]

134 confirmed that malignant cells display significantly higher IDI expression compared to

135 nonmalignant cells within these tumors (Fig. S1A). ScRNA-seq data from H3K27M-pHGG 
136 patients $(\mathrm{n}=14)$ revealed higher IDI expression in pontine H3K27M-DIPG cells compared to

137 thalamic and cortical pHGG tumors (Fig. 1H). This was confirmed in bulk RNA-seq [ICR cohort

138 (Institute for Cancer Research), n=198 (20)], in which brainstem pHGG tumors (DIPG) showed

139 significantly higher IDI expression than cortical pHGGs (Fig. 1I). High IDI expression has been

140 linked to lower overall survival (OS) in multiple cancers (21). Indeed, DIPG patients with

141 higher bulk IDI expression (ICR cohort) have lower OS (Fig. 1J). These data support that ID1 is 142 involved in the pathogenesis of human DIPG.

ID1 expression influenced by $\mathrm{H3}$ and ACVR1 mutational status in human DIPG 
In patients with germline $A C V R$ 1-mutant FOP or DIPG tumors with somatic $A C V R 1$

$160 \mathrm{H} 3 \mathrm{~K} 27 \mathrm{M}$ mutation promoting increased ID1 expression is less understood. We assessed whether

$161 \mathrm{H} 3 \mathrm{~K} 27 \mathrm{ac}$ and $\mathrm{H} 3 \mathrm{~K} 27 \mathrm{me} 3$ marks at regulatory regions of the ID1 gene could be contributing to

162 the increased IDI expression observed in human DIPG. Quantitative PCR (qPCR) demonstrated

163 ID1 expression to be higher in H3K27M and $A C V R$ 1-mutant DIPG autopsy samples ( $\mathrm{n}=4$ tumor

164 sites) compared to $\mathrm{H} 3 \mathrm{WT} / A C V R 1^{\mathrm{WT}}$ DIPG tissue (n=6 tumor sites) and normal brain tissue

165 samples ( $\mathrm{n}=4$ sites) Fig. 2B and S2A-C). ChIP-Seq at the ID1 gene loci on normal adolescent

166 pontine $(n=1), H 3{ }^{\text {WT }}$ DIPG $(n=1)$ and H3K27M DIPG $(n=4)$ samples revealed a marked increase

167 in H3K27ac deposition at ID1 gene body elements in H3K27M DIPG tumor tissue compared to

$168 \mathrm{H} 3^{\mathrm{WT}}$ DIPG tumor and normal pontine tissue, with minimal H3K27me3 marks across the ID1

169 loci in all tissue types (Fig. 2C). Subsequent ChIP-qPCR for quantification (primers in

170 Supplemental Table 1) demonstrated significantly elevated H3K27ac at predicted promotor and

171 gene body regions of the ID1 locus compared to H3WT/ACVR1 ${ }^{\text {WT }}$ DIPG tumor samples (Fig.

172 2D). Decreased H3K27me3 was also observed, though this was only significant at one of the

173 predicted promotor regions between $\mathrm{H} 3 \mathrm{~K} 27 \mathrm{M} / \mathrm{ACVR} 1^{\mathrm{MUT}}$ and $\mathrm{H} 3^{\mathrm{WT}} / \mathrm{ACVR} 1^{\mathrm{WT}}$ DIPG sample

174 groups (Fig. 2E). Taken together, however, the effects of these changes in H3K27ac and

175 K3K27me3 marks correspond with H3K27M-mutant samples being epigenetically activated for

176 ID1 expression.

177 While brainstem tumors broadly show increased IDI expression compared to normal

178 brain, we noted differences in expression by qPCR between multi-focal autopsy samples.

179 Expanded multi-focal (n=6) bulk RNA-sequencing of a single H3K27M/ACVR1-mutant DIPG

180 patient (UMPED12) confirmed varying levels of $I D 1$ expression across different regions of the 
181 tumor (Fig. 2F). This finding led us to analyze scRNA-seq in order to determine whether a

182 specific malignant cell subpopulation could be contributing to the increased IDI expression seen

183 in DIPG. Assessment of IDI expression across all malignant cell types in DIPG cells from four

184 patients showed that IDI is most highly expressed in DIPG cells with an astrocytic

185 differentiation program [“AC-like cells" (19)], followed by oligodendrocyte precursor cell-like

186 ("OPC-like") cells (Fig. 2G and S3A). OPC-like cells are known to constitute the majority of

187 cycling cells in DIPG (19). Previous analysis showed that nearly all cycling DIPG cells have an

188 OPC-like phenotype (19) and we observed higher levels of IDI expression in cycling compared

189 to non-cycling cells (Fig. S3B).

\section{Single-cell transcriptional analysis of $\mathrm{ID1}^{+}$cells in human developing brain and $\mathrm{H3K27M}$}

\section{tumors}

Anatomic location and developmental context strongly influence the formation of many

194 pediatric tumors, including DIPG. We next assessed IDI expression and histone modifications

195 across pre- and post-natal mouse brain developmental stages. RNA in-situ hybridization data

196 (Allen Brain Atlas) demonstrated ID1 to be highest expressed in the developing prenatal mouse

197 hindbrain (including the developing pons) compared to forebrain or midbrain, with minimal IDI

198 expression throughout the entire postnatal mouse brain (Fig. 3A-B and S4). In E15.5 mouse

199 brains, ENCODE data $(23,24)$ revealed H3K27ac to be elevated at IDI enhancer sites in the

200 hindbrain compared to midbrain and forebrain (Fig. S5A-B).

Analysis of developing human (25) and mouse (26) brain scRNA-seq data showed that

202 IDI expression peaks at gestational week (GW) 12-22 in the human pons (Fig. 3C) and early

203 postnatal mouse pons (P0; Fig. S6-S7), and is most highly expressed in astrocytes. ID1 
expression is also high in human endothelial cells, consistent with previous data (Fig. 3C) (27).

IHC analyses of pre- and post-natal brains confirmed elevated ID1 in the murine embryonic

brain (E18; Fig. 3D) and human GW 20.5 brain (Fig. 3E) in subventricular regions lining the $4^{\text {th }}$ ventricle, compared to all postnatal brain locations.

211 defined OAPC cell population (28) in the developing human brain (Fig. 3F). The OAPC program

212 was not enriched in OPC-like cells in any of the four DIPG tumors (Fig. 3F). OAPCs are present

213 primarily in the outer subventricular zone during the neurogenesis-to-gliogenesis switch period

214 and express both astrocyte (GFAP) and oligodendrocyte (OLIG1, OLIG2) marker genes as well

215 as SPARCL1, which is involved in regulation of cell adhesion (28). We found IDI to be a

216 marker gene for both AC-like DIPG cells and OAPCs. Immunofluorescence of human H3K27M-

217 DIPG samples revealed co-localization of ID1 and SPARCL1 expression in sub-populations of

218 cells (Fig. 3G). Assessment of SPARCL1 expression across all malignant cell types in DIPG

219 cells from four patients showed that SPARCL1 is most highly expressed in AC-like DIPG cells.

220 Importantly, AC-like DIPG cells demonstrate enrichment of gene sets involved in regulation of

221 cell adhesion and migration (Fig. S9), further implicating the potential role of $I D 1^{+} \mathrm{AC}-$ like cells

222 in the regulation of DIPG tumor cell invasion and migration.

To examine the phenotypic impact of IDI in human DIPG cells, a patient-derived DIPG 
ID1-targeting shRNA or scrambled shRNA control (Fig. 4A). ID1 knockdown (shRNA-64) resulted in reduced SPARCL1 expression in DIPG007 cells by western blot, further implicating the role of $I D I$ in the regulation of this OAPC/AC-like cell marker gene (Fig. 4B). IDI knockdown significantly reduced DIPG007 invasion (Fig. 4C) and migration, as measured by

231 scratch assay percent wound closure (Fig. 4D-E). In comparison, invasion and migration of

232 human embryonic kidney cell line HEK293 was not affected upon ID1 knockdown (Fig. S10A233 C).

A few compounds that reduce IDI expression include Cannabidiol (CBD), Pimozide, 2Methoxyestradiol and MK615 (29-31). Of these, CBD is the most studied, clinically available and CNS-penetrant agent $(32,33)$. CBD is the non-psychoactive compound found in Cannabis sativa (34). CBD has wide-ranging impacts on cellular behavior, including the ability to downregulate expression of $I D I$ and to inhibit invasion in multiple pre-clinical cancer models $(12,35-37)$. Based on these studies, we sought to investigate the targeting of ID1 in DIPG through use of CBD. Treatment of human DIPG007 and mouse PPK cells with CBD reduced

241 ID1 expression (Fig. 4F) and cell viability (Fig. 4G), with an $\mathrm{IC}_{50}$ of 2.4 and $2.5 \mu \mathrm{M}$,

242 respectively. We also treated two additional human DIPG cell cultures with H3K27M/ACVR1 WT 243 status, DIPGXIIIp and PBT-29, with CBD, and found reductions in cell viability at an IC 50 of 6.8 244 and $7.2 \mu \mathrm{M}$, respectively (Fig. S11A-B). Additionally, CBD treatment resulted in significantly 245 reduced invasion and migration of human DIPG007 cells (Fig. 4H-I and S12A-B) and human 246 PBT-29 cells (Fig. S12C-F) in the 5-10 uM range. CBD has been reported to increase intracellular levels of reactive oxygen species (ROS)

248 (38). In line with this, our data reveal that DIPG007 cells treated with CBD show a dose 249 dependent increase in ROS levels (Fig. 4J). Additional treatment with $\alpha$-tocopherol (TOC), a 
ROS scavenger $(37,38)$, severely restricted the ability of CBD to inhibit proliferation of

251 DIPG007 cells (Fig. 4K).

Genetic knockdown of ID1 in IUE murine model

In order to assess whether IDI suppression would impede tumor growth in PPK mice, we developed a PBase-responsive ID1-shRNA plasmid and scrambled short hairpin ("sh-control”).

PPK-ShID1 tumors. PPK-ShID1 tumors also exhibited more distinct tumor borders (e.g. reduced

261 tumor invasion into normal brain) in vivo (Fig. 5F). Implantation of DIPG007 cells with ShID1

262 (or control) into the brainstem of NSG mice also demonstrated reduced pace of luminescent

263 growth (Fig. S13A-C), although this did not affect overall tumor survival. These data indicate

264 that genetic ID1 knockdown inhibits tumor growth in vivo and reduces tumor invasion and 265 proliferation.

\section{Pharmacological inhibition of ID1 with Cannabidiol (CBD) in IUE murine model}

We next proceeded to our IUE PPK murine model to assess the impact of CBD in vivo.

269 We performed daily treatment with CBD $(15 \mathrm{mg} / \mathrm{kg})$, or vehicle control. CBD treatment

270 significantly improved median survival compared to vehicle control (Fig. 6A). Moribund tumors

271 treated with $\mathrm{CBD}$ showed reductions in ID1 and Ki67 expression following CBD treatment (Fig. 
273 compared to vehicle-treated mice (Fig. S14). Both genetic (ShID1) and pharmacologic (CBD)

274 knockdown of ID1 in murine models resulted in reduced tumor infiltration into the contralateral

275 hippocampus compared to controls (Fig. 6D). These data indicate that CBD reduces ID1

276 expression and tumor invasion and significantly improves survival of H3K27M-mutant tumors in

277 vivo.

We next assed the pharmacokinetic distribution of CBD in normal brain and brain tumor

280 concentration of CBD in the brainstem and plasma (6 and $7 \mathrm{uM}$, respectively) (Fig. 6G), which is

281 above the previously determined $\mathrm{IC}_{50}$ dose of CBD in our DIPG cells. At 2 hours, we found

282 equivalent doses of CBD in plasma, brain and brain tumor samples in our PPK model (Fig. 6H).

\section{CBD treatment in pHGG patients}

$\mathrm{CBD}$ is increasingly popular as an off-trial, non-prescribed therapy among patients with

pHGG (39), including DIPG. However, its use remains controversial as no preclinical efficacy,

287 mechanistic data, dosing or clinical studies of CBD in DIPG have been performed. We gathered

288 patient-reported CBD dosing from families of $\mathrm{pHGG}$ patients at two institutions ( $\mathrm{n}=15$ total, $\mathrm{n}=8$

289 DIPG, n=11 H3K27M), including patients on an IRB-approved prospective observational study

290 at Children's Hospital of Colorado for children and young adults with brain tumors undergoing

291 patient-directed medical marijuana therapy (NCT03052738), and retrospective interviews with

292 families of patients who underwent research autopsy at the University of Michigan. CBD was

293 obtained through medical and recreational marijuana dispensaries without prescription; and

294 given orally in all but one case (suppository) one to three times per day with a wide range of

295 dosing (0.07 mg/kg to $25 \mathrm{mg} / \mathrm{kg} /$ day, Fig. 7A). No parents reported adverse effects from the 
CBD aside from taste, and some reported improved nausea and anxiety control. We performed

297 ID1 staining on autopsy samples from high-dose and low-dose H3K27M-mutant tumors. As

298 representative cases, patient UMPED83, with the highest reported dosing (25 mg/kg/day CBD),

299 demonstrated reduced ID1 staining on autopsy sample (Fig. 7B), while UMPED86 underwent

300 low dosing (0.4 mg/kg/day) and demonstrated strong nuclear ID1 staining (Fig. 7C). Patients

301 with pHGG undergoing CBD treatment showed variable ID1 staining in post-mortem tumor

302 tissue, but lower average expression with higher-dose ( $>3 \mathrm{mg} / \mathrm{kg} /$ day) treatments (Fig. 7D).

303 Patients with H3K27M-mutant tumors treated with CBD $(n=10)$ showed improved

304 survival compared to historical controls (20), in both high ( $>3 \mathrm{mg} / \mathrm{kg} /$ day) and low ( $<3$

$305 \mathrm{mg} / \mathrm{kg} /$ day) CBD treatment groups (Fig. 7E, Supplemental Table 2). These data represent the

306 promise and feasibility of CBD treatment in DIPG, with the clear need for further data in a

307 prospective therapeutic clinical trial.

\section{DISCUSSION}

ID proteins are necessary for appropriate tissue differentiation during embryogenesis, and

311 IDI is highly expressed in the normal developing brain followed by quiescence of IDI

312 expression in CNS tissue postnatally (40). Consistent with the role of ID1 in the pathogenesis of

313 multiple human diseases and cancers (40-42), our data indicate that ID1 promotes invasion in

314 DIPG cells, which is a disease-defining feature of this infiltrative tumor. We propose a model by

315 which ID1 is upregulated through multiple mechanisms (H3K27M, ACVR1, region/micro-

316 environment) in order to "re-activate" prenatal brain developmental signaling. Our data support

317 that $I D 1^{+}$AC-like DIPG tumor cells hijack the transcriptional program of developmental $I D 1^{+}$

318 OAPC cells in the developing brain cells to produce a "migratory" transcriptional cell state (Fig. 
8). We also demonstrate the ability to reverse this ID1-driven phenotype with CBD treatment, and the potential for optimization of this therapeutic targeting.

Our studies implicate an active epigenetic state at the IDI locus shared between H3K27M tumor cells and the prenatal precursor brain cells, which is consistent with prior studies focused on $\mathrm{H} 3 \mathrm{~K} 27 \mathrm{M}$ mutations that have associated changes in $\mathrm{H} 3 \mathrm{~K} 27 \mathrm{ac} / \mathrm{H} 3 \mathrm{~K} 27 \mathrm{me} 3$ with differential regulation of key DIPG-associated genes $(43,44)$. Additionally, we provide evidence that postnatal activation of ID1 in tumor cells replicates a prenatal "migratory" transcriptional state seen in a recently discovered subset of developing OAPC brain cells. These OAPCs $\left(\right.$ Olig $^{+}$ SPARCL $1^{+} \mathrm{HOPX} X^{+}$glial progenitor cells) were recently identified as astrocyte-like at the molecular and transcriptional levels (28). In line with this, we found AC-like DIPG cells to transcriptionally mimic the program of OAPCs, with the OAPC-marker SPARCL1 and IDI co-

330 localizing in a subset of H3K27M tumor cells. Interestingly, previous work has suggested a role

331 for SPARCL1 in promoting DIPG cell invasion into the subventricular zone (SVZ) (45).

332 Secretion of SPARCL1 and pleiotrophin from neural precursor cells (NPCs) was shown to act as 333 a chemoattractant for the DIPG cells, encouraging their infiltration into the SVZ (45). Our data 334 demonstrate that IDI is most highly expressed by non-cycling AC-like cells in DIPG tumors and 335 SPARCL1 is one of the strongest expression markers of these cells. This raises the possibility that 336 SPARCL1 is expressed/secreted within DIPG cells, further coordinating or contributing to the 337 invasion of DIPG tumor cells. While further studies are needed to confirm an ID1-driven 338 OAPC/AC-like cellular state, our data raise important insights into the mechanisms underlying 339 one of the most critical and problematic features of DIPG tumors: invasion. 
342 invasion into normal brainstem tissue that is observed histologically in DIPGs, and with the role

343 of ID1 in other cancers $(11,42)$. In our experiments involving both genetically-engineered and

344 intracranial implantation models, H3K27M-mutant tumors cells with ID1 reduction show

345 reduced tumor growth and invasion.

Cannabidiol is a non-toxic and non-psychoactive member of the endocannabinoid family

347 found in Cannabis sativa. CBD has been observed to reduce IDI transcription in pre-clinical

348 models of adult cancers (12). In the present study, CBD reduced DIPG cell viability

349 and IDI expression at concentrations that are likely clinically achievable in the human brain. Our

350 PK studies demonstrated peak brain concentrations of CBD above established $\mathrm{IC}_{50}$, despite use

351 of a human equivalent doses (46) of only $3 \mathrm{mg} / \mathrm{kg}$, which is well below previously tolerated

352 human CBD dosing. In a phase 1 study, adult patients showed excellent tolerance of oral CBD at

$353750 \mathrm{mg}(15 \mathrm{mg} / \mathrm{kg})$ daily with some non-dose limiting increases in diarrhea and somatic

354 symptoms (muscle ache, fatigue) at $1500 \mathrm{mg}(30 \mathrm{mg} / \mathrm{kg}$ ) daily (47). This resulted in peak plasma

355 concentrations of CBD of $1-5 \mathrm{uM}(15 \mathrm{mg} / \mathrm{kg})$ and $1.7-10 \mathrm{uM}(30 \mathrm{mg} / \mathrm{kg})$ depending on fat

356 content in diet (47). Our data showed equivalent plasma and brain concentrations of CBD after

357 IP administration. Previous work has shown that oral administration of CBD in mice results in a

358 3-4-fold higher concentration in the brain than plasma, likely due to the high lipophilicity of

359 CBD (35). CBD is already being used for palliative purposes in pediatric oncology, and CBD has

360 been shown to decrease IDI expression and associated oncogenic phenotypes in multiple other

361 cancers in vivo $(11,12,48)$. Mechanistically, our data suggest that CBD acts to regulate ID1

362 expression and DIPG cell proliferation partially through increasing intracellular levels of ROS,

363 as previous studies have shown CBD to act through this mechanism in both breast cancer and

364 GBM cells $(37,38)$. 
367 limited by the retrospective and heterogeneous nature of our cohort, as well as an unknown

368 number of historical controls that may also have underwent treatment with CBD. Nevertheless,

369 our data make significant strides in establishing the mechanism of this controversial and popular

370 off-trial supplemental compound in high-risk brain tumor patients, and lays the groundwork for

371 future clinical trials. A recent CBD formulation (Epidiolex) has been FDA-approved for epilepsy

372 treatment (49), opening the door to a future clinical trial in DIPG (and other ID1-driven tumors).

373 Our data support a model in which multifactorial genetic and epigenetic processes

374 promote ID1-driven prenatal development transcriptional programs, which also promote the

375 invasive features of DIPG. These results improve our understanding of the pathogenesis of DIPG

376 tumors and provide a strong argument for the inclusion of ID1-targeting therapies into future

377 treatments.

\section{METHODS}

\section{Study design}

The objective of this work was to investigate the role of ID1 in the highly-invasive nature

382 of DIPG and to determine the in vivo antitumor efficacy of genetic and pharmacologic inhibition

383 of ID1 using our IUE H3.3A-K27M-mutated murine tumor model. We performed a

384 comprehensive analysis of IDI expression by RNA-sequencing of DIPG tissue samples with

$385 \mathrm{H} 3^{\mathrm{WT}}, \mathrm{H} 3 \mathrm{~K} 27 \mathrm{M} / \mathrm{ACVR} 1^{\mathrm{WT}}$, or H3K27M/ACVR ${ }^{\mathrm{MUT}}$. We next performed an integrative analysis

386 of H3K27ac and H3K27me3 deposition at the ID1 gene locus by performing Mint-ChIP-

387 sequencing on these DIPG samples. We further performed transcriptional program analyses of 
ID1-expressing DIPG tumor cells using publicly-available scRNA-seq datasets. To test the in vivo impact of ID1 inhibition, we performed IDI knockdown in our PPK tumor model. In vivo

390 pharmacological inhibition of ID1 in our PPK tumor model was performed with CBD. Sample

391 size and any data inclusion/exclusion were defined individually for each mouse experiment. The

392 number of replicates varied between experiments and is presented in figure legends. We

393 performed blinding for quantitative immunohistochemistry scoring of ID1 and Ki67 staining.

394 Finally, we measured ID1 expression in DIPG patient samples which underwent different doses

395 of CBD (non-prescribed) during the course of treatment (Supplement Table 2).

\section{Murine IUE model of pHGG}

All animal studies were conducted according to the guidelines approved by the

400 IUE was performed using sterile technique on isoflurane/oxygen-anesthetized pregnant CD1

401 females at embryonic stage E13.5, using established methodology. In this study, we injected the

402 following four plasmids together: [1] PBase, [2] PB-CAG-DNp53-Ires-Luciferase (dominant negative TP53 or TP53 hereafter), [3] PB-CAG-PdgfraD824V-Ires-eGFP (PDGFRA D842V), and [4] PB-CAG-H3.3 K27M-Ires-eGFP (H3K27M), referred to as "PPK" model (as previously published) (17) (see Supplementary for details).

\section{Whole exome and transcriptome sequencing (Sick Kids, Toronto)}


411 was used for total RNA extraction with the RNeasy mini kit (QIAGEN, CA, USA) (see

412 Supplementary for details).

\section{Mint-ChIP-sequencing}

Analyses for the two classical histone modifications H3K27ac and H3K27me3

416 representing accessible and repressed chromatin states were performed as part of a MiNT-ChIP

417 analysis for 9 tumor samples of DIPG patients in comparison to a control tissue sample of

418 healthy pons according to the protocol published by Buenstro et al., 2013 (see Supplementary for 419 details).

\section{ScRNA-seq analysis from developing brain and H3K27M-mutant DIPGs}

Single-cell gene expression data and their clusters in the developing brain were obtained

from GSE133531 (mouse pons), GSE120046 (human pons, gestational week 8-28), and

GSE144462 (human cortex, gestational week 21-26) (see Supplementary for details).

\section{Native ChIP-qPCR}

Native ChIP-qPCR was performed on post-mortem tissue using antibodies against H3K27ac (2 $\mu$, cat\# 07360, Millipore Sigma), H3K27me3 (1 $\mu$ g, cat\# 07449, Millipore Sigma), and control IgG (2 $\mu \mathrm{g}$ Cat\#12370, Millipore Sigma) (see Supplementary for details).

\section{Invasion assay}


436 Migration (scratch) assay

437 Scratches were made in 80\%-confluent 6-well plates, and migration was monitored using

438 the IncuCyte ${ }^{\circledR}$ system (see Supplementary for details).

\section{CBD treatment studies in murine IUE PPK model}

Mice harboring IUE-generated PPK HGG tumors were treated with CBD when tumors

442 reached logarithmic growth phase (minimum $2 \times 10^{6}$ photons/sec via bioluminescent imaging).

443 Mice litters from each experimental group were randomized to treatment with: (A) $15 \mathrm{mg} / \mathrm{kg}$

444 CBD (10\% CBD suspended in Ethanol, 80\% DPBS, 10\% Tween-80) and (B) control treatment

445 (10\% Ethanol, 80\% DPBS, 10\% Tween-80). Mice were treated 5 days/week until morbidity (see

446 Supplementary for details).

\section{CBD pharmacokinetic analysis}

CBD administration to non-tumor bearing CD1 mice and PPK tumor bearing mice for PK studies were performed by IP injection at zero time point. Timeline for CBD injection and

451 plasma, brainstem and/or tumor collection were depicted in Fig. 7 E-F (see Supplementary for 452 details).

\section{$454 \quad$ Human studies}


457 Children's Hospital of Colorado for children and young adults with brain tumors undergoing

458 patient-directed medical marijuana therapy (NCT03052738) (see Supplementary for details).

Fig. S1. ID1 expression in DIPG by cell malignancy and tumor location.

Fig. S2. Multifocal ChIP-qPCR analysis of ID1 expression in human DIPG.

Fig. S3. ID1 expression from scRNA-seq of six different H3K27M-DMG patients across varying regions and malignant cell types.

Fig. S4. In situ hybridization for IDI RNA in developing mouse brain.

Fig. S5. H3K27ac at ID1 locus during murine development. normal developing murine pons. across varying malignant cell types.

Fig. S10. ID1 knockdown in HEK293 cells.

Fig. S11. Impact of CBD treatment on ID1 expression in human DIPG cells. 
Fig. S12. Effect of pharmacologic (CBD) suppression of ID1 on DIPG007 and PBT-29 tumor cell invasion and migration.

Fig. S13. ID1-deficient DIPG007 cells display slower in vivo tumor growth.

Fig. S14. Tumor cell invasion assessment in CBD- vs control-treated PPK mice.

Fig. S15. Detailed vector map of pGIPZ lentiviral vector.

Table S1. Primer sequences for use in ChIP-qPCR and qPCR.

Table S2. Clinical details of pHGG patients treated with CBD.

\section{References and Notes}

487 1. K. M. Schroeder, C. M. Hoeman, O. J. Becher, Children are not just little adults: recent 488 advances in understanding of diffuse intrinsic pontine glioma biology. Pediatr Res $\mathbf{7 5}$, 205-209 (2014).

$490 \quad$ 2. Z. Miklja, A. Pasternak, S. Stallard, T. Nicolaides, C. Kline-Nunnally, B. Cole, R. Beroukhim, P. Bandopadhayay, S. Chi, S. H. Ramkissoon, B. Mullan, A. K. Bruzek, A. pediatric gliomas: review and consensus recommendations. Neuro Oncol, (2019).

495 3. D. Castel, C. Philippe, R. Calmon, L. Le Dret, N. Truffaux, N. Boddaert, M. Pages, K. R. 
HIST1H3B K27M mutations define two subgroups of diffuse intrinsic pontine gliomas with different prognosis and phenotypes. Acta Neuropathol 130, 815-827 (2015).

500 4. D. A. Khuong-Quang, P. Buczkowicz, P. Rakopoulos, X. Y. Liu, A. M. Fontebasso, E. Bouffet, U. Bartels, S. Albrecht, J. Schwartzentruber, L. Letourneau, M. Bourgey, G.

507 5. K. M. Chan, D. Fang, H. Gan, R. Hashizume, C. Yu, M. Schroeder, N. Gupta, S. Mueller,

511 6. F. Mohammad, S. Weissmann, B. Leblanc, D. P. Pandey, J. W. Hojfeldt, I. Comet, C.

516 7. S. Nagaraja, M. A. Quezada, S. M. Gillespie, M. Arzt, J. J. Lennon, P. J. Woo, V. 
8. J. D. Norton, R. W. Deed, G. Craggs, F. Sablitzky, Id helix-loop-helix proteins in cell growth and differentiation. Trends Cell Biol 8, 58-65 (1998).

9. R. Benezra, R. L. Davis, D. Lockshon, D. L. Turner, H. Weintraub, The protein Id: a negative regulator of helix-loop-helix DNA binding proteins. Cell 61, 49-59 (1990).

10. S. Fong, R. J. Debs, P. Y. Desprez, Id genes and proteins as promising targets in cancer therapy. Trends Mol Med 10, 387-392 (2004).

11. L. Soroceanu, R. Murase, C. Limbad, E. Singer, J. Allison, I. Adrados, R. Kawamura, A. aggressiveness and a novel therapeutic target. Cancer Res 73, 1559-1569 (2013). as a novel inhibitor of Id-1 gene expression in aggressive breast cancer cells. Mol Cancer

533 13. P. Buczkowicz, C. Hoeman, P. Rakopoulos, S. Pajovic, L. Letourneau, M. Dzamba, A. Barszczyk, Y. Chornenkyy, M. Bourgey, G. Bourque, A. Montpetit, F. Cordero, P. 
14. C. M. Hoeman, F. J. Cordero, G. Hu, K. Misuraca, M. M. Romero, H. J. Cardona, J. Nazarian, R. Hashizume, R. McLendon, P. Yu, D. Procissi, S. Gadd, O. J. Becher, ACVR1 R206H cooperates with H3.1K27M in promoting diffuse intrinsic pontine glioma pathogenesis. Nat Commun 10, 1023 (2019).

15. J. Fortin, R. Tian, I. Zarrabi, G. Hill, E. Williams, G. Sanchez-Duffhues, M. Thorikay, P. Ramachandran, R. Siddaway, J. F. Wong, A. Wu, L. N. Apuzzo, J. Haight, A. You-Ten,

16. B. Schmierer, C. S. Hill, TGF $\beta-$ SMAD signal transduction: molecular specificity and

18. P. W. Lewis, M. M. Muller, M. S. Koletsky, F. Cordero, S. Lin, L. A. Banaszynski, B. A. 
Rosen, K. W. Wucherpfennig, D. N. Louis, M. Monje, I. Slavc, K. L. Ligon, T. R. Golub, A. Regev, B. E. Bernstein, M. L. Suva, Developmental and oncogenic programs in H3K27M gliomas dissected by single-cell RNA-seq. Science 360, 331-335 (2018).

20. A. Mackay, A. Burford, D. Carvalho, E. Izquierdo, J. Fazal-Salom, K. R. Taylor, L. Bjerke, M. Clarke, M. Vinci, M. Nandhabalan, S. Temelso, S. Popov, V. Molinari, P. Raman, A. J. Waanders, H. J. Han, S. Gupta, L. Marshall, S. Zacharoulis, S. Vaidya, H. C. Mandeville, L. R. Bridges, A. J. Martin, S. Al-Sarraj, C. Chandler, H. K. Ng, X. Li, K. Mu, S. Trabelsi, D. H. Brahim, A. N. Kisljakov, D. M. Konovalov, A. S. Moore, A. M. Carcaboso, M. Sunol, C. de Torres, O. Cruz, J. Mora, L. I. Shats, J. N. Stavale, L. T. Bidinotto, R. M. Reis, N. Entz-Werle, M. Farrell, J. Cryan, D. Crimmins, J. Caird, J. Pears, M. Monje, M. A. Debily, D. Castel, J. Grill, C. Hawkins, H. Nikbakht, N. Jabado, S. J. Baker, S. M. Pfister, D. T. W. Jones, M. Fouladi, A. O. von Bueren, M. Baudis, A. Resnick, C. Jones, Integrated Molecular Meta-Analysis of 1,000 Pediatric High-Grade and Diffuse Intrinsic Pontine Glioma. Cancer Cell 32, 520-537 e525 (2017).

21. S. F. Schoppmann, M. Schindl, G. Bayer, K. Aumayr, J. Dienes, R. Horvat, M. Rudas, M. Gnant, R. Jakesz, P. Birner, Overexpression of Id-1 is associated with poor clinical outcome in node negative breast cancer. Int J Cancer 104, 677-682 (2003).

22. G. Wu, A. K. Diaz, B. S. Paugh, S. L. Rankin, B. Ju, Y. Li, X. Zhu, C. Qu, X. Chen, J. Zhang, J. Easton, M. Edmonson, X. Ma, C. Lu, P. Nagahawatte, E. Hedlund, M. Rusch, S. Pounds, T. Lin, A. Onar-Thomas, R. Huether, R. Kriwacki, M. Parker, P. Gupta, J. Becksfort, L. Wei, H. L. Mulder, K. Boggs, B. Vadodaria, D. Yergeau, J. C. Russell, K. Ochoa, R. S. Fulton, L. L. Fulton, C. Jones, F. A. Boop, A. Broniscer, C. Wetmore, A. Gajjar, L. Ding, E. R. Mardis, R. K. Wilson, M. R. Taylor, J. R. Downing, D. W. Ellison, 
J. Zhang, S. J. Baker, The genomic landscape of diffuse intrinsic pontine glioma and pediatric non-brainstem high-grade glioma. Nat Genet 46, 444-450 (2014).

23. E. P. Consortium, An integrated encyclopedia of DNA elements in the human genome. Nature 489, 57-74 (2012).

24. C. A. Davis, B. C. Hitz, C. A. Sloan, E. T. Chan, J. M. Davidson, I. Gabdank, J. A. Hilton, K. Jain, U. K. Baymuradov, A. K. Narayanan, K. C. Onate, K. Graham, S. R.

25. X. Fan, Y. Fu, X. Zhou, L. Sun, M. Yang, M. Wang, R. Chen, Q. Wu, J. Yong, J. Dong, 
610 27. D. Lyden, A. Z. Young, D. Zagzag, W. Yan, W. Gerald, R. O'Reilly, B. L. Bader, R. O.

611 Hynes, Y. Zhuang, K. Manova, R. Benezra, Id1 and Id3 are required for neurogenesis, 612 angiogenesis and vascularization of tumour xenografts. Nature 401, 670-677 (1999).

613 28. Y. Fu, M. Yang, H. Yu, Y. Wang, X. Wu, J. Yong, Y. Mao, Y. Cui, X. Fan, L. Wen, J.

614 Qiao, F. Tang, Heterogeneity of glial progenitor cells during the neurogenesis-to-

615 gliogenesis switch in the developing human cerebral cortex. Cell Rep 34, 108788 (2021).

616 29. R. Sachdeva, M. Wu, S. Smiljanic, O. Kaskun, K. Ghannad-Zadeh, A. Celebre, K. Isaev, 617 A. S. Morrissy, J. Guan, J. Tong, J. Chan, T. M. Wilson, S. Al-Omaishi, D. G. Munoz, P. 618 B. Dirks, M. F. Moran, M. D. Taylor, J. Reimand, S. Das, ID1 Is Critical for 619 Tumorigenesis and Regulates Chemoresistance in Glioblastoma. Cancer Res 79, 4057$620 \quad 4071(2019)$.

621 30. K. Tada, K. Kawahara, S. Matsushita, T. Hashiguchi, I. Maruyama, T. Kanekura, 622 MK615, a Prunus mume Steb. Et Zucc ('Ume') extract, attenuates the growth of A375 melanoma cells by inhibiting the ERK1/2-Id-1 pathway. Phytother Res 26, 833-838 (2012).

625 31. J. I. Huh, A. Calvo, R. Charles, J. E. Green, Distinct tumor stage-specific inhibitory 626 effects of 2-methoxyestradiol in a breast cancer mouse model associated with Id-1 627 expression. Cancer Res 66, 3495-3503 (2006).

628 32. F. Afrin, M. Chi, A. L. Eamens, R. J. Duchatel, A. M. Douglas, J. Schneider, C. Gedye, 629 A. S. Woldu, M. D. Dun, Can Hemp Help? Low-THC Cannabis and Non-THC 630 Cannabinoids for the Treatment of Cancer. Cancers (Basel) 12, (2020).

631 33. G. Wilkie, B. Sakr, T. Rizack, Medical Marijuana Use in Oncology: A Review. JAMA 632 Oncol 2, 670-675 (2016). 
633 34. M. M. Bergamaschi, R. H. Queiroz, A. W. Zuardi, J. A. Crippa, Safety and side effects of cannabidiol, a Cannabis sativa constituent. Curr Drug Saf 6, 237-249 (2011).

635 35. S. Deiana, A. Watanabe, Y. Yamasaki, N. Amada, M. Arthur, S. Fleming, H. Woodcock,

641 36. O. Kovalchuk, I. Kovalchuk, Cannabinoids as anticancer therapeutic agents. Cell Cycle 19, 961-989 (2020).

643 37. S. D. McAllister, R. Murase, R. T. Christian, D. Lau, A. J. Zielinski, J. Allison, C. oncology 2, 670-675 (2016).

652 40. S. F. Tzeng, J. de Vellis, Id1, Id2, and Id3 gene expression in neural cells during development. Glia 24, 372-381 (1998).

654 41. M. T. Ling, X. Wang, X. Zhang, Y. C. Wong, The multiple roles of Id-1 in cancer 
656

657

658

659

660

661

662

663

664

665

666

667

668

669

670

671

672

673

674

675

676

677

42. R. Sachdeva, M. Wu, S. Smiljanic, O. Kaskun, K. Ghannad-Zadeh, A. Celebre, K. Isaev, A. S. Morrissy, J. Guan, J. Tong, J. Chan, T. M. Wilson, S. Al-Omaishi, D. G. Munoz, P. B. Dirks, M. F. Moran, M. D. Taylor, J. Reimand, S. Das, ID1 Is Critical for Tumorigenesis and Regulates Chemoresistance in Glioblastoma. Cancer Res, (2019).

43. A. Piunti, R. Hashizume, M. A. Morgan, E. T. Bartom, C. M. Horbinski, S. A. Marshall, E. J. Rendleman, Q. Ma, Y. H. Takahashi, A. R. Woodfin, A. V. Misharin, N. A. Abshiru, R. R. Lulla, A. M. Saratsis, N. L. Kelleher, C. D. James, A. Shilatifard, Therapeutic targeting of polycomb and BET bromodomain proteins in diffuse intrinsic pontine gliomas. Nat Med 23, 493-500 (2017).

44. J. D. Larson, L. H. Kasper, B. S. Paugh, H. Jin, G. Wu, C. H. Kwon, Y. Fan, T. I. Shaw, A. B. Silveira, C. Qu, R. Xu, X. Zhu, J. Zhang, H. R. Russell, J. L. Peters, D. Finkelstein, B. Xu, T. Lin, C. L. Tinkle, Z. Patay, A. Onar-Thomas, S. B. Pounds, P. J. McKinnon, D. W. Ellison, J. Zhang, S. J. Baker, Histone H3.3 K27M Accelerates Spontaneous Brainstem Glioma and Drives Restricted Changes in Bivalent Gene Expression. Cancer Cell 35, 140-155 e147 (2019).

45. E. Y. Qin, D. D. Cooper, K. L. Abbott, J. Lennon, S. Nagaraja, A. Mackay, C. Jones, H. Vogel, P. K. Jackson, M. Monje, Neural Precursor-Derived Pleiotrophin Mediates Subventricular Zone Invasion by Glioma. Cell 170, 845-859 e819 (2017).

46. S. Reagan-Shaw, M. Nihal, N. Ahmad, Dose translation from animal to human studies revisited. The FASEB journal 22, 659-661 (2008).

47. L. Taylor, B. Gidal, G. Blakey, B. Tayo, G. Morrison, A phase I, randomized, doubleblind, placebo-controlled, single ascending dose, multiple dose, and food effect trial of 
the safety, tolerability and pharmacokinetics of highly purified cannabidiol in healthy subjects. CNS drugs 32, 1053-1067 (2018).

680

48. C. T. Campbell, M. S. Phillips, K. Manasco, Cannabinoids in Pediatrics. J Pediatr Pharmacol Ther 22, 176-185 (2017).

49. O. Devinsky, C. Verducci, E. A. Thiele, L. C. Laux, A. D. Patel, F. Filloux, J. P. patients with CDKL5 deficiency disorder and Aicardi, Dup15q, and Doose syndromes. Epilepsy Behav 86, 131-137 (2018).

50. C. R. Justus, N. Leffler, M. Ruiz-Echevarria, L. V. Yang, In vitro cell migration and invasion assays. $J$ Vis Exp, (2014). Commun 11, 6216 (2020). sequence data. Bioinformatics 30, 2114-2120 (2014).

695 53. B. Li, C. N. Dewey, RSEM: accurate transcript quantification from RNA-Seq data with or without a reference genome. BMC Bioinformatics 12, 323 (2011).

697 54. D. Pratt, S. Camelo-Piragua, K. McFadden, D. Leung, R. Mody, A. Chinnaiyan, C. vol. 6, pp. 24. 
55. C. Koschmann, Y.-M. Wu, C. Kumar-Sinha, R. Lonigro, P. Vats, K. Kasaian, M. Cieslik, children and young adults with high-risk glial brain tumors. JCO precision oncology $\mathbf{2}, 1$ 34 (2018).

56. H. C. Gits, M. Anderson, S. Stallard, D. Pratt, B. Zon, C. Howell, C. Kumar-Sinha, P. Vats, K. Kasaian, D. Polan, M. Matuszak, D. E. Spratt, M. Leonard, T. Qin, L. Zhao, J. Leach, B. Chaney, N. Y. Escorza, J. Hendershot, B. Jones, C. Fuller, S. Leary, U. Bartels, from the International DIPG Registry. Acta neuropathologica communications 6, 67 (2018). brainstem-targeted in utero electroporation. Neuro-oncology 22, 381-392 (2020). Magnetic Beads. Medicinal Chemistry 4, 3 (2014). 
H3K27me3 and DNA hypomethylation are major drivers of gene expression in K27M mutant pediatric high-grade gliomas. Cancer Cell 24, 660-672 (2013).

60. T. D. Schmittgen, K. J. Livak, Analyzing real-time PCR data by the comparative C(T) method. Nat Protoc 3, 1101-1108 (2008).

61. M. Lerdrup, J. V. Johansen, S. Agrawal-Singh, K. Hansen, An interactive environment for agile analysis and visualization of ChIP-sequencing data. Nat Struct Mol Biol 23, 349-

62. J. T. Robinson, H. Thorvaldsdottir, W. Winckler, M. Guttman, E. S. Lander, G. Getz, J. P. Mesirov, Integrative genomics viewer. Nat Biotechnol 29, 24-26 (2011). web server 2016 update. Nucleic Acids Res 44, W90-97 (2016).

64. C. C. Liang, A. Y. Park, J. L. Guan, In vitro scratch assay: a convenient and inexpensive

Acknowledgments: The authors thank the patients and their families for participation in this study. method for analysis of cell migration in vitro. Nat Protoc 2, 329-333 (2007).

\section{Funding:}

National Institutes of Health/National Institute of Neurological Disorders and Stroke grant K08-NS099427-01 (CK)

The University of Michigan Chad Carr Pediatric Brain Tumor Center

The ChadTough Defeat DIPG Foundation

The DIPG Collaborative

U CAN-CER VIVE

Catching Up with Jack

The Morgan Behen Golf Classic 
National Institutes of Health Clinical Sequencing Exploratory Research Award grant 1UM1HG006508 (AC)

National Institutes of Health grant R44CA206723 (SM and PYD)

The Research Council of Norway 187615 (SMW)

The South-Eastern Norway Regional Health Authority (SMW)

The University of Oslo (SMW)

\section{Author contributions:}

Conception and design of study: VNY, MKH, CK

Competing interests: Authors declare that they have no competing interests.

Data and materials availability: All data are available in the main text or the 

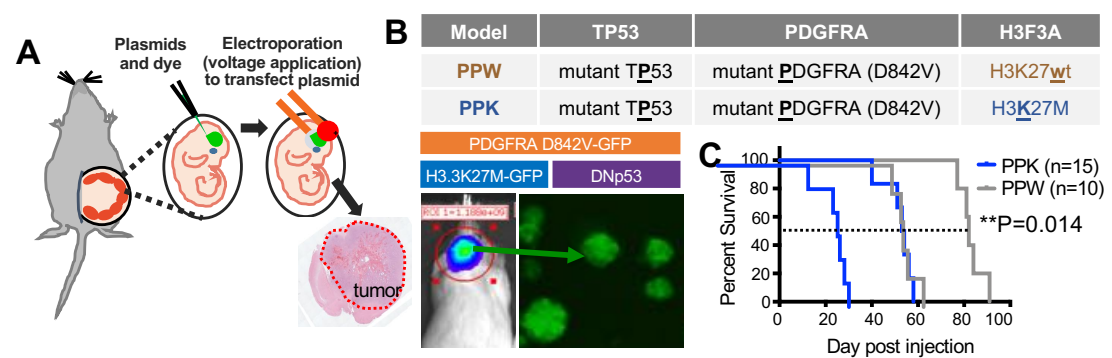

Figure 1

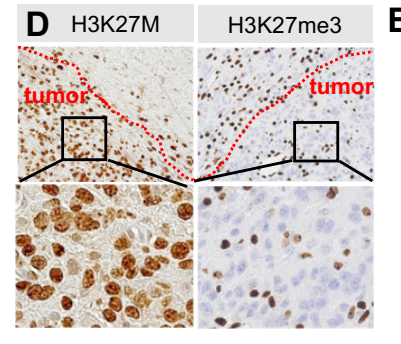

E
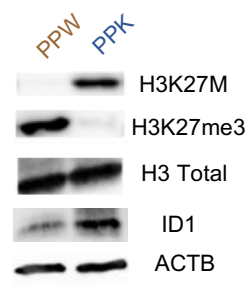

$\mathbf{F}$
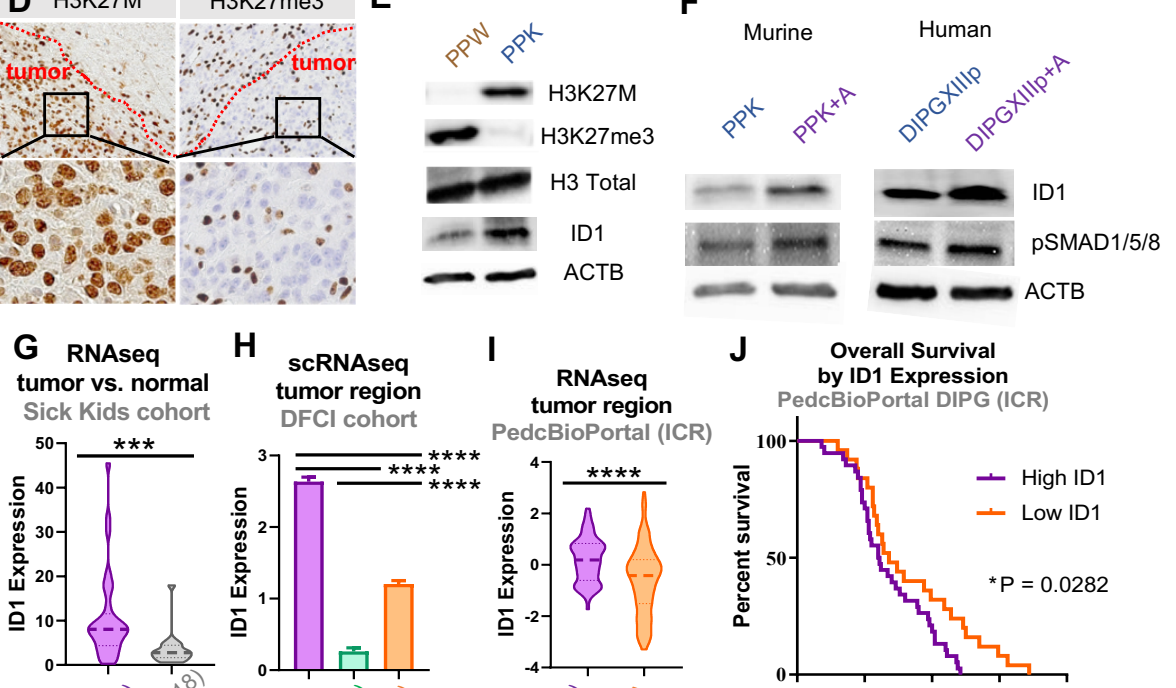
PedcBioPortal (ICR)

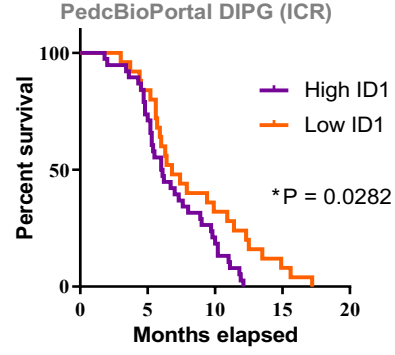

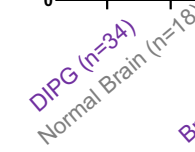

K
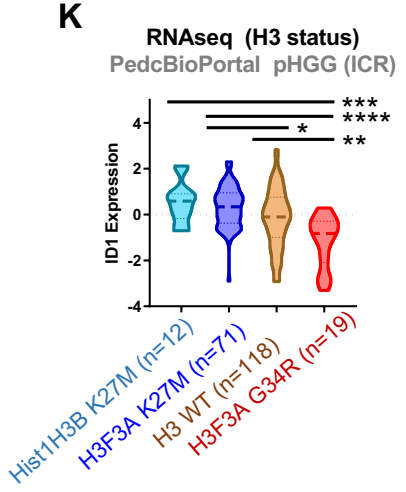

L RNAseq (ACVR1 status) PedcBioPortal pHGG (ICR)

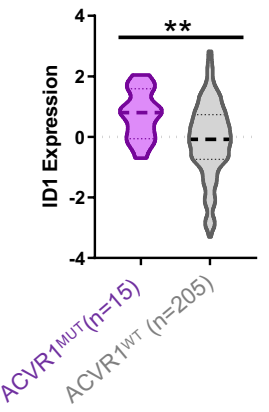

M RNAseq (H3/ACVR1 status) PedcBioPortal pHGG (ICR)

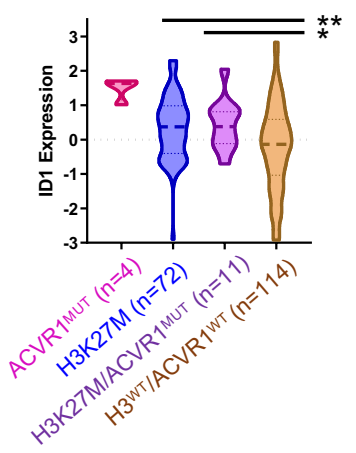
model. (B) PDGFRA ${ }^{\text {MUT }}$-p53 $3^{\text {MUT }}$-H3 ${ }^{\text {WT }}$ (“PPW") and PDGFRA ${ }^{\text {MUT }}$-p53 $3^{\text {MUT }}-\mathrm{H} 3 \mathrm{~K} 27 \mathrm{M}$ (“PPK”) tumors are generated by IUE. Tumor growth is monitored by in vivo bioluminescence imaging and primary neurosphere cell cultures are generated by dissociation of tumor tissue. (C) Survival 
776

777

778

779

780

781

782

783

784

785

786

787

788

789

790

791

792

793

794

795

796

797

curve for PPW and PPK mice displays significantly reduced survival of PPK compared to PPW mice; **P=0.014, log-rank test. (D) IHC-stained images of PPK tumor show tumor-specific H3K27M expression and reduced H3K27me3 (representative of n=3 PPK tumors).

Magnification $=10 \mathrm{x}$ (top row); 40x (bottom row). (E) Western blot (WB) of PPW and PPK primary neurospheres for assessment of H3K27M, H3K27ac and ID1 expression by H3 mutational status. (F) WB of murine PPK and PPK $+A C V R 1^{\mathrm{MUT}}$ ("PPK $+\mathrm{A}$ ") cells, and human DIPGXIIIp and DIPGXIIIp $+A C V R 1^{\mathrm{MUT}}$ cells, for assessment of ID1 and pSMAD expression. (G) ID1 expression of DIPG tissue $(\mathrm{n}=34)$ compared to matched normal brain tissue $(\mathrm{n}=18)$ from the SickKids cohort; $* * * \mathrm{P}<.001$, unpaired parametric t-test. (H) IDI expression by scRNA-seq from the DFCI cohort, including brainstem $(n=4)$, thalamus $(n=2)$ and cortex $(n=8)$;

$* * * * \mathrm{P}<0.0001$, one-way ANOVA t-test. (I) IDI expression of DIPG tissue $(\mathrm{n}=68)$ compared to hemispheric pHGG tissue $(\mathrm{n}=130)$. Data from ICR cohort; $* * * * \mathrm{P}<0.0001$, unpaired t-test. (J) Kaplan-Meier survival curve of DIPG patients $(\mathrm{n}=66)$ grouped by high and low IDI expression. *P $=0.0282$, Mantel-Cox test. (K) ID1 expression across Hist1H3B (H3C2) K27M (n=12), H3F3A (H3.3A) K27M (n=71), H3 ${ }^{\mathrm{WT}}(\mathrm{n}=118)$ and H3F3A (H3.3A) G34R (n=19) DIPG tumors. Data from ICR cohort, presented in Mackay et al; $* \mathrm{P}<0.05, * * \mathrm{P}<0.01, * * * \mathrm{P}<0.001$, ****P $<0.0001$, one-way ANOVA t-test. (L) IDI expression of pHGG tissue by ACVRI mutational status $\left(\mathrm{n}=15\right.$ ACVR1 $\left.^{\mathrm{MUT}} ; \mathrm{n}=205 \mathrm{ACVR}^{\mathrm{WT}}\right)$. Data from ICR cohort; $* * \mathrm{P}<0.01$, unpaired parametric t-test. (M) IDI expression of pHGG tumors with ACVRI mutation only (n=4), H3K27M only (n=72), H3K27M and ACVR1 mutations $(\mathrm{n}=11)$ and neither mutation (H3WT/ACVR1 WT; $\mathrm{n}=114$ ). Data from ICR cohort; $* \mathrm{P}<0.05, * * \mathrm{P}<0.01$, one-way ANOVA ttest. 

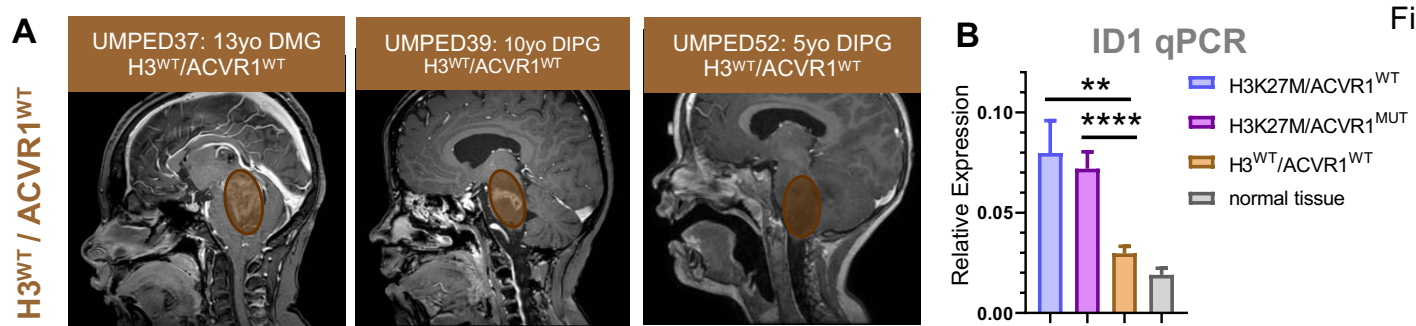

Figure 2
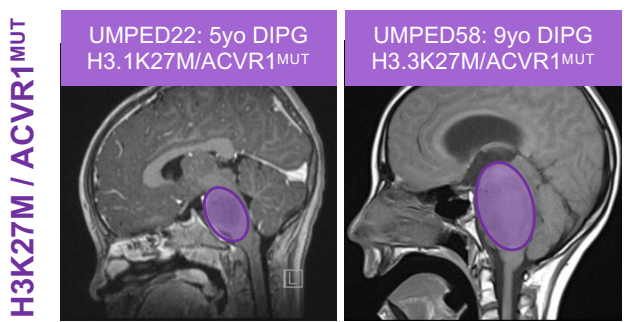

C ChIP-seq - human pons/DIPG tissue (ID1 loci)

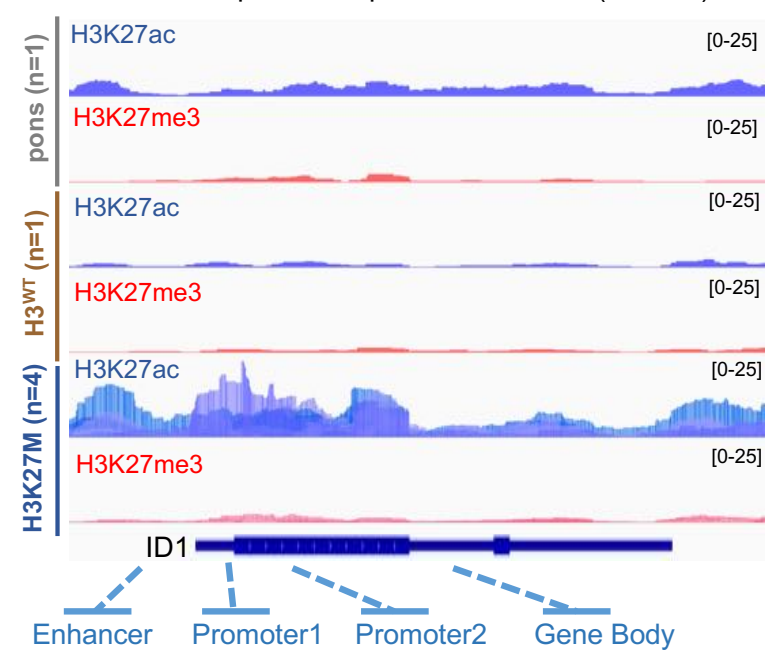

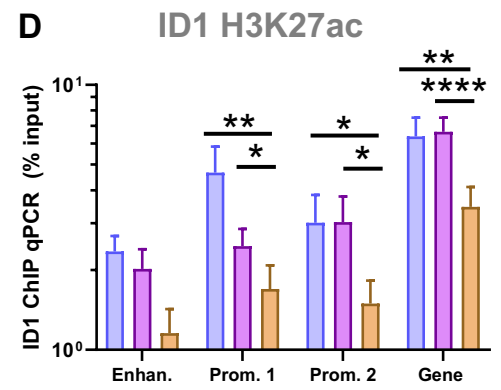

$\mathbf{F}$

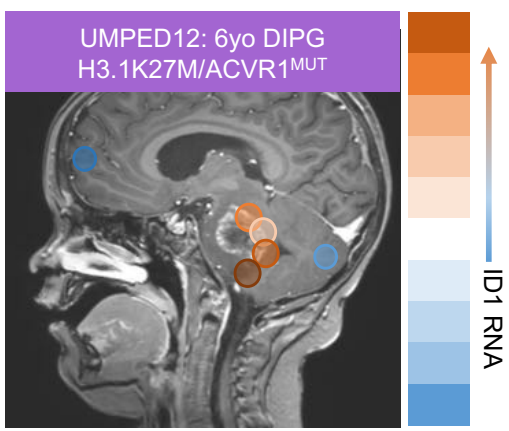

E

ID1 H3K27me3

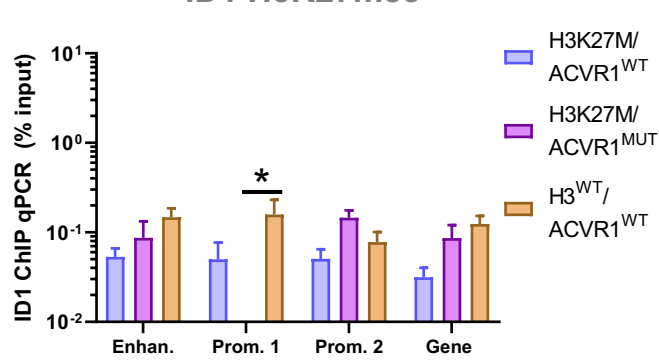

G

scRNAseq DIPG - cell type DFCl cohort

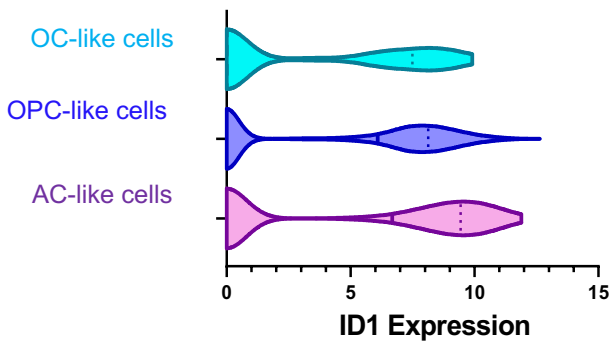

Fig. 2. ID1 is epigenetically active in H3K27M-DIPG. (A) Multifocal DIPG tumor samples

799 were obtained at autopsy from $\mathrm{n}=2$ patients with $\mathrm{H} 3 \mathrm{~K} 27 \mathrm{M}$ mutation and wildtype $A C V R 1$

$800\left(\mathrm{ACVR} 1^{\mathrm{WT}}\right), \mathrm{n}=2$ patients with $\mathrm{H} 3 \mathrm{~K} 27 \mathrm{M}$ mutation and $A C V R 1$ mutation (ACVR1 ${ }^{\mathrm{MUT}}$ ) and $\mathrm{n}=3$ 
801 patients with wildtype $\mathrm{H} 3$ and $A C V R 1$. Circles over MRI images represent the approximate 802 region of tumor. (B) IDI expression (qPCR) for multifocal samples collected from patients in 803 (A). Data represent mean+/-SEM; $* * \mathrm{P}<0.01, * * * * \mathrm{P}<0.0001$, one-way ANOVA t-test. (C) ChIP804 sequencing of $\mathrm{H} 3 \mathrm{~K} 27 \mathrm{ac}$ and $\mathrm{H} 3 \mathrm{~K} 27 \mathrm{me} 3$ deposition at the IDI gene locus in normal human 805 pontine tissue ( $\mathrm{n}=1)$, H3 ${ }^{\mathrm{WT}}$ DIPG tumor tissue ( $\left.\mathrm{n}=1\right)$ and H3K27M DIPG tumor tissue (n=1). (D806 E) ChIP-qPCR quantification of deposited (D) H3K27ac, and (E) H3K27me3 marks at gene 807 body elements identified in part C for the IDI gene. Data represent samples from patients in (A), 808 mean+/-SEM; $* \mathrm{P}<0.05,{ }^{*} \mathrm{P}<0.01,{ }^{* * * *} \mathrm{P}<0.0001$, one-way ANOVA t-test. (F) MRI image of $809 \mathrm{H} 3 \mathrm{~K} 27 \mathrm{M} / \mathrm{ACVR} 1^{\mathrm{MUT}}$ DIPG patient with circles representing regions where samples were 810 obtained at autopsy. Color scale on right displays relative level of IDI expression by qPCR 811 (orange=higher $I D I$ expression; blue=lower $I D 1$ expression. (G) ScRNA-seq data (DFCI, $\mathrm{n}=4$

812 DIPGs) of malignant DIPG cells plotted to show ID1 expression across varying subtypes of cells 813 [oligodendrocyte-like (OC-like); OPC-like; AC-like]. 
Figure 3

A

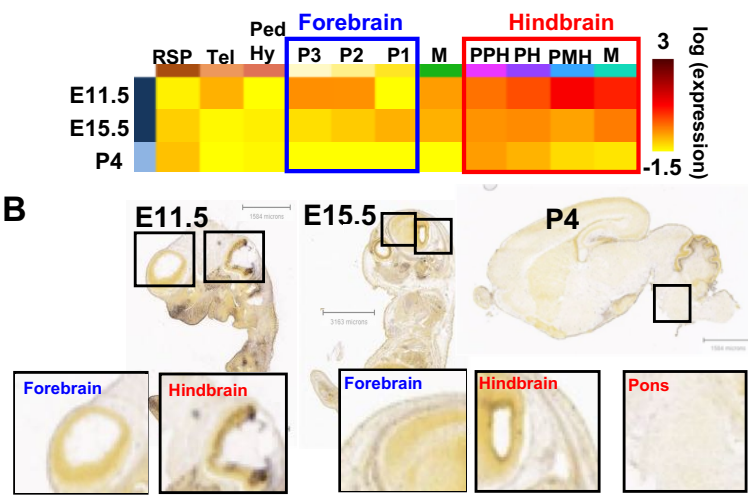

C
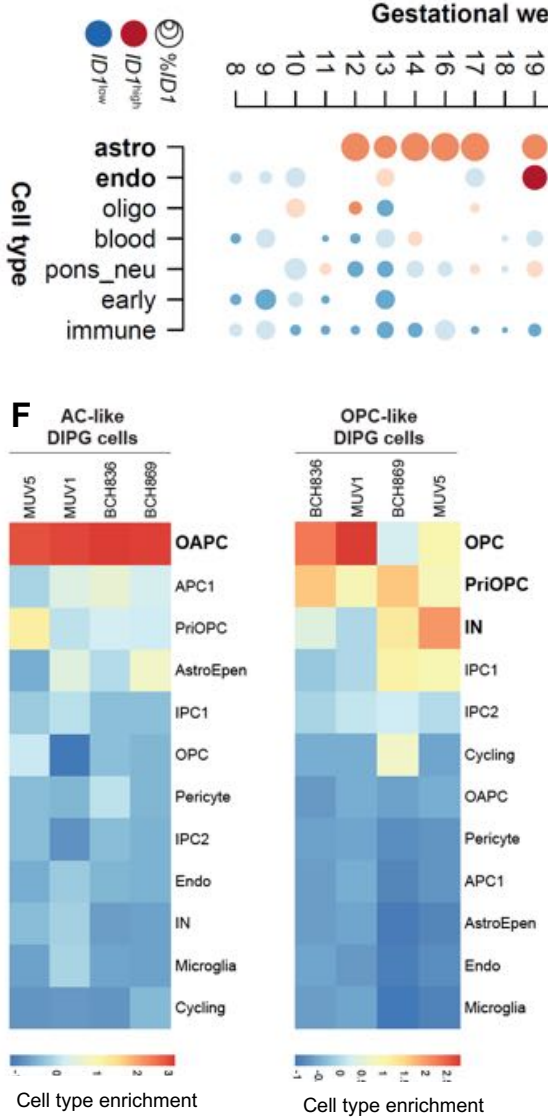

ID1 expression in developing human brain (scRNA-seq)

Gestational week

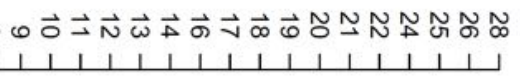

00000

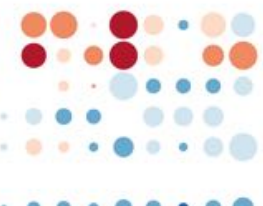

G

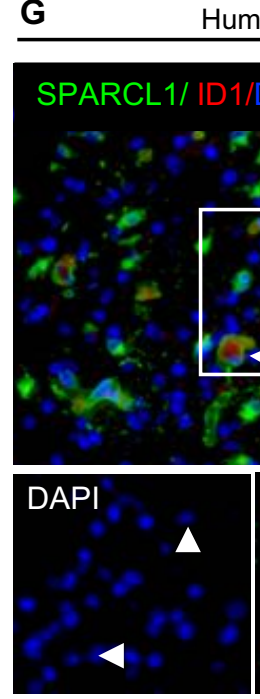

$\underline{D}$

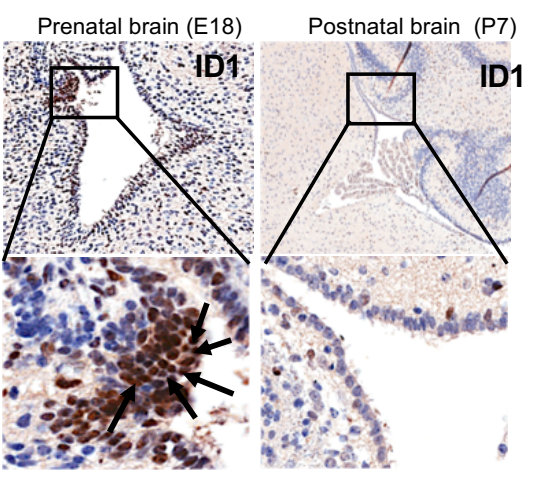

E Human Pons

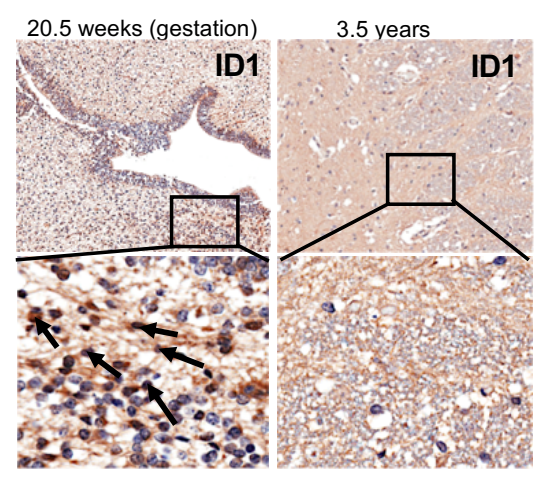

Human H3.3K27M tumor
|D1/DAP|
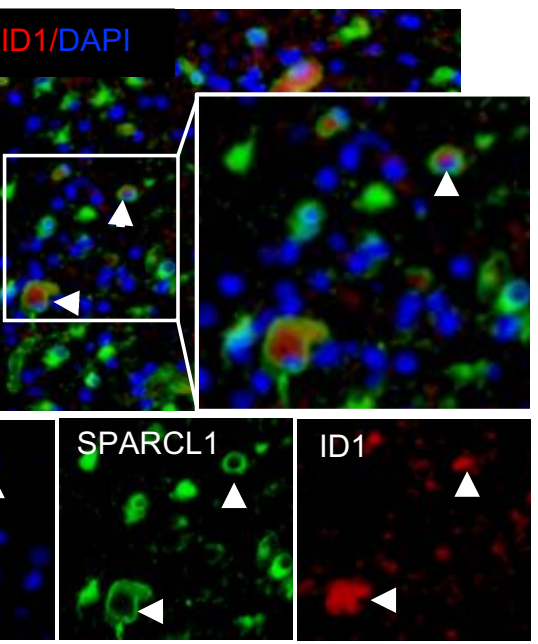

ID1

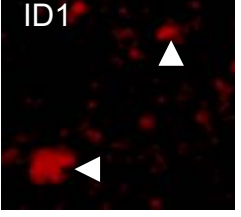


817 in murine brain across development. Available from: http://developingmouse.brain-map.org/.

818 ISH of sagittal developing murine brain sections showing higher IDI RNA in embryonic

819 hindbrain than forebrain, and minimal IDI RNA in all post-natal brain [Allen Developing Mouse

820 Brain Atlas. Available from: http://developingmouse.brain-map.org/]. (C) Heatmap of ID1

821 expression across varying cell types during normal human pontine development [data from Fan

822 et al. (25)]. Circle size indicates the percentage of cells that express ID1 and color indicates the

823 expression level in ID1 ${ }^{+}$cells (red=high expression; blue=low expression). (D) ID1 IHC staining

824 of normal human pontine tissue displays higher ID1 expression in cells lining the $4^{\text {th }}$ ventricle at 82520.5 weeks gestation and minimal expression in brain tissue at 3.5 years of age. (E) ID1 IHC of

826 normal murine pontine tissue at embryonic day 18 (E18) displays higher ID1 expression

827 compared to postnatal day 7 (P7). Magnification $=10 \mathrm{x}$ (top row); 40x (bottom row). (F) Overlap

828 of genes expressed by cell types in the developing human pons Fu et al. (28) in DIPG tumor cell

829 subsets. (Red=cell type marker genes enriched in DIPG cells; blue $=$ cell type marker genes not

830 enriched in DIPG cells). (G) Immunostaining of SPARCL1 (green) and ID1 (red) in human

831 DIPG tissue showing co-localization of ID1 and SPARCL1 in a subset of cells (white arrow).

832 Scale bar, $20 \mu \mathrm{m}$. Tumor nuclei were stained with DAPI (blue). [For (A), from left to right (row

833 headings), RSP: rostral secondary prosencephalon, Tel: telencephalic vesicle, PedHy: peduncular

834 (caudal) hypothalamus, P3: prosomere 1, P2: prosomere 2, P1: prosomere 3, M: midbrain, PPH:

835 prepontine hindbrain, $\mathrm{PH}$ : pontine hindbrain, $\mathrm{PMH}$ : pontomedullary hindbrain, $\mathrm{MH}$ : medullary

836 hindbrain (medulla); from top to bottom (column headings), E11.5/15.5: embryonic day

837 11.5/15.5, P4: postnatal day 4]. 

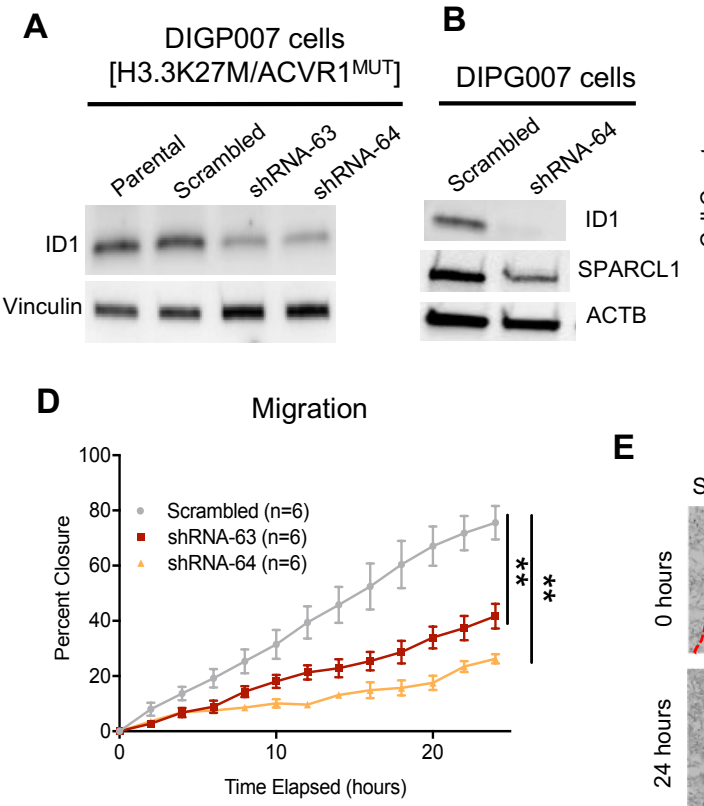

F DIGP007 human cells

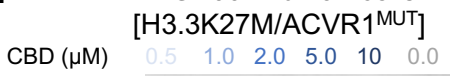

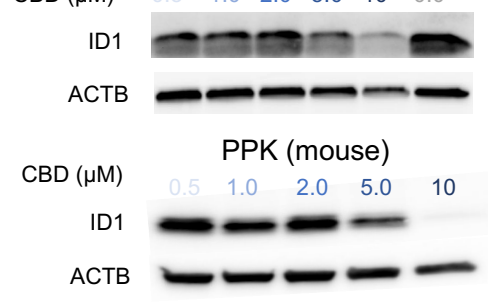

H Matrigel Invasion Assay - DIPG007

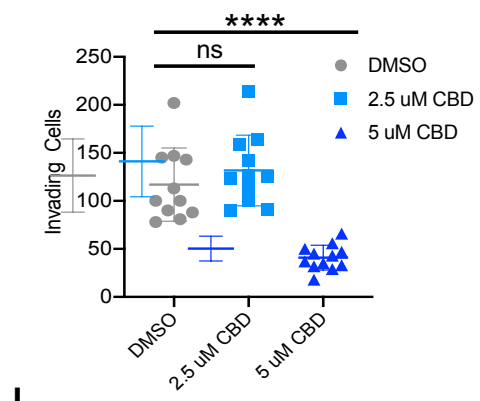

$\mathbf{J}$ ROS production (Flow cytometry) DIPG007

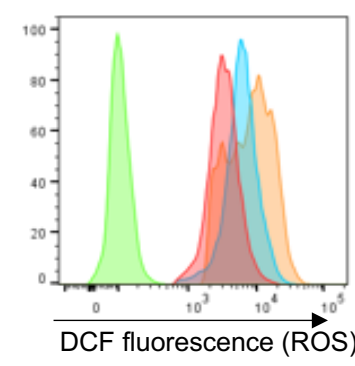

\section{G}

K
E
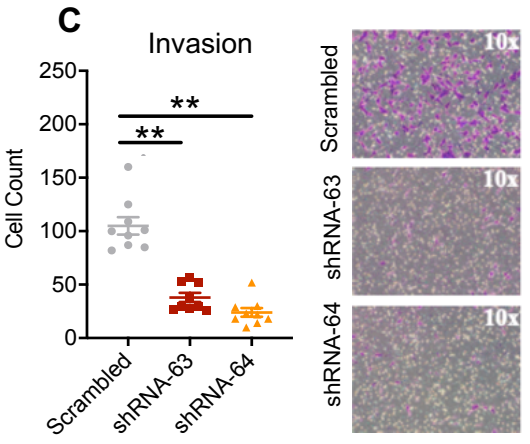

Figure 4

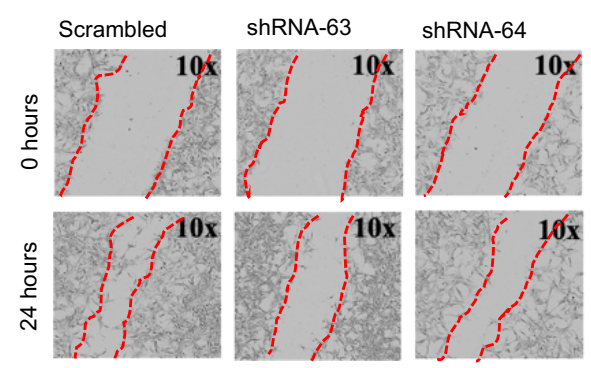

Viability
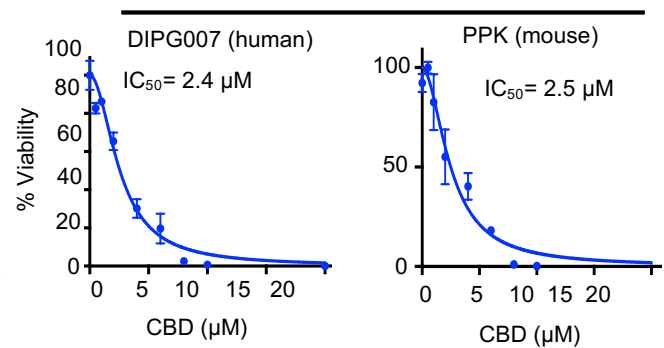

Migration Assay - DIPG007

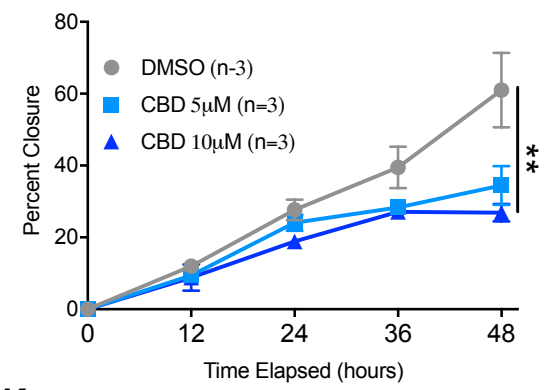

Cell proliferation - DIPG007 CBD Treatment +/- ROS scavenger

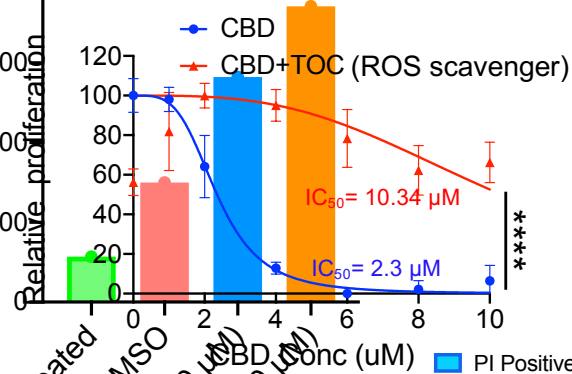


migration. (A) Western blot (WB) confirming ID1 knockdown in DIPG007 cells. (B) WB depicting reduction in SPARCL1 expression along with decreased ID1 expression in ID1-

841 knockdown DIPG007 cells. (C) Effect of ID1 knockdown on invasion as measured by Matrigel842 coated Boyden chamber assay. Images show invading cells stained with crystal violet. Each data 843 point represents an individual image; $* * \mathrm{P}<0.01$, unpaired parametric t-test. (D-E) Effect of IDI 844 knockdown on DIPG007 migration as measured by scratch assay, quantified as percent wound 845 closure. Images show representative scratch at 0 and 24 hours outlined in dotted red line.

846 Experiment was completed in triplicate and data points represent mean+/-SEM, **P $<0.01$;

847 images taken with Incucyte; area measured by ImageJ. (F) WB for ID1 and ACTB expression in 848 DIPG007 and PPK cells treated with increasing concentrations of CBD or DMSO control. (G) 849 Viability of DIPG007 and PPK cells treated with increasing concentrations of CBD $(0.5-20 \mu \mathrm{M})$ 850 relative to DMSO-treated control. Experiment was completed in triplicate and data points 851 represent mean+/-SEM. (H) DIPG007 cells were treated for 2 days with DMSO (control), $2.5 \mu \mathrm{M}$ 852 or $5 \mu \mathrm{M} \mathrm{CBD}$ and invasion was measured by Matrigel-coated Boyden chamber. Each data point 853 represents an individual image, mean+/-SEM; ****P $<0.0001$, unpaired parametric t-test. (I) 854 Effect of CBD treatment $(5-10 \mu \mathrm{M})$ on DIPG007 migration as measured by scratch assay, 855 quantified as percent wound closure. Experiment was completed in triplicate and data points 856 represent mean+/-SEM, $* * \mathrm{P}<0.005$, two-way ANOVA t-test. (J) Histogram showing increase 857 in DCF (ROS) with increasing doses of CBD. (K) Production of ROS mediates the inhibitory 858 activity of CBD through ID1. DIPG007 cells were treated for 72 hours with vehicle (DMSO) or 859 different concentrations of $\operatorname{CBD}(10,8,6,4,2,1 \mu \mathrm{M})$ in the presence and absence of $50 \mu \mathrm{M}$ 860 TOC. $\mathrm{IC}_{50}$ was $2.3 \mu \mathrm{M}$ for $\mathrm{CBD}$ treatment alone and $10.34 \mu \mathrm{M}$ for $\mathrm{CBD}+\mathrm{TOC} ; * * * * \mathrm{P}<0.0001$, 861 two-way ANOVA t-test. Cell proliferation was measured using XTT assay. 
Figure 5
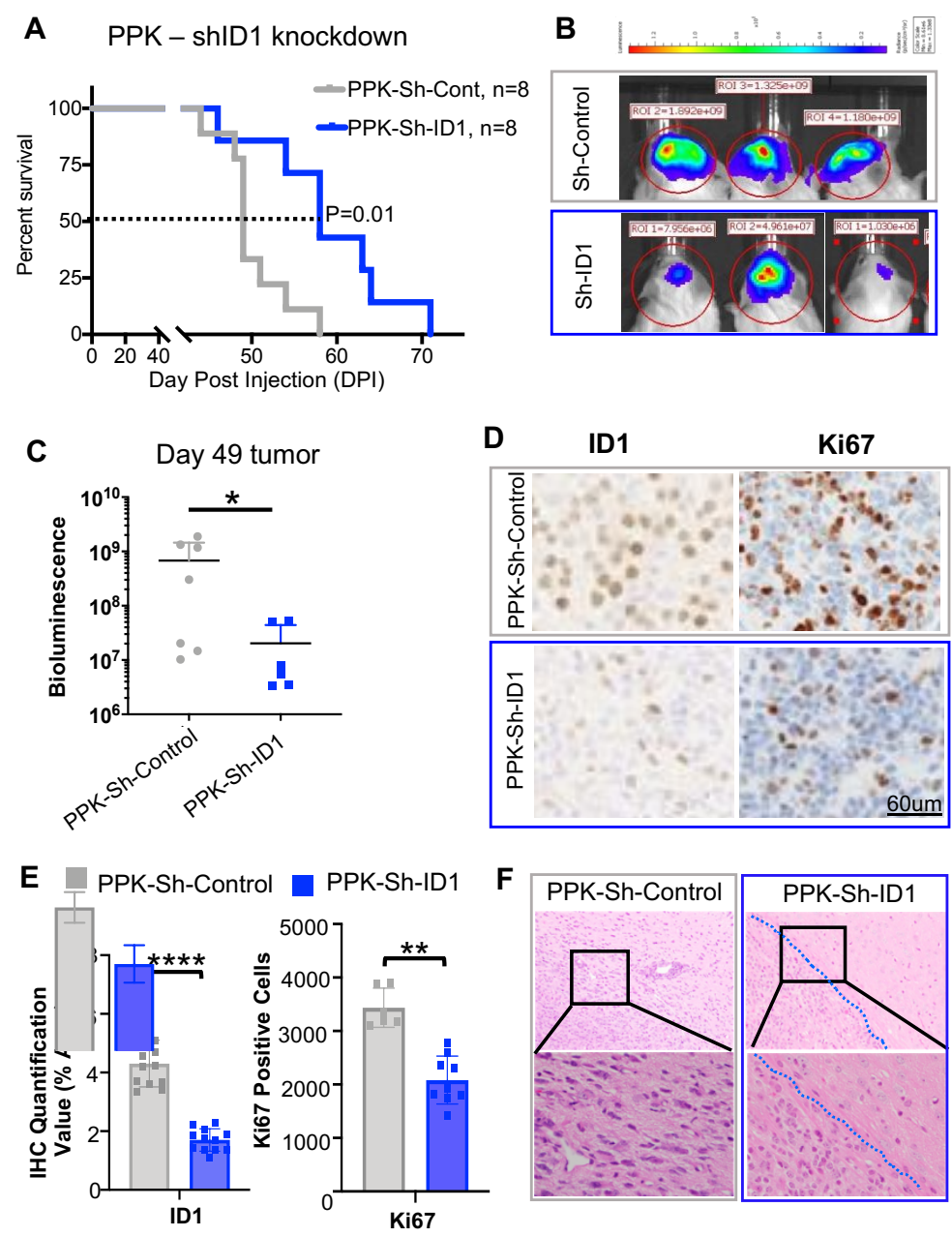

862 Fig. 5. Genetic targeting of ID1 decreases cell viability and slows murine tumor growth in

863 PPK IUE tumor model. (A) Standard Kaplan-Meier survival plot reveals notable increase in

864 survival for PPK-Sh-ID1 [PDGFRA-, TP53- and H3K27M-mutant with ID1 knockout (n=8)]

865 mice with median survival 58 days post-IUE injection compared to PPK-Sh-control $(\mathrm{n}=8)$ mice

866 with median survival of 49 days; $\mathrm{P}=0.01$, Log-rank test. (B) Representative bioluminescence

867 images of PPK-Sh-control tumors and PPK-Sh-ID1 (representative from $n=8$ ), 49 days after IUE

868 injection, displaying lower average luminescence in the PPK-Sh-ID1 group than in the PPK-Sh-

869 control. (C) IUE PPK bioluminescence tumor monitor growth data with statistical significance

870 between PPK-Sh-control and PPK-Sh-ID1 groups 49 days after IUE injection. $*$ P $<0.05$, one-way

871 ANOVA t-test. (D) IHC analysis of ID1 and Ki67 expression in tumors from PPK-Sh-ID1 and 
872 PPK-Sh-control mice. Images representative of each experimental cohort. Magnification=40x.

873 (E) IHC quantification for PPK-Sh-control and PPK-Sh-ID1 mice for ID1 and Ki67 expression 874 levels. ${ }^{* *} \mathrm{P}=0.0065$ and ${ }^{* * * *} \mathrm{P} \leq 0.0001$, one-way ANOVA t-test. Data points include 3 animals 875 per treatment group and 4 images per animal. Data represent the mean+/-SEM. (F) Images of 876 IUE-generated PPK-Sh-Control and PPK-Sh-ID1 tumor borders for assessment of tumor cell 877 invasiveness. Magnification $=10 \mathrm{x}$ (top row); 40x (bottom row). 
Figure 6
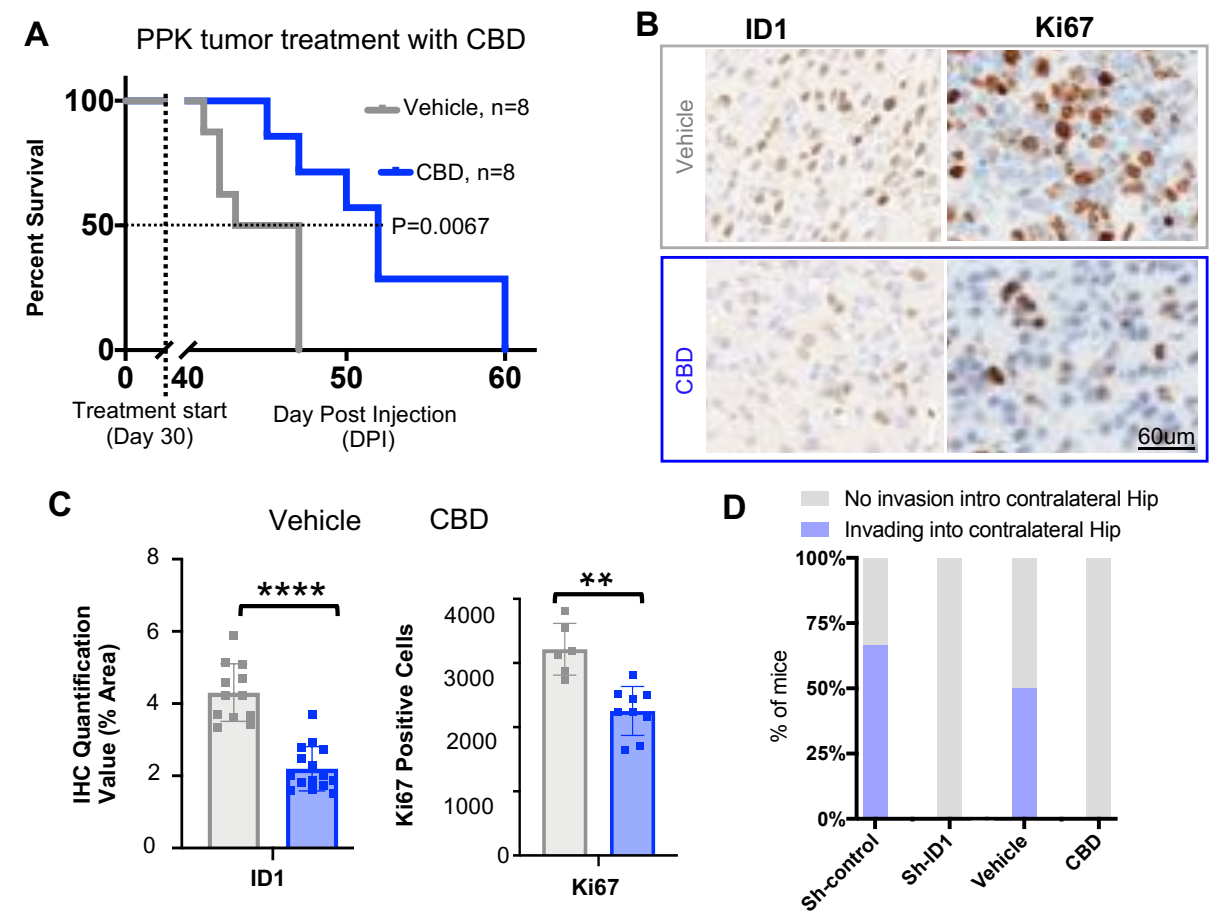

D $\quad$ No invasion intro contralateral Hip
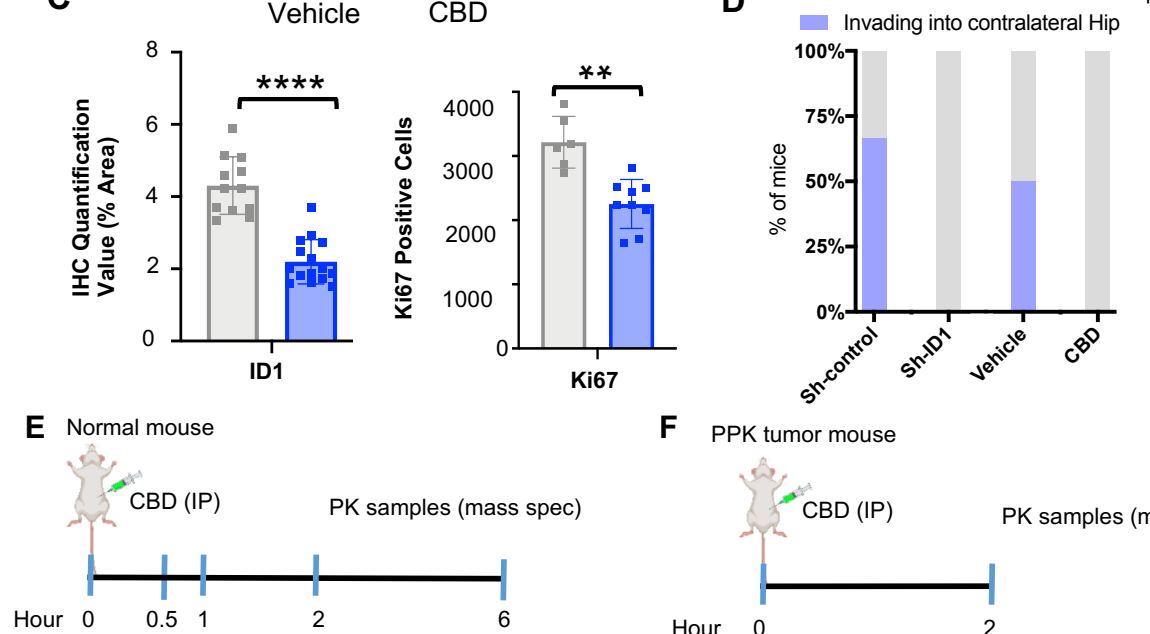

F PPK tumor mouse
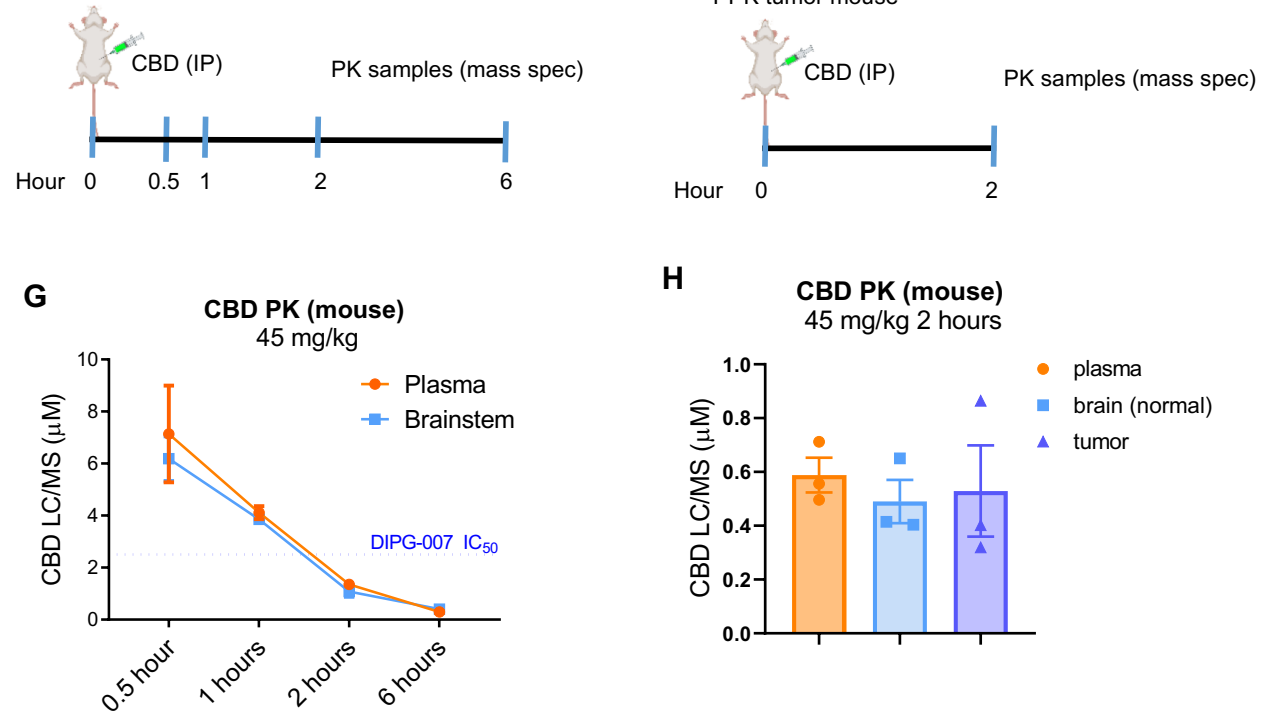

H $\quad$ CBD PK (mouse)

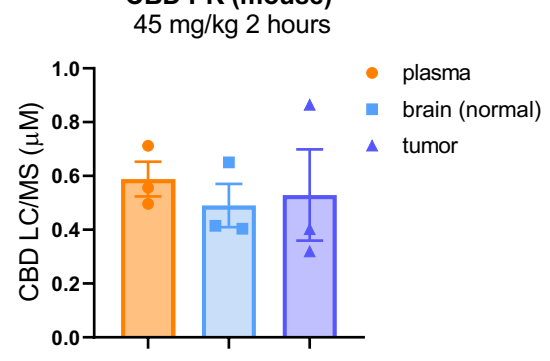

879 survival of PPK tumor-bearing mice. (A) Survival curve for PPK mice shows that median

880 survival for control condition was 45 days post-IUE injection $(n=8)$ and 55 days for CBD

881 condition $(15 \mathrm{mg} / \mathrm{kg}, \mathrm{n}=8) . * * \mathrm{P}<0.005$, Log-rank test. (B-C) IHC analysis and quantification of

882 tumor images reveals that CBD treatment reduced expression of ID1 and Ki67 compared to 
883 vehicle-treated tumors (representative of $\mathrm{n}=3$ tumors); $* * \mathrm{P}=0.0065$ and $* * * * \mathrm{P} \leq 0.0001$,

884 Dunnett's multiple comparisons test. $\mathrm{N}=3$ animals per treatment group and 4 images per animal.

885 Data represent the mean+/-SEM. Magnification=10x. (D) Analysis of tumor invasion in tumor-

886 bearing mice ( $\mathrm{n}=3$ mice per group) with genetic (sh-ID1) or pharmacologic (CBD) ID1

887 knockdown. Invasion was defined as tumor infiltration into the contralateral hippocampus (Hip).

888 (E) Timeline for pharmacokinetic (PK) liquid chromatography (LC)/mass spectrometry (MS)

889 analysis of CBD treatment by intraperitoneal (IP) injection in normal mouse plasma and

890 brainstem. (F) Timeline for PK mass spec analysis of CBD treatment by IP injection in PPK

891 mouse plasma, normal brain and tumor. (G) PK analysis results for normal (non-tumor-bearing)

892 mice treated with $45 \mathrm{mg} / \mathrm{kg} \mathrm{CBD}$ ( $\mathrm{n}=3$ mice per time point). Data represent CBD concentrations

893 as determined by LC/MS for the plasma and brainstem; mean+/-SEM. Blue dashed line

894 represents estimated $\mathrm{IC}_{50}$ of CBD for DIPG007 cells. (H) PK analysis results for $\mathrm{n}=3$ PPK mice

895 treated with $45 \mathrm{mg} / \mathrm{kg}$ CBD. Data represent CBD concentrations as determined by LC/MS for

896 the plasma, normal brain and tumor; mean+/-SEM. 
Figure 7
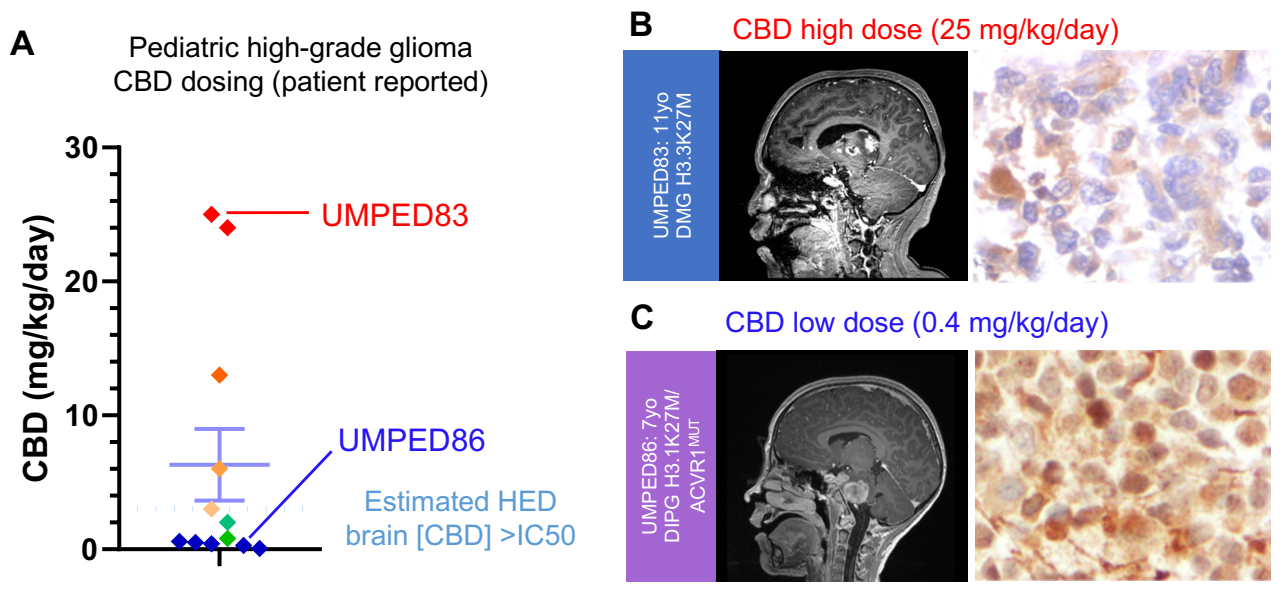

D Pediatric high-grade glioma

$\mathbf{E}$

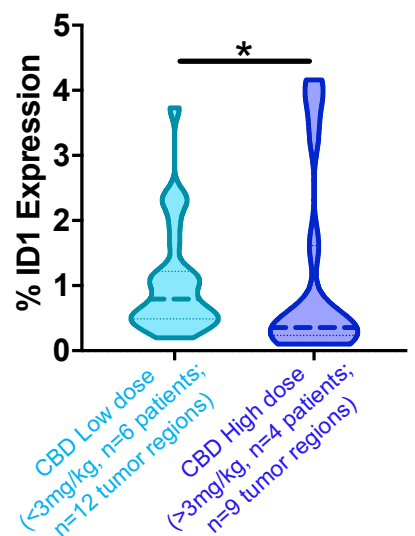

Pediatric diffuse midline glioma Overall survival - by CBD treatment

Fig. 7. Treatment of human pHGG patients with CBD. (A) Plot representing the CBD dosing range (mg/kg/day) in human patients, including one high (UMPED83) and one low (UMPED86)

899 dose of CBD, as indicated by red and blue lines. (B-C) IHC-stained tumor tissue from DIPG

900 patients (B) UMPED83 treated with CBD (25 mg/kg) and (C) UMPED86 treated with CBD (0.4

$901 \mathrm{mg} / \mathrm{kg} /$ day) during treatment course for assessment of ID1 expression. IHC images

902 representative of $n=3$ images taken using Aperio ImageScope, magnification=40x. (D) ID1 IHC

903 analysis and quantification of human DIPG tumor samples with low $(n=6)$ and high dose $(n=4)$

904 of $\mathrm{CBD} ;{ }^{*} \mathrm{P}=0.0388$, Mann-Whitney U test. (E) Survival of H3K27M-mutant tumor patients

905 treated with CBD from higher than $3 \mathrm{mg} / \mathrm{kg}(\mathrm{n}=4)$ and lower than $<3 \mathrm{mg} / \mathrm{kg}(\mathrm{n}=6)$ with historical

906 control $(n=98)$. 
Figure 8

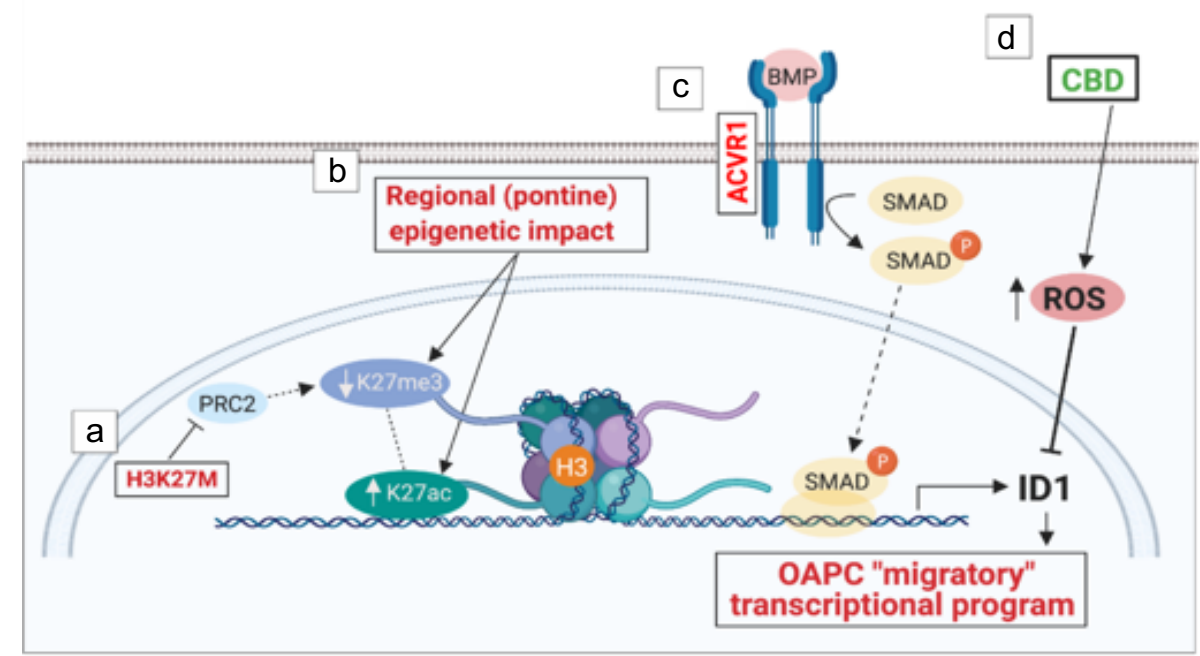

907 Fig. 8. Proposed model of ID1 activation in DIPG with H3K27M and ACVR1 mutations

908 and its inhibition with CBD. The proposed model is made up of the following sub-sections: (a)

$909 \mathrm{H} 3 \mathrm{~K} 27 \mathrm{M}$ inhibits PRC2, leading to global decreases in H3K27me3 and subsequently allowing

910 for increased H3K27ac. (b) Regional or tissue-specific factors and/ or (c) constitutively

911 activating $A C V R 1$ mutations increase $I D 1$ expression via SMAD protein signaling. We propose

912 that ID1 expression replicates the developing cell subtype OAPC transcriptional program, which

913 promotes migration. (d) ID1 expression is reduced by CBD treatment, which partially acts

914 through increasing intracellular levels of reactive oxygen species (ROS). Image created with

915 BioRender.

916

917

918 
920

921

922

923

924

925

926

927

928

929

930

931

932

933

934

935

936

937

938

939

940

941

942

\section{Supplementary Materials}

\section{Supplementary Methods}

\section{Whole exome and transcriptome sequencing (Sick Kids, Toronto)}

Use of patient tissues was approved by the Hospital for Sick Children (Toronto) Research Ethics Board. WES/WGS (accession EGAS00001000575) from DIPG samples plus matched normal was using DNA extracted from fresh-frozen tissues as described (13). Fresh-frozen tissue was used for total RNA extraction with the RNeasy mini kit (QIAGEN, CA, USA). 34 DIPG and 17 normal brain samples passed quality control. The TruSeq Stranded Total RNA Library Prep with Ribo-Zero Gold Kit (Illumina, CA, USA) was used and paired end sequencing generated with Illumina HiSeq 2500 machines (accession EGAD00001006450) (51). Sequencing quality was confirmed with FastQC v0.11 (http://www.bioinformatics.babraham.ac.uk/projects/fastqc/).

Reads were quality trimmed with Trimmomatic (52) v0.35 before being aligned with RSEM (53) v1.2 to human transcriptome build GRCh37 v75. Gene expression was quantified FPKM.

\section{Whole exome and transcriptome sequencing of tumor/normal tissue (University of} Michigan)

Clinically integrated sequencing was performed according to previously published methodology $(54,55)$. For living patients with DIPG/HGG, the PEDS-MIONCOSEQ study was approved by the Institutional Review Board of the University of Michigan Medical School and all patients or their parents or legal guardians provided informed consent (written assent if $>10$ years). For deceased patients, parents were consent for research autopsy and brain tumor/normal banking separately from the MIONCOSEQ protocol. Tumor (FFPE or frozen) and normal (cheek swab or blood, when available) samples were submitted for whole exome (paired tumor 
943 and germline DNA) and transcriptome (tumor RNA) sequencing. Nucleic acid preparation, high-

944 throughput sequencing, and computational analysis were performed by the Michigan Center for

945 Translational Pathology (MCTP) sequencing laboratory using standard protocols in adherence to

946 the Clinical Laboratory Improvement Amendments (CLIA) (56).

Analysis of tumors from Institute for Cancer Research (ICR)

Whole exome and transcriptome sequencing data from 1067 pediatric high grade gliomas (pHGGs) (compiled from the Jones lab, ICR London, Cancer Cell 2017) was retrieved from the

951 ICR cohort (20). Specimens with mRNA sequencing $(n=247)$ were then separated by location 952 into brainstem/pons $(n=68)$, hemispheric $(n=130)$, and midline $(n=49)$. PHGGs of the brainstem 953 were considered DIPGs. Of the 68 DIPGs from the ICR cohort, 2 did not have survival data and

954 were removed. Overall survival was defined from day of diagnosis to death of patient. High IDI 955 expression was defined as having a $\mathrm{z}$-score greater than $0.2(\mathrm{n}=38)$, and low IDI expression as 956 less than $0.2(n=25)$.

\section{In Utero Electroporation (IUE) and generation of primary cell lines from IUE tumors} PiggyBac transposon plasmids containing PDGFRA mutation, TP53 mutation, $H 3 F 3 A$ K27M, and $H 3 F 3 A$-WT, were kind gifts from Dr. Timothy Phoenix (Cincinnati Children's

961 Hospital, Cincinnati, OH) (57). In utero electroporation was performed on isoflurane/oxygen962 anesthetized pregnant female mice at embryonic day E13.5 in the cortex. Subcutaneous delivery 963 of Vetergesic and Carpofen at $0.1 \mathrm{mg} / \mathrm{kg}$ and $5 \mathrm{mg} / \mathrm{kg}$, respectively, was also provided pre964 emptively. Briefly, IUE were performed using sterile technique on isoflurane/oxygen965 anesthetized pregnant CD1 females at E13.5. Uterine horns were exposed through a $1 \mathrm{~cm}$ 
966 incision and embryos were digitally manipulated into the correct orientation. Borosilicate

967 capillaries were loaded with endotoxin-free DNA and Fast Green dye (0.05\%, Sigma) for

968 visualization. Lateral ventricles were then injected with the DNA-dye mixture using a

969 microinjector (Eppendorf). 3-5 plasmids were injected at the same time, each at a concentration

970 of $2 \mu \mathrm{l} / \mu \mathrm{l} .1-2 \mu \mathrm{l}$ of total solution was injected into each embryo. DNA was electroporated into

971 cortical neural progenitors using $3 \mathrm{~mm}$ tweezertrodes (BTX), applying 5 square pulses at $35 \mathrm{~V}$,

$97250 \mathrm{~ms}$ each with $950 \mathrm{~ms}$ intervals. Embryos were then returned into abdominal cavity, muscle

973 and skin sutured, and animal monitored until full recovery. Periodically, tumor growth was

974 monitored by IVIS as mice are treated starting 33 days post injection (dpi).

975 Primary cell lines with specific genetic alterations were generated from IUE-induced

976 pediatric high grade glioma models. Mice with confirmed large tumors (bioluminescence $10^{7}-$

$97710^{8} \mathrm{photons} / \mathrm{s} / \mathrm{cm}^{2} / \mathrm{sr}$ ) were selected. Mice were euthanized with an overdose of isoflurane,

978 decapitated, and brain was dissected from the skull. Brain was then placed in a Petri dish, and

979 coronal cuts were made anterior and posterior to tumor using sterile scalpel. Tumor was

980 identified and dissected with fine forceps and placed in a $1.5 \mathrm{ml}$ tube containing $300 \mu \mathrm{l}$ of Neural

981 Stem Cell Media (NSC Media: DMEM/F12 with B-27 supplement, N2 supplement, and

982 Normocin, supplemented with human recombinant EGF and bFGF at a concentration of 20

$983 \mathrm{ng} / \mathrm{ml}$ each). Tumor was gently homogenized using a plastic pestle. $1 \mathrm{ml}$ of enzyme free tissue

984 dissociation solution was added to homogenized tumor, and then incubated at $37^{\circ} \mathrm{C}$ for 5

985 minutes. Then, cell suspension was passed through a $70 \mu \mathrm{m}$ cell strainer, centrifuged at $300 \mathrm{x} \mathrm{g}$

986 for $4 \mathrm{~min}$. Supernatant was decanted, and pellet resuspended in $7 \mathrm{ml}$ of NSC media. Solution was

987 then plated onto a T25 tissue culture flask, and placed in tissue culture incubator at $37^{\circ} \mathrm{C}$ with

988 atmosphere of $95 \%$ air and $5 \% \mathrm{CO}_{2}$. After 3 days, neurospheres were removed and re-plated into 
989 a T75 tissue culture flask. Cells were then maintained in NSC media appropriately. No

990 mycoplasma testing regimen was performed on murine cell lines as they are early passage tumor991 derived cells. If frozen, cells were cultured for 2 to 3 passages ( 2 weeks) following thawing for 992 experiments.

993

994 Mint-ChIP-sequencing of tumor tissue

Analyses for the two classical histone modifications H3K27ac and H3K27me3

996 representing accessible and repressed chromatin states were performed as part of a MiNT-ChIP

997 analysis for 9 tumor samples of DIPG patients in comparison to a control tissue sample of

998 healthy pons according to the protocol published by Buenstro et al., 2013. Up to $50 \mathrm{~mm}^{3}$ snap

999 frozen tumor tissue was digested with $2.5 \mathrm{mg} / \mathrm{ml}$ collagenase IV (Sigma-Aldrich, Germany) and

1000 dissociated via the gentleMACS Dissociator (Miltenyi, Germany). Subsequent

1001 immunoprecipitation for H3K27Ac and H3K27me3 was performed with $5 \mu \mathrm{g}$ of ChIP-grade

1002 antibodies, monoclonal murine anti-H3K27Ac (MABI0309, ActiveMotif, Belgium) and a

1003 polyclonal rabbit anti-H3K27m3 (Merck Millipore, Germany).

1004 Over 50 mio reads were sequenced in 50 bp paired-end sequencing runs on a NovaSeq

10056000 system (NGS Core Facility, University Hospital, Bonn, Germany) and demultiplexed as

1006 described by Buenstro et al., 2013 (Core Unit Bioinformatics Data Analysis, University Hospital

1007 Bonn, Germany). Reads were aligned against the human reference genome hg19 by Bowtie 2

1008 (v2.4.2). Tag directories of piled up reads were created using HOMER (v4.11)

1009 makeTagDirectory and visualized makeUCSCfile with the -fsize $5 \mathrm{e} 8$ option.

1010

1011 Native ChIP-qPCR 
1012 Protocol for native ChIP-qPCR was adapted from previously described methods, and

1013 optimized for frozen human tissue (58). Antibodies against H3K27ac (2 $\mu 1$, cat\# 07360,

1014 Millipore Sigma), H3K27me3 (1 $\mu \mathrm{g}$, cat\# 07449, Millipore Sigma), and control IgG (2 $\mu \mathrm{g}$

1015 Cat\#12370, Millipore Sigma) were used for immunoprecipitation.

1016 Quantitative-PCR was performed per below methods, using $1 \mu 1$ of eluted ChIP DNA. Primers

1017 for IDI enhancer and promoter region target sites were predicted based on H3K27ac peaks

1018 observed in the four H3K27M DIPG tumor tissue samples analyzed via ChIP-sequencing in

1019 main Figure 2C. For a complete list of primers used in ChIP-qPCR, see Supplementary Table S1.

1020 NCBI RefSeq hg19 was used as reference genome (43). Enrichment at target sites was quantified

1021 using the percent input method as has been previously described (59). Gene expression was

1022 quantified relative to GAPDH using the comparative $\mathrm{C}_{\mathrm{T}}$ method as previously described (60).

1023 For a complete list of primer sequences used in qPCR for gene expression, see Supplementary

1024 Table S2.

1025

1026 Analysis of developing murine brain

1027 Call sets from the ENCODE portal (https://encodeproject.org/) were downloaded with the

1028 following identifiers: ENCSR691NQH, ENCSR428GHF, and ENCSR066XFL. ChIP-

1029 Sequencing peaks were quantified using EaSeq (http://easeq.net) (61). Graphic depictions of

$1030 \mathrm{H} 3 \mathrm{~K} 27 \mathrm{ac}$ peaks at the IDI locus were generated using IGV browser (62). ID1 in situ

1031 hybridization (ISH) data and images from the 2014 Allen Developing Mouse brain Atlas

1032 (http://developingmouse.brain-map.org/) were downloaded and analyzed.

1033

1034 ScRNA-seq analysis from developing brain and H3K27M-mutant DIPGs 1035 
Single-cell gene expression data and their clusters in the developing brain were obtained

1037 from GSE133531 (mouse pons), GSE120046 (human pons, gestational week 8-28), and

1038 GSE144462 (human cortex, gestational week 21-26). Raw mouse expression data was

1039 normalized to counts-per-million for each cell. Cells were assigned to clusters based on the joint

1040 clustering of cells from all four developmental stages (E15.5, P0, P3, P6). 1,792 cells were

1041 removed due to missing cluster assignments and Id1 expression was analyzed in the remaining

104222,682 cells. Analysis of normalized human pontine expression data was restricted to 4,228 cells

1043 that were detected across 18 gestational time points in the pons ( $>=3$ cells per gestational week).

1044 Normalized human expression data for H3K27M-mutant DMGs was obtained from GSE102130.

1045 Tumor cells with an astrocytic differentiation (AC-like), oligodendrocytic differentiation (OC-

1046 like), and OPC-like program were determined using stemness- and lineage scores from Filbin et

1047 al. (19) and $k$-means clustering. Mann-Whitney U (MWU) tests were used to identify for each

1048 patient genes that separate AC-like and OPC-like cells. Cell type enrichments were calculated

1049 using significant marker genes (cell type set A) and full summary statistics obtained from

1050 differential marker gene analysis (enrichment score=z-transformed median -log10 MWU P

1051 values). Functional enrichment analysis of marker genes was performed using the Enrichr web

1052 service (63) and top 200 marker genes (sorted by MWU P-value).

1053

1054 DIPG immunohistochemistry (IHC) staining and quantification

1055 Mouse PPK tumor and human DIPG paraffin embedded tissue were sectioned and sent to 1056 Dr. Daniel Martinez (Department of Pathology, Children's Hospital of Philadelphia, PA) for ID1 1057 and Ki67 staining. Briefly, ID1 antibody (Biocheck BCH-1) was used to stain formalin-fixed 1058 paraffin embedded tissue slides. Slides were rinsed in 2 changes of xylene for 5 min each then 
1059 rehydrated in a series of descending concentrations of ethanol. Slides were treated with .3\%

$1060 \mathrm{H} 2 \mathrm{O} 2 /$ methanol for 30min. and then treated in a pressure cooker (Biocare Medical) with $0.01 \mathrm{M}$

1061 Citrate buffer $\mathrm{pH}$ 7.6. After cooling, slides were rinsed in 0.1M Tris Buffer and then blocked

1062 with $2 \%$ fetal bovine serum for 5 min. Slides were then incubated with ID1 antibody at a 1:25

1063 dilution overnight at 4 degrees C. Slides were then rinsed and incubated with biotinylated anti-

1064 Rabbit IgG (Vector Laboratories BA-1000) for 30min at room temp. After rinsing, slides were

1065 incubated with the avidin biotin complex (Vector Laboratories PK-6100) for $30 \mathrm{~min}$ at room

1066 temp. Slides were then rinsed and incubated with DAB (DAKO Cytomation K3468) for 10 min

1067 at room temp. Slides were counterstained with hematoxylin, then rinsed, dehydrated through a

1068 series of ascending concentrations of ethanol and xylene, then coverslipped. Ki67(SP6) antibody

1069 (Abcam ab16667) was used to stain formalin-fixed, paraffin-embedded tissue. Staining was

1070 performed on a Bond Max automated staining system (Leica Microsystems). The Bond Refine

1071 staining kit (Leica Microsystems DS9800) was used. The standard protocol was followed with

1072 the exception of the primary antibody incubation which was extended to 1 hour at room

1073 temperature. Ki67 was used at 1:400. Antigen retrieval was performed with E2 (Leica

1074 Microsystems) retrieval solution for 20min. After drying, slides were scanned at 20x

1075 magnification with an Aperio CS-O (Leica Biosystems) slide scanner and images were viewed

1076 using the Aperio ImageScope software. An individual blinded to the experiment captured five

1077 random images from each IHC slide at 10X magnification. Quantification of images for precent

1078 positive area were measured by ImageJ software.

1079

1080 Human cell cultures 
Primary H3.3K27M-mutant cell line DIPG007 was obtained from Dr. Rintaru Hashizume

1082 from (Northwestern University, Chicago, IL) who obtained them originally from Dr. Angel

1083 Carcaboso (Hospital Sant Joan dr Deu, Barcelona, Spain). DIPG-XIII was obtained from Dr.

1084 Michelle Monje (Stanford University, Stanford, CA). PBT-29 was obtained from Dr. Nicholas

1085 Vitanza,(Seattle Children's, Seattle, WA). Immortalized human embryonic kidney 293

1086 (HEK293) cells were obtained from Dr. Sriram Venneti (University of Michigan, Ann Arbor,

1087 MI). Cells were cultured for 2 to 3 passages ( 2 weeks) following thawing for experiments.

1088

1089 DIGP007, DIPGXIIIp and PBT-29 cells

1090 DIPG007, DIPGXIIIp and PBT-29 cells were cultured in TSM N5 media: $250 \mathrm{ml}$ DMEM (1X,

1091 Cat\#11995065, Gibco); 250 ml NeuroBasal-A Medium (1X, Cat\#0888022, Gibco); 5 ml HEPES

1092 (1M, Cat\#15630080, Gibco); 5 ml Sodium Pyruvate (100mM, Cat\#11360070, Gibco); B-27

1093 Supplement without Vitamin A (50X, Cat \#12587010, Gibco); 5 ml MEM NEAA (100X,

1094 Cat\#11140050, Gibco); 5 ml Antibiotic-Antimycotic (100X, Cat\#15240062, Gibco); $250 \mu 1$

1095 Heparin Solution (Cat\#07980, STEMCELL Technologies); $10 \mu 1$ human PDGF-AA every 3 days

1096 (10 ng/ml, Cat\#10016, Shenandoah Biotechnology); $1 \mathrm{ml}$ Normocin (Cat\#antnr1, InvivoGen); 10

$1097 \mu \mathrm{l}$ human PDGF-BB every 3 days (10 ng/ml, Cat\#10018, Shenandoah Biotechnology); $20 \mu \mathrm{l}$

1098 FGF every 3 days (20 ng/ml, Cat\#10018B, PeproTech); $20 \mu 1$ EGF every 3 days ( $20 \mathrm{ng} / \mathrm{ml}$,

1099 Cat\#10047, PeproTech). For adherent conditions, FBS was diluted in media to 10\%. For

1100 neurosphere culture, FBS was not added. At each passage, cells were dissociated using StemPro

1101 Accutase (Cat\#A1110501, Gibco). 
1104 HEK293 cells were cultured in: 500 ml DMEM (1X, Cat\#11995065, Gibco); 333 $\mu 1$ Gluta-Max

1105 (200 mM, Cat\#25030081, Gibco); $1 \mathrm{ml}$ Normocin (Cat\#antnr1, InvivoGen). FBS was diluted in 1106 media to 10\%. At each passage, cells were dissociated using StemPro Accutase (Cat\#A1110501, 1107 Gibco).

1108

1109

1110

1111

1112

1113

1114

1115

1116

1117 replaced with $1.35 \mathrm{ml}$ of fresh media. Then, $0.15 \mathrm{ml}$ of $10 \mathrm{x}$ viral supernatant was added, along

1118 with $2.5 \mu \mathrm{l}$ of $4 \mathrm{mg} / \mathrm{ml}$ Polybrene (Cat\#G062, ABM). Plate was then rocked gently on shaker to

1119 evenly distribute virus and Polybrene. Cells were then placed in cell incubator at $37^{\circ} \mathrm{C}$ for

1120 approximately 24 hours. Exact time was dependent on when cells began expressing GFP, which

1121 was contained in the lenti-vector.

\section{Western Blotting}

1124 Western blotting was performed using antibodies against ID1 (1:1000, Cat\#133104,

1125 Santa Cruz Biotechnology), Vinculin (1:10000, Cat\#700062, Invitrogen), H3K27M (1:500, 
1126 EMD, Cat\#ABE419), H3K27me3 (1:500, EMD, Cat\#07-449) and ACTB (1:10000, Cat\#A2228,

1127 Sigma-Aldrich), Secondary antibodies biotinylated horse anti-mouse IgG (Cat\#BA2000, Vector

1128 Laboratories), HRP goat anti-rabbit IgG (Cat\#PI1000, Vector Laboratories), and m-IgG $\mathrm{k}_{\mathrm{k}}$ BP-

1129 HRP (Cat\#sc516102, Santa Cruz Biotechnology) were used. Chemiluminescent blots were

1130 imaged and processed using the FluroChem M system (ProteinSimple, San Jose, CA).

1132 Cannabidiol treatment studies in vitro

1133 Treatment was performed as previously described (12). 3,000 primary DIPG007 and PPK

1134 cells were plated in 96-well plates and incubated for 24 hours. The next day, cells were treated

1135 with different doses of cannabidiol (CBD) cat \# 90080 (Cayman Chemical). After 72 hours, in

1136 vitro cell viability was monitored by XTT Cell Proliferation Assay kit (Cayman Chemical).

1138 Invasion assay

1139 Invasion assays were performed using growth factor-reduced matrigel invasion chambers

1140 with $8 \mathrm{uM}$ pores (Cat \#354483, Corning) as described in previously published work (50).

1141 Seeding density and incubation time was optimized for each cell line. FBS was used as

1142 chemoattractant. Invading cells were stained with crystal violet. To count invading cells,

1143 transwell membranes were viewed underneath an inverted microscope at 10x magnification, and

1144 four pictures were taken at random locations to get an average sum.

1146 Migration (scratch) assay

1147 Migration assays were performed following a previously published protocol with slight

1148 modifications (64). Cells were seeded in 6-well plates, and grown to approximately $80 \%$ 
1149 confluence. Scratches were made using a $200 \mu \mathrm{l}$ pipette tip, and migration was then monitored

1150 using the IncuCyte ${ }^{\circledR}$ live-cell analysis system (Sartorius, Ann Arbor, MI). Images were analyzed

1151 using ImageJ's MRI Wound healing tool (http://dev.mri.cnrs.fr/projects/imagej-

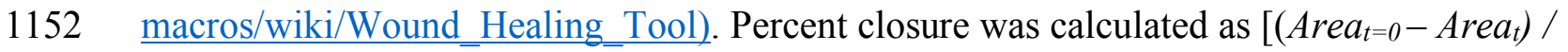

1153 Area $\left._{t=0}\right]^{*} 100$.

1154

1155 Proliferation and viability assays

1156 Cell viability was quantified using the MTT Cell Proliferation Assay Kit (Cat\#ab211091,

1157 ABCAM), following manufacturer instruction for adherent cells. For proliferation, cells were

1158 seeded in 96-well plates and monitored for confluence using the IncuCyte ${ }^{\circledR}$ live-cell analysis

1159 system (Sartorius, Ann Arbor, MI).

1160

1161 Implantation of DIPG007 cells and bioluminescence imaging

1162 Implantation of mouse cells

1163 Male and female NSG ${ }^{\mathrm{TM}}$ mice were obtained from Jackson Labs (Bar Harbor, ME) and

1164 were 6-10 weeks of age at the start of surgery. All animal studies were conducted according to

1165 the guidelines approved by the Institutional Animal Care \& Use Committee (IACUC) at the

1166 University of Michigan. Mice were anesthetized with injection of $120 \mathrm{mg} / \mathrm{kg}$ ketamine and 0.5

$1167 \mathrm{mg} / \mathrm{kg}$ dexmedetomidine. Hair above scalp was shaven, disinfected with iodine, and a $1 \mathrm{~cm}$

1168 incision was made above scalp to expose cranium. The periosteum was removed with scalpel.

1169 Next, a $0.6 \mathrm{~mm}$ burr hole was drilled $2 \mathrm{~mm}$ right of midline and $0.2 \mathrm{~mm}$ anterior to the bregma

1170 with the Ideal Micro Drill (MD-1200 120V) from Braintree Scientific Inc. Mice were placed in a

1171 Mouse/Neonatal Rat Adaptor stereotactic frame (\#51615) from Stoelting. A 10 ul syringe 
1172 (\#7635-01) fitted with 33-gauge needle (\#7762-06) from Hamilton, was filled with cell

1173 suspension $(15,000$ cells per $\mathrm{uL})$ and penetrated $3 \mathrm{~mm}$ into brain tissue. After waiting two

1174 minutes, one microliter of cell suspension was injected over one minute and needle was slowly

1175 removed after waiting 3 minutes after injection. Incision was closed with 4-0 nylon and mouse

1176 was given $1 \mathrm{mg} / \mathrm{kg}$ atipamezole for reversal and monitored for recovery. Mice were monitored

1177 for symptoms of morbidity, including impaired mobility, scruffed fur, hunched posture, ataxia,

1178 and seizures.

1179 Bioluminescence imaging

1180 Mice were imaged using IVIS Spectrum \#2 machine at the Center for Molecular Imaging

1181 at the University of Michigan Core Facility. Mice were injected with $160 \mathrm{mg} / \mathrm{kg}$ D-luciferin

1182 (\#115144-35-9) from Gold Biotechnology and anesthetized with 2\% isoflurane. 10 minutes after

1183 luciferin injection, mice were placed into machine in a prone position and bioluminescence was

1184 measured. Mice were imaged until peak signal was obtained for each mouse. Tumor

1185 bioluminescent signal is measured in radiance (photons) $\left(\mathrm{p} / \mathrm{s} / \mathrm{cm}^{3} / \mathrm{sr}\right)$ in a circular region of 1186 interest (ROI) over the cranium of each mouse with Living Image Software (PerkinElmer Inc).

\section{CBD treatment studies in murine IUE PPK model}

1189 Mice harboring IUE-generated PPK HGG tumors were treated with CBD when tumors

1190 reached logarithmic growth phase (minimum $2 \times 10^{6}$ photons/sec via bioluminescent imaging).

1191 Mice litters from each experimental group were randomized to treatment with: (A) $15 \mathrm{mg} / \mathrm{kg}$

1192 CBD (10\% CBD suspended in Ethanol, 80\% DPBS, 10\% Tween-80) and (B) control treatment

1193 (10\% Ethanol, 80\% DPBS, 10\% Tween-80). Mice were treated 5 days/week until morbidity.

1194 Animals displaying symptoms of morbidity after treatment were euthanized for 
1195 immunohistochemistry (IHC) analysis. For IHC analysis, mice were perfused with Tyrode's

1196 Solution followed by $4 \%$ paraformaldehyde fixative solution to preserve the structures of the

1197 brain. For IHC quantification (Ki67 and ID1), 3-4 random images per tumor ( $\mathrm{n}=3$ tumors per

1198 group) were taken at 10x magnification using Aperio ImageScope and percent positive area was

1199 calculated using ImageJ software.

1200

1201 CBD Pharmacokinetic analysis

1202 Mouse PK sample procurement

1203 CBD administration to non-tumor bearing CD1 mice and PPK tumor bearing mice for PK

1204 studies were performed by IP injection at zero time point. Timeline for CBD injection and

1205 plasma, brainstem and/or tumor collection were depicted in Fig. 7 E-F. At half, one, two, and six

1206 hours after the CBD injection, the mice were isoflurane/oxygen-anesthetized and $500 \mathrm{uL}$ to $1 \mathrm{~mL}$

1207 of blood was drawn from the apex of the heart within the mouse's enclosed cavity. Immediately,

1208 the withdrawn blood was centrifuged within a microvette EDTA coated conical tube for 10

1209 minutes at $10,000 \mathrm{RPM}$, and the plasma was separated and stored at $-80^{\circ} \mathrm{C}$ until PK analysis was

1210 performed. Following the blood draw, the mouse was sacrificed and the brain, brain stem, and/or

1211 tumor were extracted separately and stored at $-80^{\circ} \mathrm{C}$ until $\mathrm{PK}$ analysis was performed.

1212

1213 Chemicals and reagents

1214 For PK studies, CBD powder was procured from Cayman chemical USA. Liquid

1215 chromatography-mass spectrometry (LC-MS) grade acetonitrile was purchased from Sigma-

1216 Aldrich. Formic acid (98\%; LC-MS grade) was obtained from Fluka. A Milli-Q water system

1217 from Millipore was used to obtain ultrapure deionized water. 
Sample preparation

Plasma $(40 \mu \mathrm{L})$ was dispensed into a Fisher Scientific 96-well plate, to which $40 \mu \mathrm{L}$ of

1221 ice-cold acetonitrile (100\%) and $120 \mu \mathrm{L}$ of internal standard solution $(1000 \mathrm{ng} / \mathrm{mL})$ were added.

1222 Next, the plate was vortexed for 10 minutes. The plate was then centrifuged at 3500 revolutions

1223 per minute (RPM) for 10 minutes at $4^{\circ} \mathrm{C}$ to precipitate the protein. $\mathrm{LC}$-tandem mass

1224 spectrometry (LC-MS/MS) was used to analyze $5 \mu \mathrm{L}$ of the supernatant. The plasma samples

1225 were sonicated prior to being transferred to the 96-well plates. Tissue samples were weighed and

1226 suspended in $20 \%$ acetonitrile ( $80 \%$ water; $1: 5 \mathrm{wt} / \mathrm{vol})$. The samples were then homogenized

1227 four times for 20 seconds each time at 6,500 RPM in a Precellys Evolution system. For LC-

1228 MS/MS analysis, the CBD in brain tissue homogenates were extracted from the samples in the

1229 same manner as the CBD in plasma. Prior to extraction, samples that were above the upper limit

1230 of qualification were diluted with the same matrix. Calibrator-standard samples and quality

1231 control samples were prepared by mixing $40 \mu \mathrm{L}$ of blank bio matrix, $40 \mu \mathrm{L}$ of working solution, 1232 and $120 \mu \mathrm{L}$ of internal standard solution.

\section{Calibration curve}

1235 Analytical curves were made with 12 nonzero standards by plotting the peak area ratio of $1236 \mathrm{CBD}$ to the internal standard vs the concentration. The curve was created with linear regression 1237 and weighted (1/X2). The correlation coefficient demonstrated the linearity of the relationship 1238 between peak area ratio and concentration.

1240 Liquid chromatography tandem-mass spectrometry 
The concentrations of CBD were determined with a Sciex AB-5500 Qtrap mass

1242 spectrometer with electrospray ionization source, interfaced with a Shimadzu high-performance

1243 LC system. The LC-MS/MS system was controlled with Analyst Software version 1.6 from

1244 Applied Biosystems; this was also used for acquisition and processing of data. Separation was

1245 performed on a Waters Xbridge C18 column $(50 \times 2.1 \mathrm{~mm} \mathrm{ID,} 3.5 \mu \mathrm{m})$; the flow rate was 0.4

$1246 \mathrm{~mL} / \mathrm{min}$. A (100\% H2O with $0.1 \%$ formic acid) and B (100\% acetonitrile with $0.1 \%$ formic acid)

1247 comprised the mobile phase. The gradient began with 5\% B for 30 seconds and then linearly

1248 increased to $99 \% \mathrm{~B}$ at 2 minute and then reduced to $5 \% \mathrm{~B}$ at 4.1 minutes to 5.5 minutes with a

1249 runtime of 6 minutes in total. The mass spectrometer was operated in positive mode; multiple

1250 reaction monitoring was used for analysis. The Q1 m/z and Q3 m/z was 487.9 and 401.1,

1251 respectively.

1252

1253 Statistical analyses

1254 Statistical analyses were performed in consultation with a bioinformatician. Graphs were

1255 plotted and statistical analyses were performed using GraphPad Prism software (version

1256 7.00/8.00, GraphPad, La Jolla, CA) and Microsoft Excel. Unpaired, two-sided analysis of

1257 variance (ANOVA) followed by multiple comparison analyses were used to analyze data as

1258 indicated. Survival analyses in animals were performed using Kaplan-Meier analyses with the

1259 Log-Rank test. Data were considered significant if $p$ values were below 0.05 (95\% confidence

1260 intervals).

1261

1262 Human studies 
1263 Informed consent was obtained for all patient samples. Two patients (CHCO01 and

1264 CHC002) were enrolled on an ongoing IRB-approved prospective observational study at

1265 Children's Hospital of Colorado for children and young adults with brain tumors undergoing

1266 patient-directed medical marijuana therapy (NCT03052738). The University of Michigan cohort

1267 consisted of retrospective interviews with families of patients who underwent research autopsy.

1268 The patients all underwent research autopsy consent and were contacted to confirm use of patient

1269 details and tumor samples for this study. Patients who reported CBD therapy at any point in their

1270 care were included in this study, and CBD dosage was confirmed by pictures of CBD bottle,

1271 discussion with dispensary, etc., when possible.

1272

1273

1274

1275

1276

1277

1278 
1279 Supplementary figures

A ScRNAseq

B

Figure S1

tumor vs. normal DFCI DIPG cohort $(n=4)$

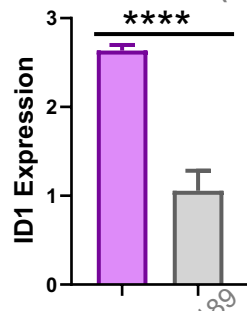

\begin{tabular}{|c|c|c|c|c|c|c|}
\hline Patient ID & Age [years] & Gender & Survival [months] & Location & K27M mutation & $\%$ ID1+ cells \\
\hline MUV10 & 9 & $\mathrm{~F}$ & 8 & Thalamus & H3F3A & $6 \%$ \\
\hline MUV1 & 4 & $F$ & $>22$ & Thalamus & H3F3A & $9 \%$ \\
\hline BCH1126 & 10 & $\mathrm{~F}$ & $>8$ & Pons & H3F3A & $35 \%$ \\
\hline ВСH869 & 7 & $\mathrm{~F}$ & 10,5 & Pons & H3F3A & $51 \%$ \\
\hline MUV5 & 2,5 & $M$ & $>19$ & Pons & HIST1H3B & $56 \%$ \\
\hline ВCH836 & 5 & $\mathrm{~F}$ & 3,5 & Pons & H3F3A & $69 \%$ \\
\hline
\end{tabular}

1280 Supplementary Figure S1. ID1 expression in DIPG by cell malignancy and tumor location.

1281 (A) ID1 expression of DIPG tumor by cell malignancy from the Dana-Farber Cancer Institute

1282 (DFCI) DIPG cohort ( $\mathrm{n}=4$ patients). ID1 expression was compared between malignant DIPG

1283 cells $(\mathrm{n}=1841)$ and non-malignant tumor cells $(\mathrm{n}=189)$ from single-cell RNA-seq (scRNA-seq)

1284 data. Data represent mean $+/-\mathrm{SEM} ; * * * * \mathrm{P}<0.0001$, unpaired parametric $\mathrm{t}$ test. (B) IDI is

1285 frequently (35-69\%) expressed in pontine DIPG cells and rarely (6-9\%) expressed in thalamic

1286 DMGs. 

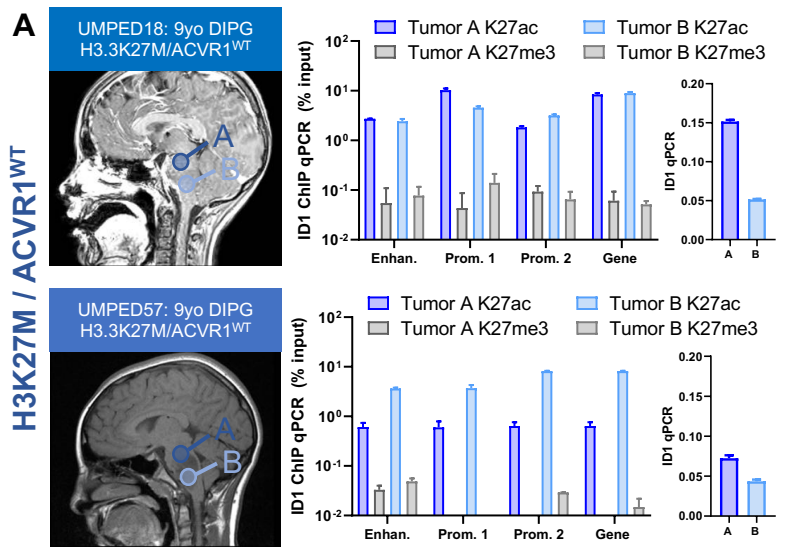

Figure S2
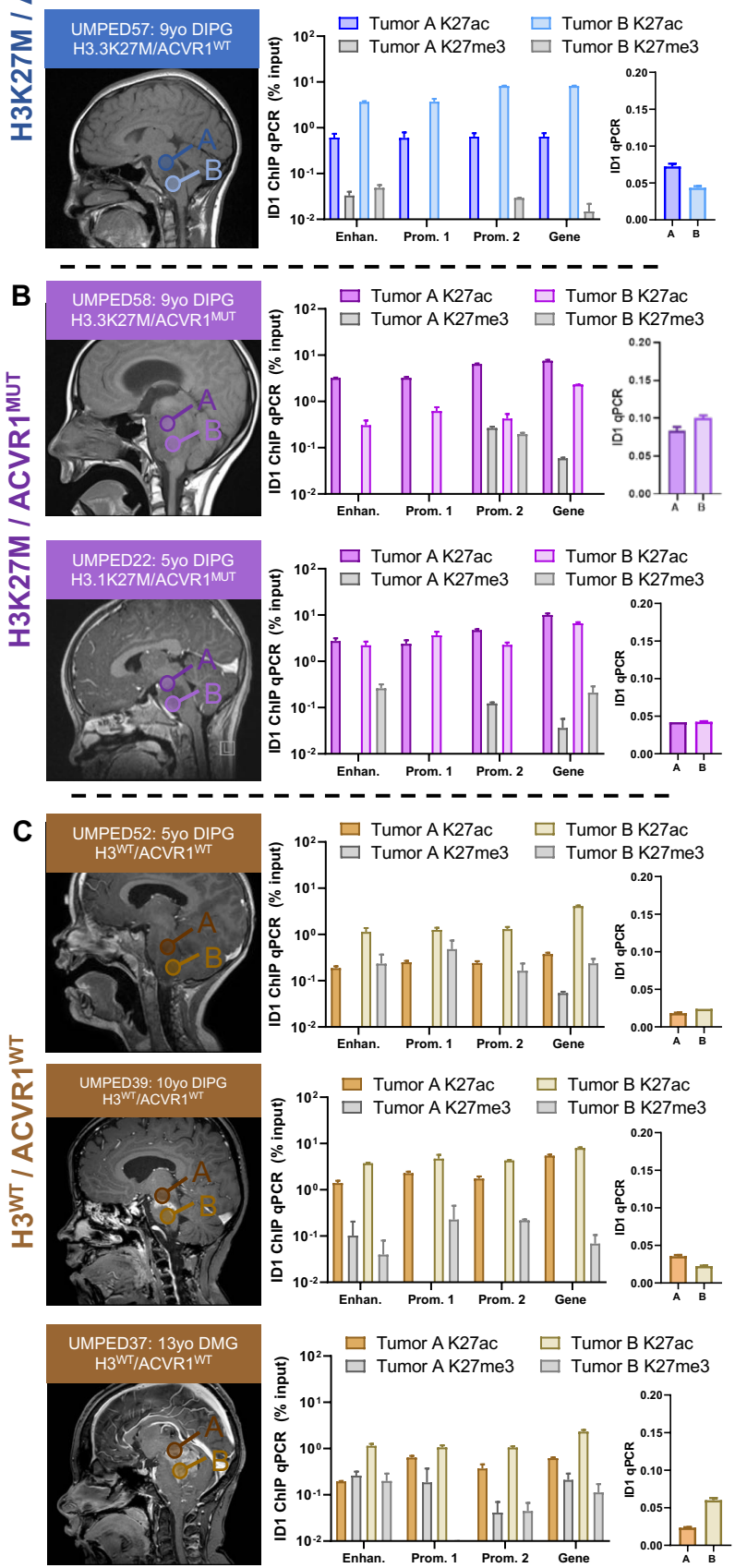

Supplementary Figure S2. Multifocal ChIP-qPCR analysis of ID1 expression in human

1289 DIPG. (A-C) [Left panel]: Multifocal DIPG tumor samples (2 per tumor) were obtained at

1290 autopsy from $\mathrm{n}=2$ patients with $\mathrm{H} 3 \mathrm{~K} 27 \mathrm{M}$ mutation and wildtype $A C V R 1$ (ACVR ${ }^{\mathrm{WT}}$ ), $\mathrm{n}=2$ 
1291 patients with $\mathrm{H} 3 \mathrm{~K} 27 \mathrm{M}$ mutation and $A C V R 1$ mutation (ACVR1 ${ }^{\mathrm{MUT}}$ ) and $\mathrm{n}=3$ patients with 1292 wildtype $\mathrm{H} 3\left(\mathrm{H} 3^{\mathrm{WT}}\right)$ and $A C V R 1$. Circles labeled "A" and "B" over MRI images represent the 1293 approximate region of tumor where a sample was obtained from. [Right panel]: Graphs on left 1294 represent percent relative enrichment for H3K27ac and H3K27me3 marks by ChIP-qPCR for 1295 each of the predicted IDI gene body elements shown in main figure 2. Graphs on right represent 1296 IDI expression, measured by qPCR, for the multifocal samples collected from patients in shown 1297 in left MRI images. Data represent mean +/- SEM. 
A ID1 expression is highest in AC-like DIPG cells

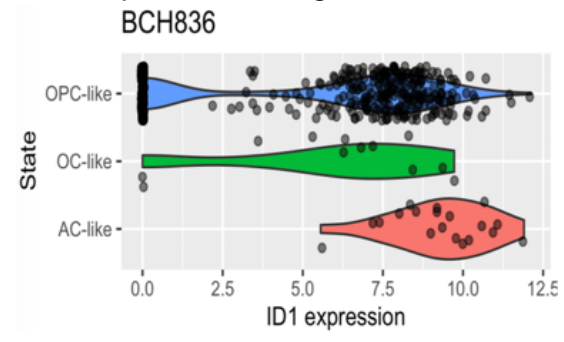

MUV5

BCH869
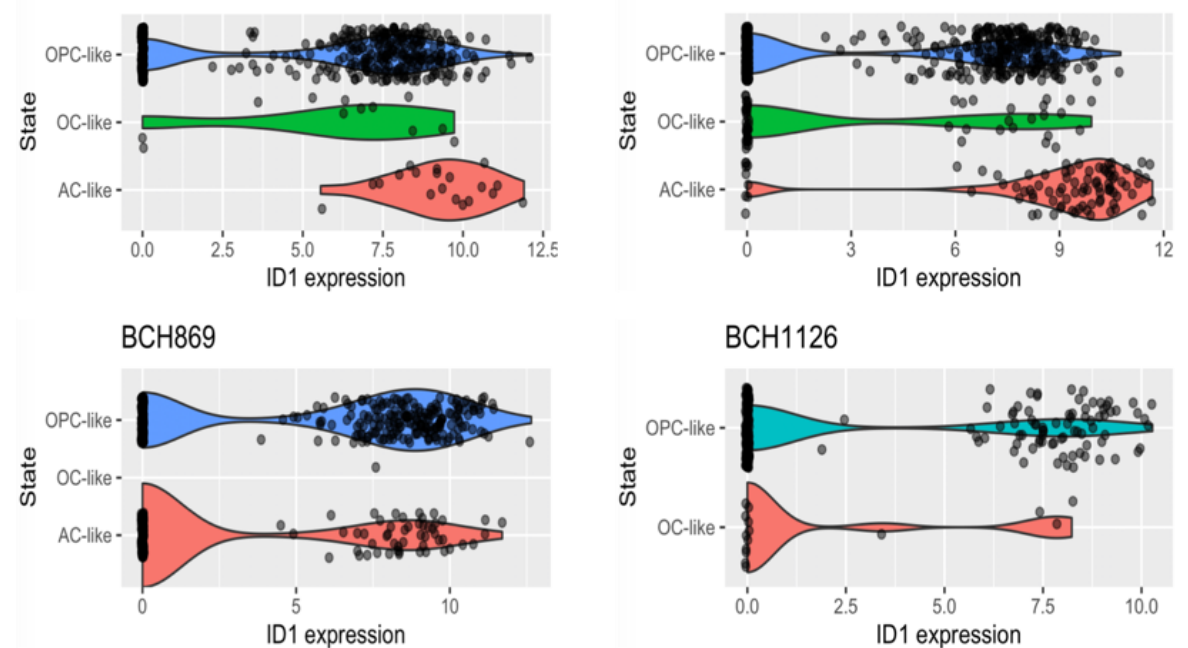

BCH1126

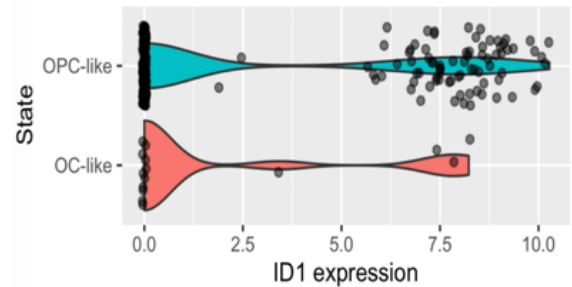

B ID1 expression is higher in cycling OPC-like DIPGs

H3K27M-mutant DIPG

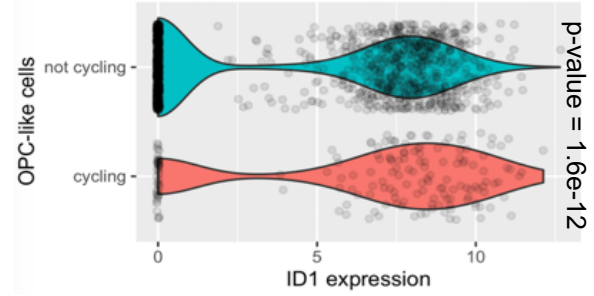

1311

1312 Supplementary Figure S3. ID1 expression from single cell RNA-sequencing of six different

1313 H3K27M-DMG patients across varying regions and malignant cell types. (A) Violin plots

1314 depicting ID1 expression in three subtypes of H3K27M-DIPG malignant cells [Data from

1315 pontine DIPG patients in Fig. 1B]. (B) Violin plots depicting ID1 expression in cycling vs non-

1316 cycling malignant H3K27M-DIPG cells; $\mathrm{P}=1.6 \mathrm{e}^{-12}$, Mann-Whitney U test. [OPC-

1317 Oligodendrocyte precursor cell; OC- Oligodendrocyte; AC- Astrocyte]. Primary data for parts

1318 (A) and (B) from Filbin et al., Science, 2018. 
Figure S4

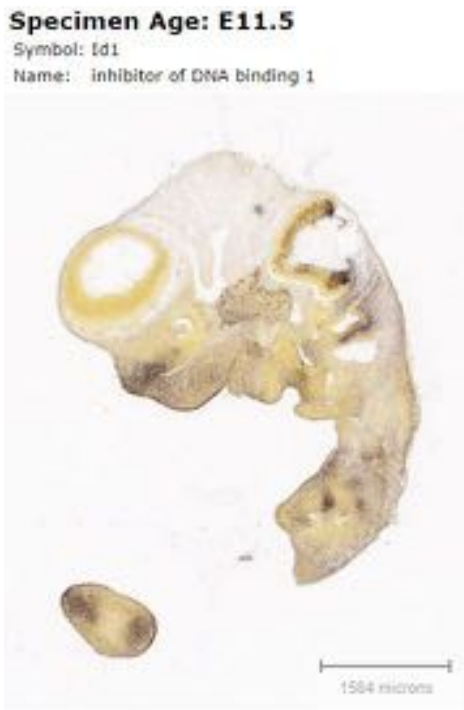

Specimen Age: E18.5

Symbol: $t d 1$
Name: inhlbitor of owA binding 1
Specimen Age: E13.S

Sprmbol: td1

of Dowa binding 1

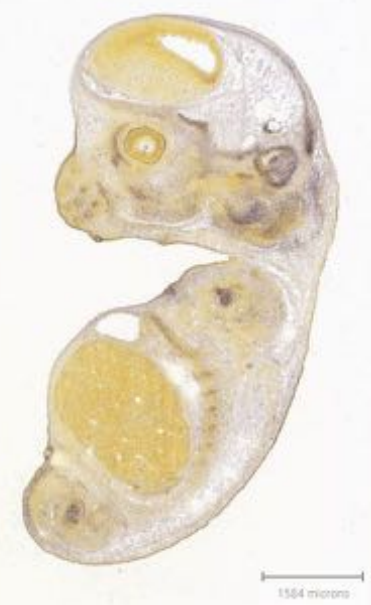

Specimen Age: E15.5

Symbol: Id 1

Name: inhibitor of DNA, binding a

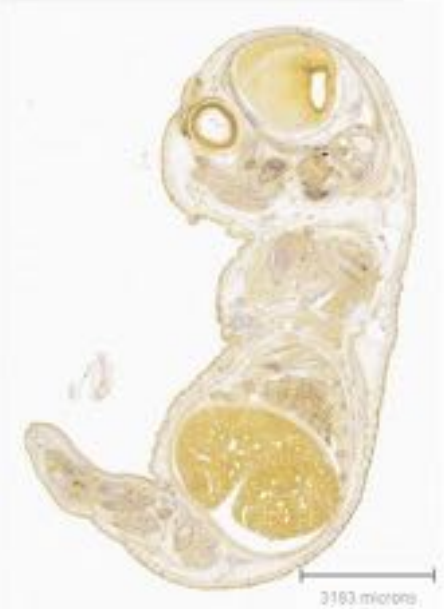

$$
\text { Specimen Age: P4 }
$$

Name: inhibitor of DNA binding 1
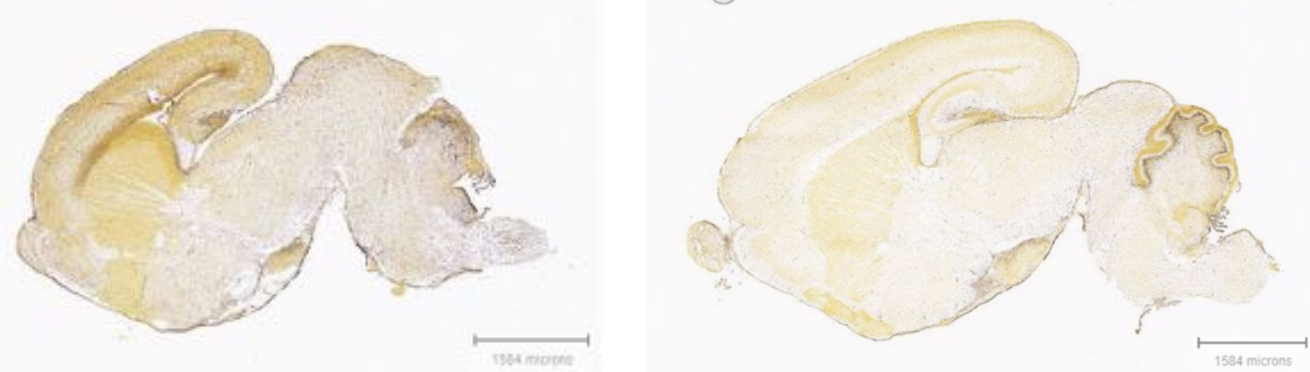

1319 Supplementary Figure S4. In situ hybridization for ID1 RNA in developing mouse brain.

1320 IDI RNA is high in the developing embryonic murine brain, and drastically reduced in the post-

1321 natal brain. Image credit: Allen Institute. (C) 2014 Allen Developing Mouse Brain Atlas.

1322 Available from: http://developingmouse.brain-map.org/ 
A

Figure S5

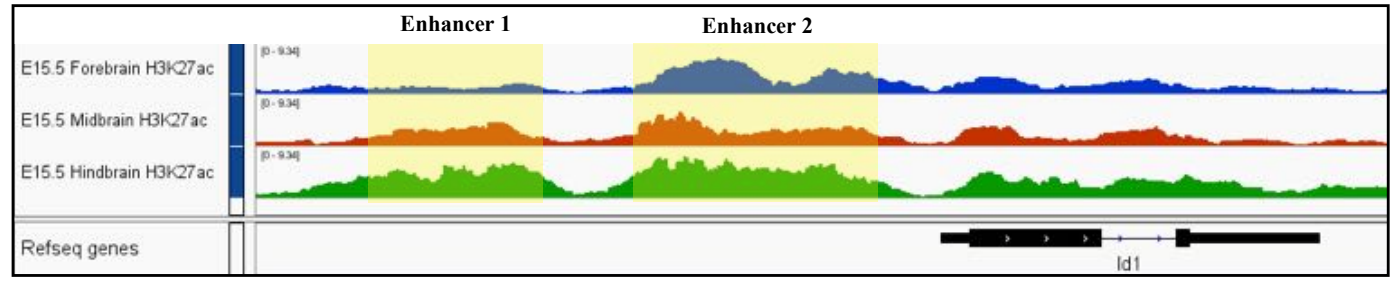

B $\quad 8 \quad H 3 K 27$ ac

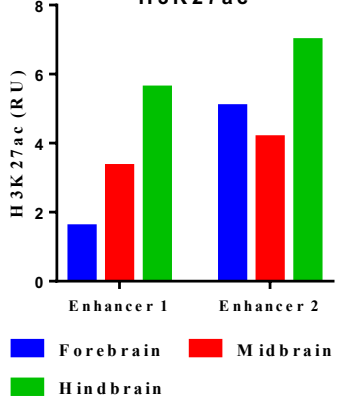

1327 Supplementary Figure S5. H3K27ac at ID1 locus during murine development. (A) H3K27ac

1328 peaks at the ID1 locus in E15.5 mouse brain and predicted ID1 enhancer regions [Image

1329 generated using IGV browser]. (B) Relative enrichment of H3K27ac at predicted ID1 enhancers

1330 in E15.5 murine brain regions. Data retrieved from ENCODE Consortium; highlighted regions

1331 quantified using EaSeq (http://easeq.net).

1332

1333

1334

1335

1336

1337

1338 
A ID1 expression in developing human pons

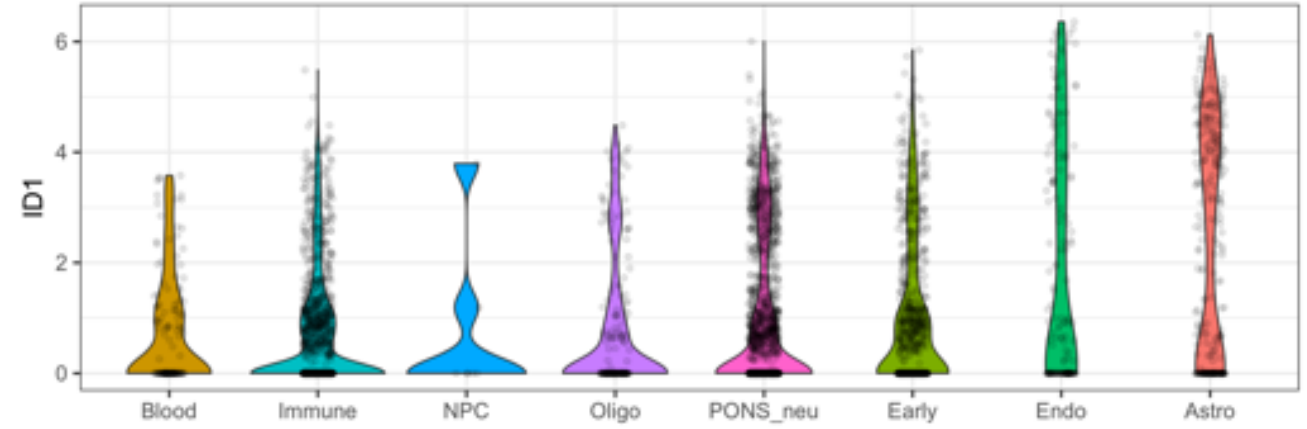

B ID1 expression in developing human pons

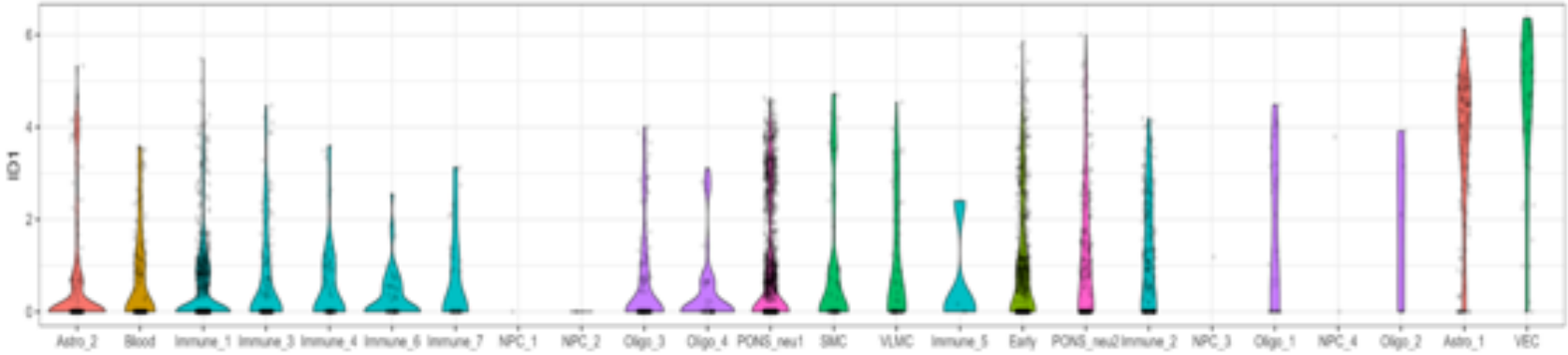

1339 Supplementary Figure S6. ID1 expression in varying cell types during normal murine

1340 pontine development. (A-B) Violin plots from analysis of Fan et al., Science Advances, 2020,

1341 depicting that AC-like cells show maximum ID1 expression during normal murine pontine

1342 development. Data points from all gestational weeks are combined for each cell type and sorted

1343 by median. [Astro- Astrocyte].

1344

1345

1346

1347

1348

1349

Figure S6 
A

(1)

B

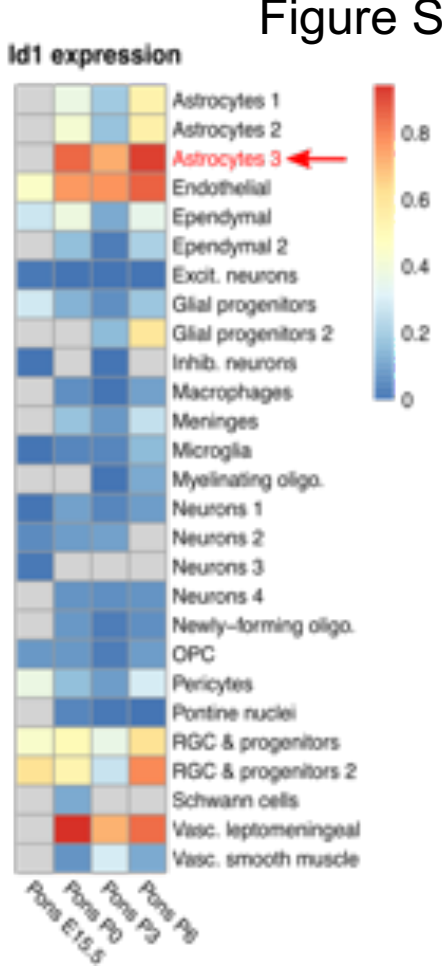

Supplementary Figure S7. ID1 expression from single-cell transcriptome analysis of

varying cell types in normal developing murine pons. (A) Single-cell ID1 expression in

varying cell types in normal murine pontine development. (B) Heatmap of ID1 expression during normal murine pontine development [E15.5- Embryonic day 15.5; P0- Postnatal day 0]. Red arrow indicates increased ID1 expression in astrocytes from P0-P6. Primary data for parts (A) and (B) from Jessa et al., Nature Genetics, 2019.

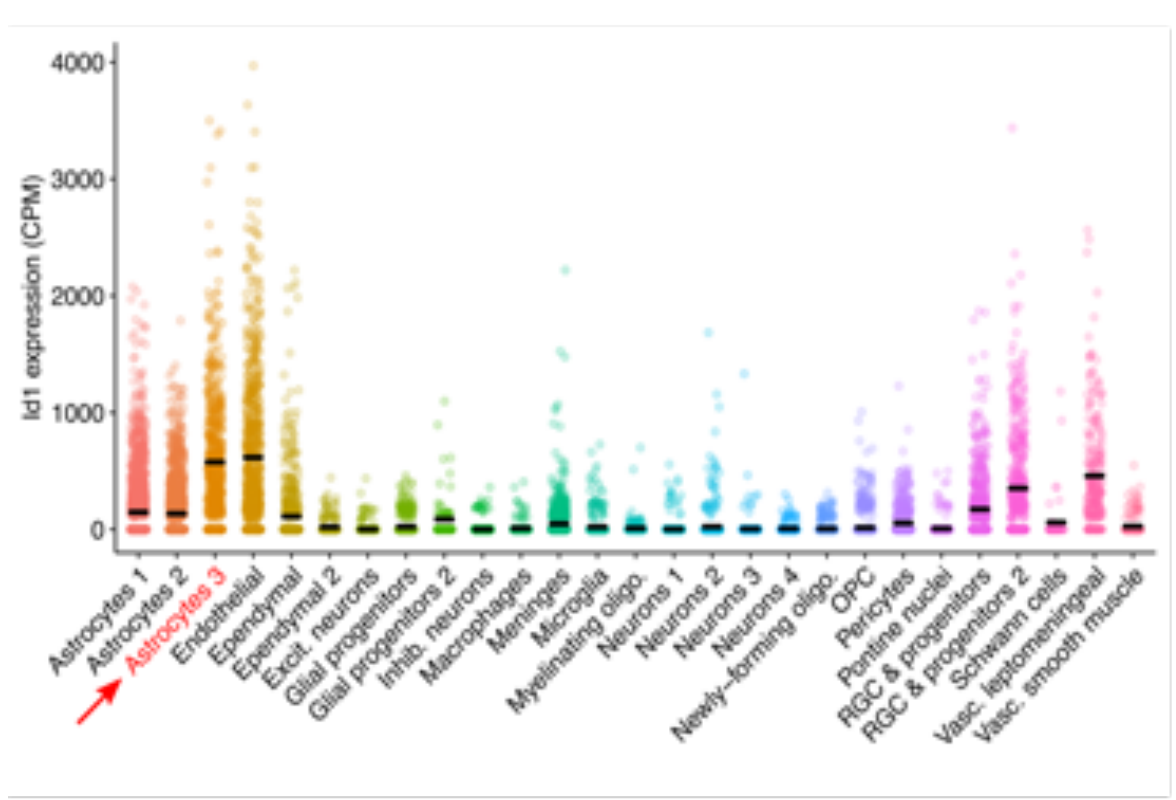



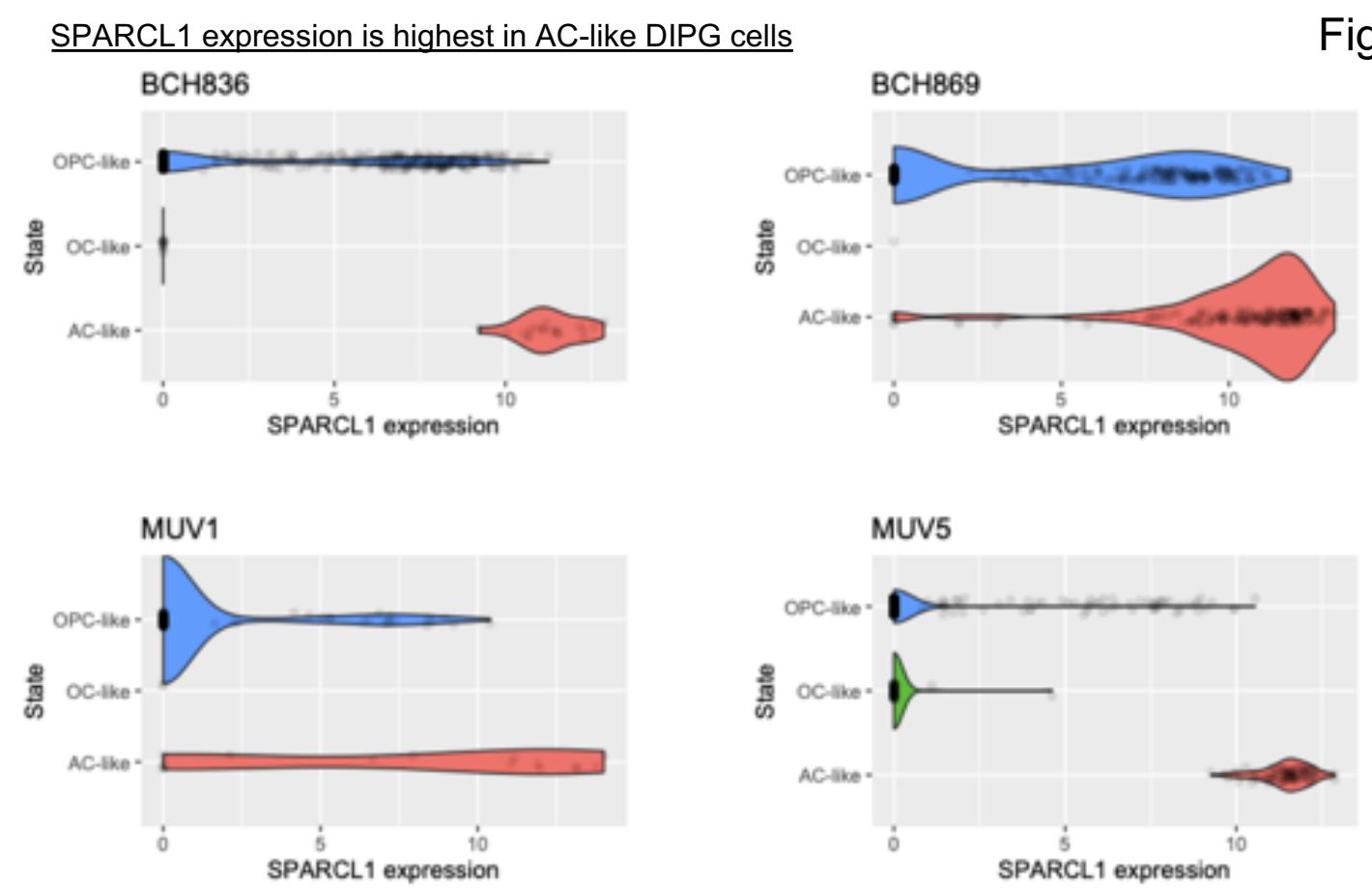

1362 Supplementary Figure S8. ID1 expression from single cell RNA-sequencing of four

1363 different H3K27M-DMG patients across varying malignant cell types. Violin plots depicting

1364 SPARCL1 expression in three subtypes of H3K27M-DIPG malignant cells [Data from pontine

1365 DIPG patients in Fig. S1B]. Primary data from Filbin et al., Science, 2018. Patients MUV5,

1366 BCH836, BCH869- pontine tumors. Patient MUV1- thalamic tumor. [OPC- Oligodendrocyte

1367 precursor cell; OC- Oligodendrocyte; AC- Astrocyte]. 
Figure S9

\begin{tabular}{|c|c|}
\hline \multicolumn{2}{|c|}{ 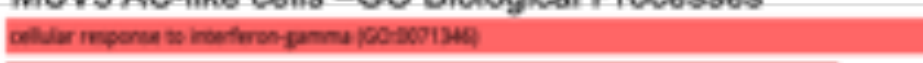 } \\
\hline 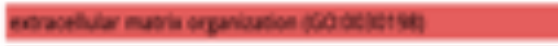 & $\longleftarrow$ \\
\hline 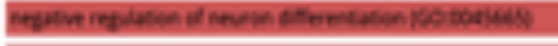 & \\
\hline 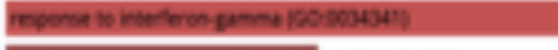 & \\
\hline 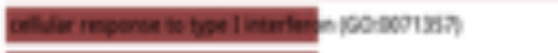 & \\
\hline 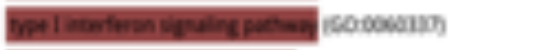 & \\
\hline 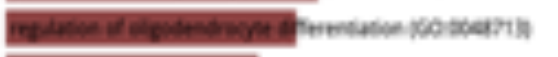 & \\
\hline 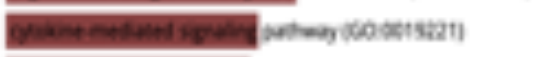 & \\
\hline 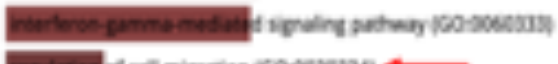 & \\
\hline
\end{tabular}

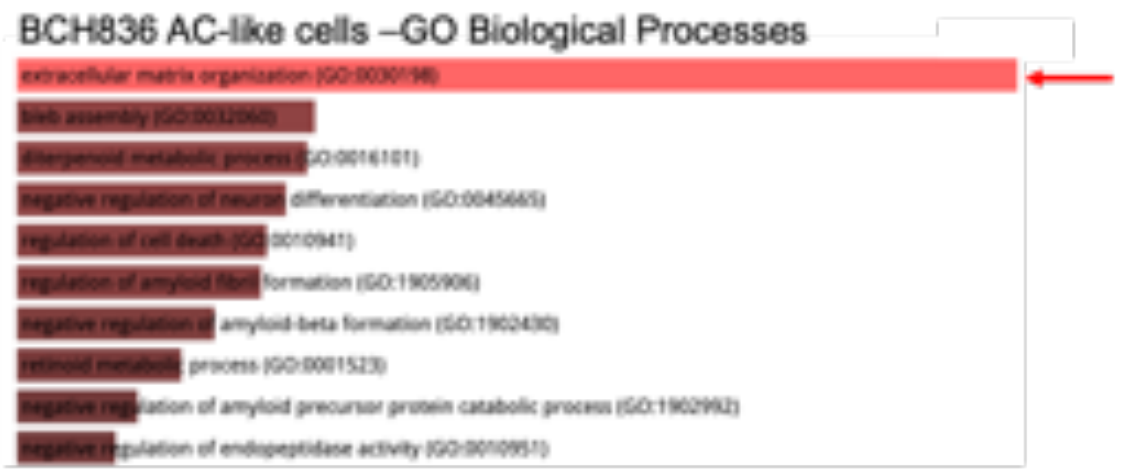

BCH869 AC-like cells -GO Biological Processes

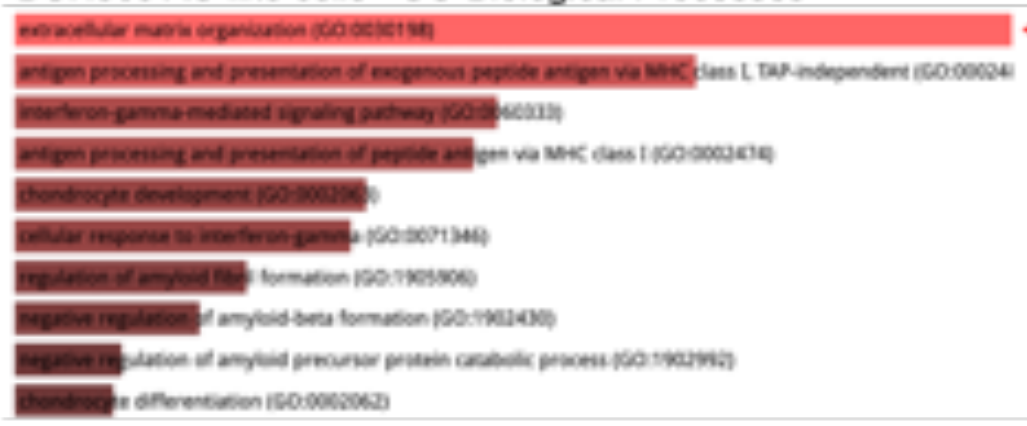

MUV1 AC-like cells -GO Biological Processes

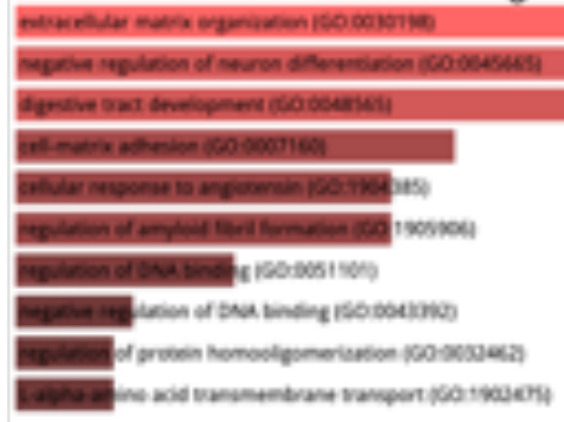


1370 Supplementary Figure S9. Gene ontology (GO) analysis of higher ID1-expressing AC-like

1371 cells from H3K27M-mutated tumor patients. GO analysis of primary data from Filbin et al.,

1372 Science, 2018, demonstrates increased expression of genes related to extracellular matrix

1373 organization and regulation of cell migration in AC-like cells. Patients MUV5, BCH836,

1374 BCH869- pontine tumors. Patient MUV1- thalamic tumor.

1375
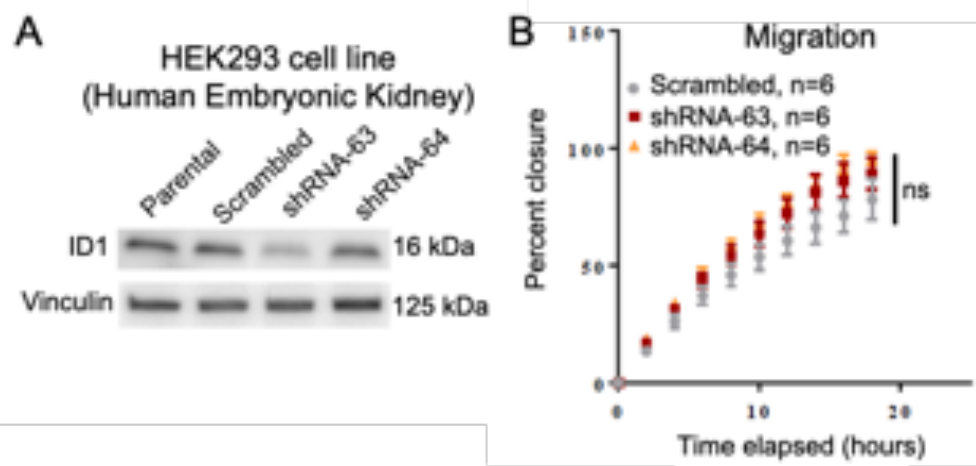

Figure S10

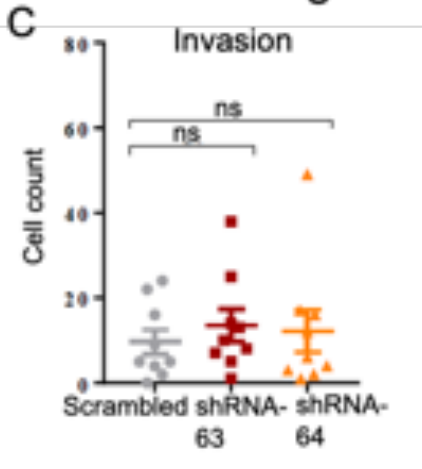

1376 Supplementary Figure S10. ID1 knockdown in HEK293 cells. (A) Western blot confirming

1377 ID1 knockdown in HEK293 cells. (B) Effect of ID1 knockdown on cell invasion, as measured by

1378 Matrigel-coated Boyden chamber assays. Each data point represents an individual image (4

1379 random images were taken per well). NS, P > 0.05, unpaired t test. (C) Effect of IDI knockdown

1380 on migration as measured by scratch assay. NS, $\mathrm{P}>0.05$, unpaired t test. 


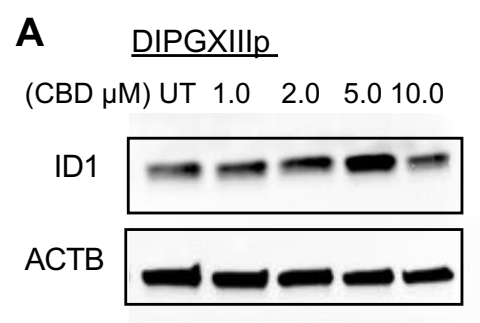

B Viability

Figure $\mathrm{S} 11$
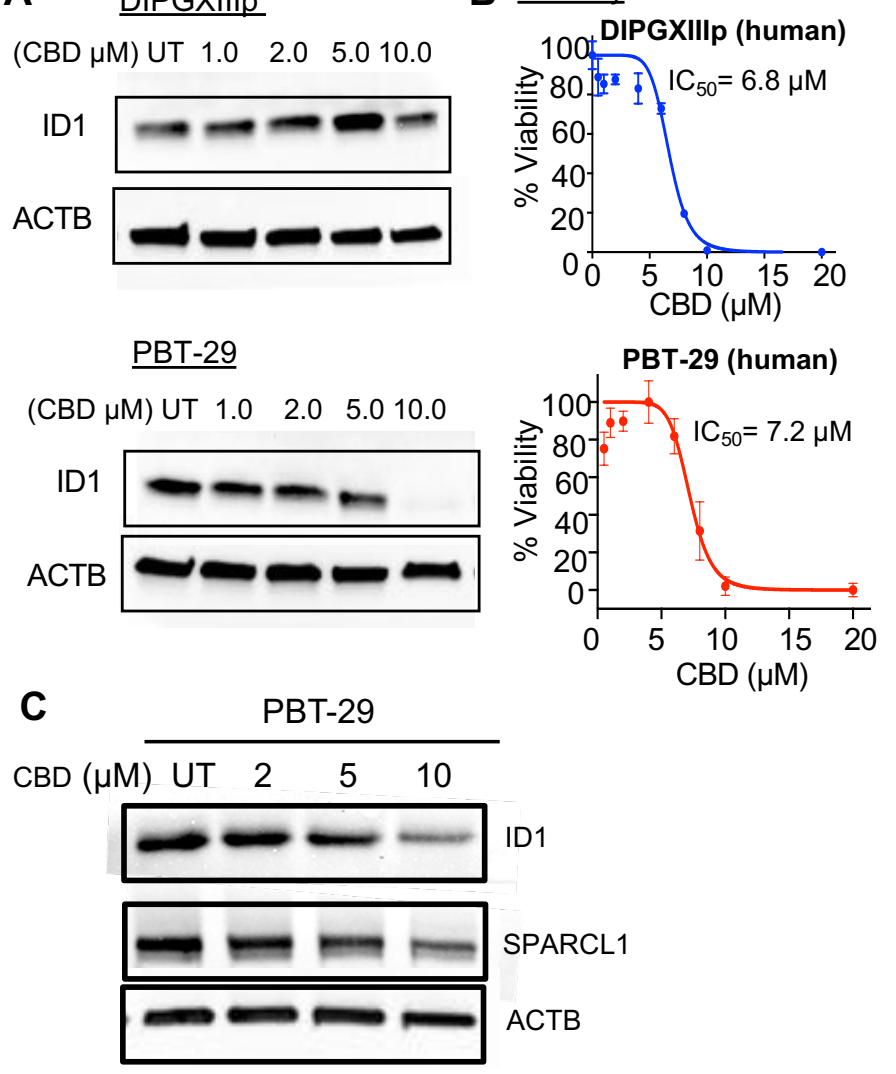

1382 Supplementary Figure S11. Impact of CBD treatment on ID1 expression in human DIPG

1383 cells. (A) ID1 western blot of human DIPGXIIp and PBT-29 cells treated with increasing

1384 concentrations of CBD, or DMSO control (UT- untreated). Expression levels of ID1 and ACTB

1385 were measured. (B) Viability of DIPGXIIIp and PBT-029 cells treated with increasing

1386 concentrations of CBD $(0.5 \mu \mathrm{M}$ to $20 \mu \mathrm{M})$ relative to DMSO-treated control. Experiment was

1387 completed in triplicate and data points represent mean +/- SEM. (C) Western blot of ID1 and

1388 SPARCL1 expression in PBT-29 cells treated with increasing concentrations of CBD or DMSO

1389 control (UT). Experiments for all western blots were completed in triplicate. 
A

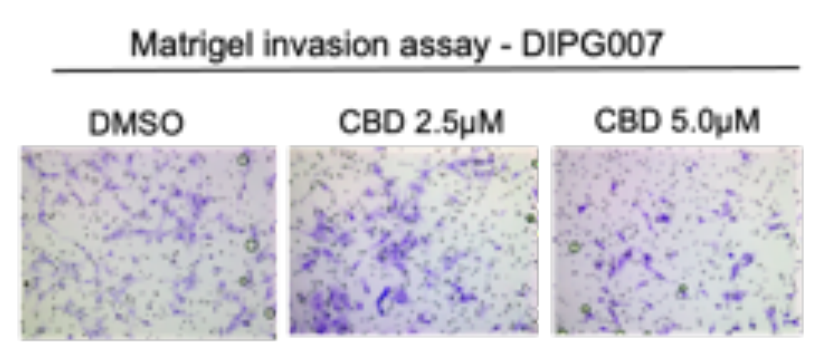

C

D

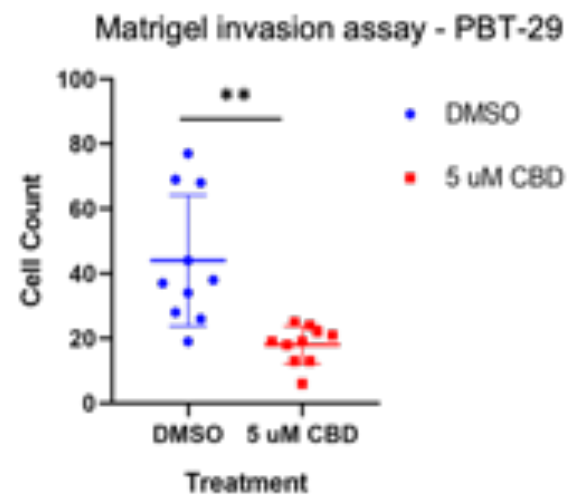

Figure $\mathrm{S} 12$
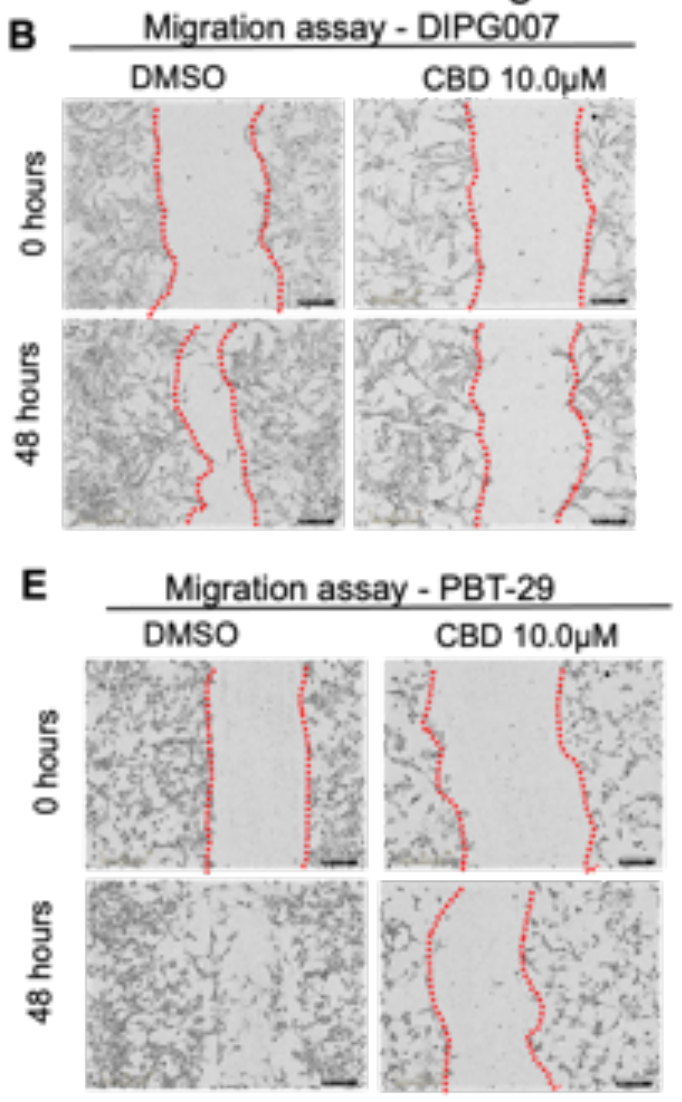

F

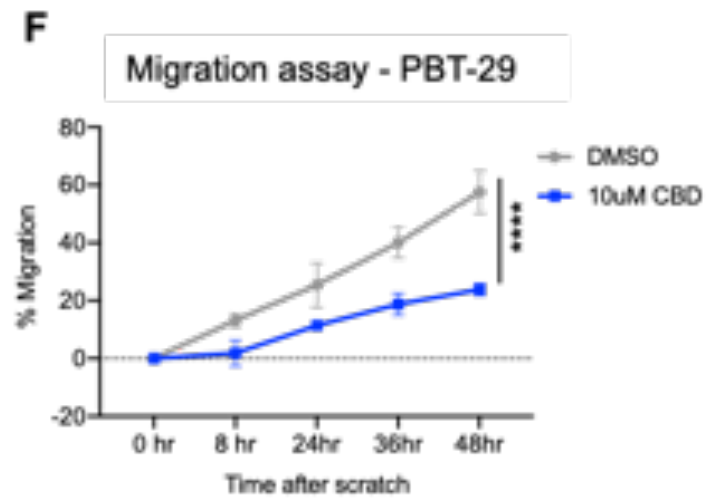

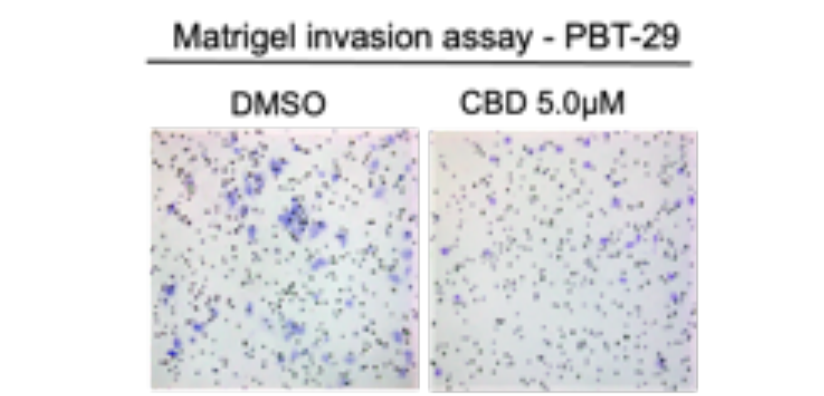

1392

\section{Supplementary Figure S12. Effect of pharmacologic (CBD) suppression of ID1 on DIPG007} and PBT-29 tumor cell invasion and migration. (A) Effect of CBD treatment $(2.5 \mu \mathrm{M}-5 \mu \mathrm{M})$

on invasion of human DIPG007 cells as measured by Matrigel-coated Boyden chamber assay. Images show invading cells stained with crystal violet. Number of invading cells were counted using ImageJ software. (B) Images displaying effect of CBD treatment (DMSO control vs 
$139710 \mu \mathrm{M}$ ) on DIPG007 cell migration as measured by scratch assay. (C) Effect of CBD treatment $1398(5 \mu \mathrm{M})$ on invasion of human PBT-29 cells as measured by Matrigel-coated Boyden chamber 1399 assay. (D) Quantification of invading PBT-29 cells treated with either DMSO (control) or $5 \mu \mathrm{M}$ $1400 \mathrm{CBD}$ shown in part $\mathrm{C}$ determined using ImageJ; ${ }^{*} \mathrm{P}<0.01$, unpaired parametric $\mathrm{t}$ test. (E-F) 1401 Images displaying effect of CBD treatment (DMSO control vs $5 \mu \mathrm{M}$ ) on PBT-29 cell migration 1402 as measured by scratch assay. Migration was quantified using ImageJ to determine percent 1403 wound (outlined with red dashed line) closure. Experiment was completed in triplicate. Data 1404 represent mean $+/-\mathrm{SEM} ; * * * * \mathrm{P}<0.0001$, unpaired $\mathrm{t}$ test. [Magnification for all images is $20 \mathrm{x}$ ]. 
Figure S13
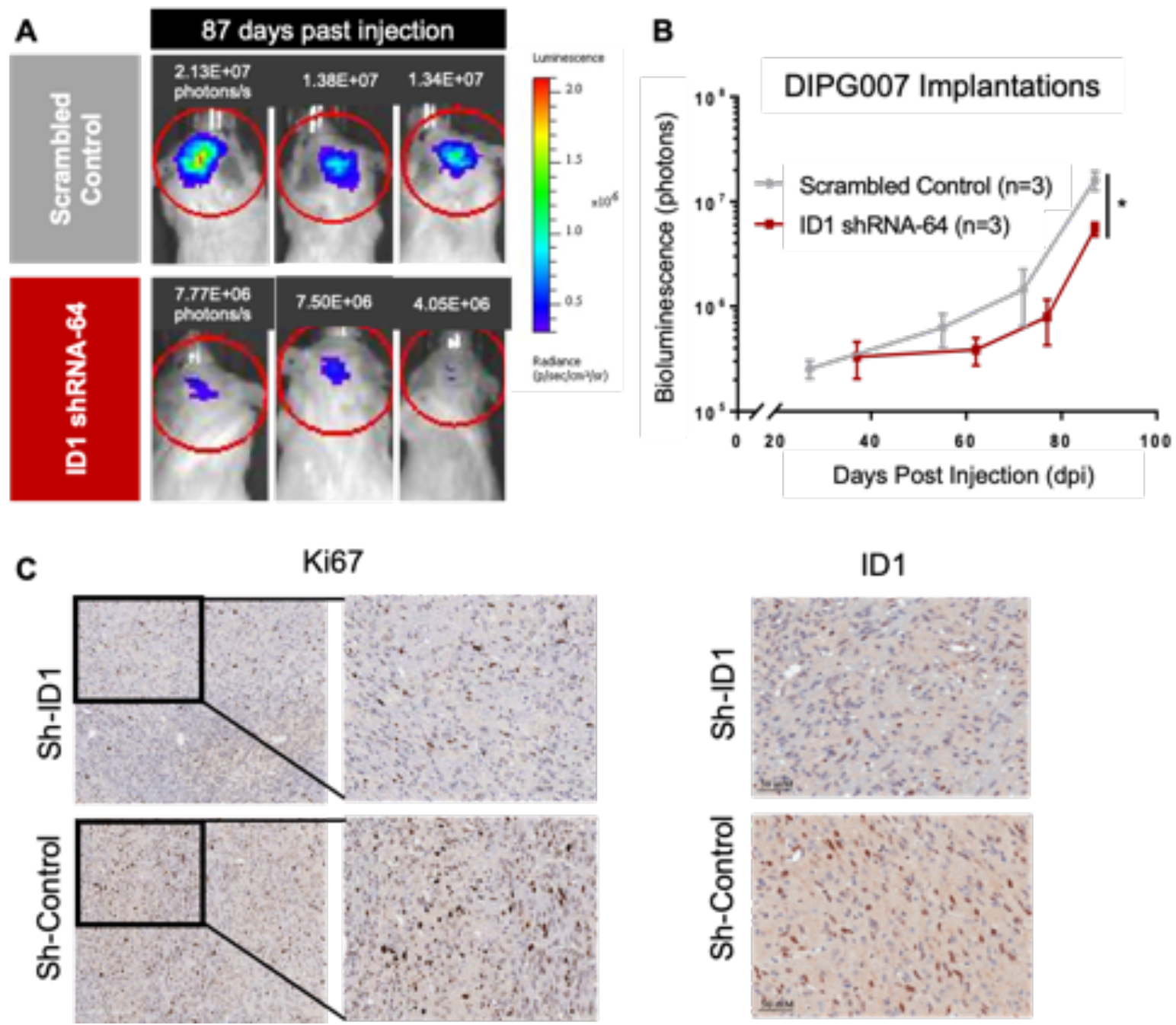

1408 Supplementary Figure S13. ID1-deficient human DIPG007 cells display slower tumor

1409 growth in in vivo model (A) Representative images of bioluminescent tumors from intracranial

1410 injection of scrambled-control or ID1-shRNA DIPG007 cells at DPI-97. (B) Bioluminescence of

1411 intracranially-injected scrambled or ID1-shRNA DIPG007 cells over days-post-injection. (C)

1412 Example images of IHC staining for Ki67 (left) and ID1 (right) in a sagittal tissue section

1413 (tumors generated from implantation of DIPG007 cells). Magnification is 20x. 
Figure S14
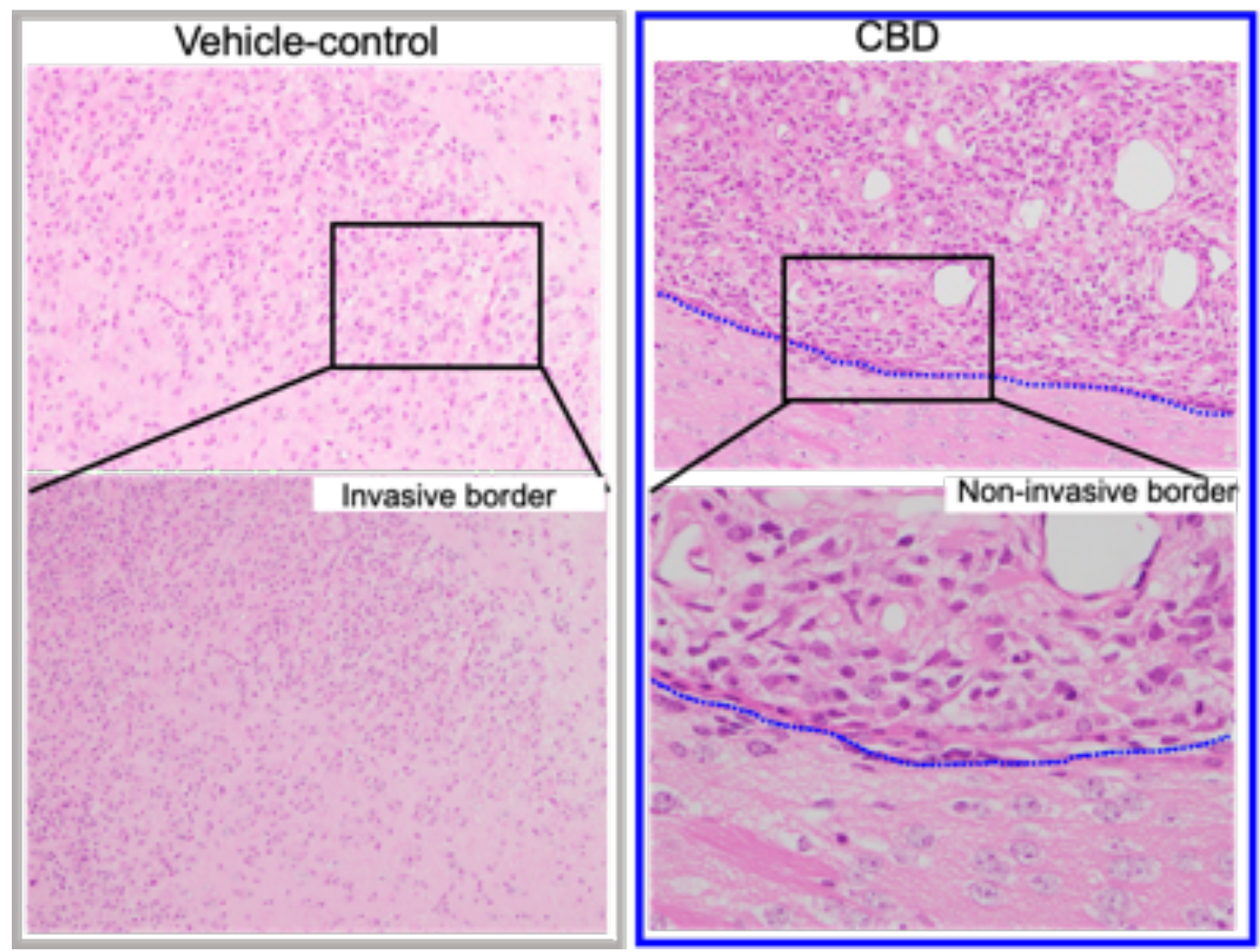

1415

1416 Supplementary Figure S14. Tumor cell invasion assessment in CBD- vs control-treated

1417 PPK mice. Images of IUE-generated PPK tumor borders treated with or without CBD (DMSO

1418 vs. $15 \mathrm{mg} / \mathrm{kg} \mathrm{CBD}$ ) for assessment of tumor cell invasiveness. Magnification for top row images

1419 is 10x and magnification for bottom row is $40 \mathrm{x}$. 
Figure S15

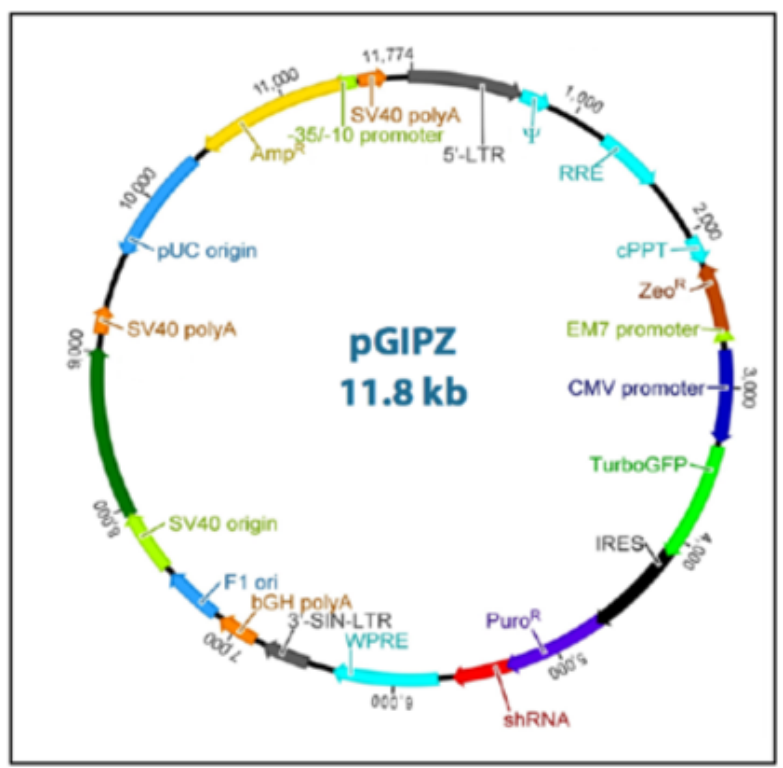

1430 Supplementary Figure S15. Detailed vector map of pGIPZ lentiviral vector. Lentivirus

1431 vector backbone used for ID1-targeting shRNA constructs. Image credit: Dharmacon. Available

1432 from: https://dharmacon.horizondiscovery.com/uploadedFiles/Resources/gipz-lentiviral-shrna-

1433 manual.pdf

Supplementary Table S1. Primer sequences for use in ChIP-qPCR and qPCR

\begin{tabular}{|c|c|c|c|}
\hline Primer & Forward & Reverse & Species \\
\hline $\begin{array}{c}\text { ID1 } \\
\text { Enhancer }\end{array}$ & CTGGCGTCTAACGGTCT & CTGCGGAGCTACAGTCT & Human \\
\hline $\begin{array}{c}\text { ID1 Promoter } \\
1\end{array}$ & GAGGCTGGACCTAGGAG & GAGCCACAGCTTGTCTTT & Human \\
\hline $\begin{array}{c}\text { ID1 Promoter } \\
2\end{array}$ & CTCTCATTCCACGTTCTTAAC & CTGGCGACTTTCATGATTC & Human \\
\hline $\begin{array}{c}\text { ID1 Gene } \\
\text { Body }\end{array}$ & AGATCCAGATCCGACCAC & AGGTACCCGCAAGGATG & Human \\
\hline $\begin{array}{c}\text { PAX4 } \\
\text { Promoter }\end{array}$ & TGGCTGAGGACTGGATCTTT & CTGGAGACAACAGCTGTCCA & Human \\
\hline
\end{tabular}

Primers for use in $\mathrm{qPCR}$ for gene expression analysis

\begin{tabular}{|c|c|c|c|}
\hline Primer & Forward & Reverse & Species \\
\hline ID1 & CGAGGCGGCATGCGTTC & GGAGACCCACAGAGCACGTAAT & Human \\
\hline GAPDH & CGCTCTCTGCTCCTCCTGTT & CCATGGTGTCTGAGCGATGT & Human \\
\hline
\end{tabular}




\section{Supplementary Table S2. Clinical details of pediatric HGG patients treated with CBD.}

\begin{tabular}{|c|c|c|c|c|c|c|c|}
\hline Patient ID & Age & Diagnosis & Molecular & $\begin{array}{l}\text { Therapies } \\
\text { given }\end{array}$ & $\begin{array}{l}\text { Time to first } \\
\text { progression }\end{array}$ & $\begin{array}{l}\text { Overall } \\
\text { survival } \\
\text { from } \\
\text { Diagnosis }\end{array}$ & $\begin{array}{l}\text { CBD duration/dosing/toxicity } \\
\text { noted }\end{array}$ \\
\hline CHCOO1 & 11 & $\begin{array}{l}\text { DMG, } \\
\text { H3K27M } \\
\text { (thalamus) }\end{array}$ & $\begin{array}{l}\text { H3K27M } \\
\text { mutant }\end{array}$ & Radiation & 24 months & $\begin{array}{l}40 \text { months } \\
\text { (still alive) }\end{array}$ & $\begin{array}{l}\text { CBD } 2.5 \mathrm{~g} \mathrm{mg} \mathrm{(} 0.07 \mathrm{mg} / \mathrm{kg} / \text { day); } \\
\text { PO daily; CBD therapy started } \\
\text { adjuvantly after initial radiation }\end{array}$ \\
\hline $\mathrm{CHCOO2}$ & 15 & $\begin{array}{l}\text { DMG, H3 WT } \\
\text { (bi-thalamic) }\end{array}$ & $\begin{array}{l}\text { H3 WT; } \\
\text { BARD1 E19* } \\
\text { mutation; } \\
\text { increased } \\
\text { tumor } \\
\text { mutational } \\
\text { burden }\end{array}$ & $\begin{array}{l}\text { Radiation; } \\
\text { TMZ/CCNU; } \\
\text { olaparib; } \\
\text { pembrolizumab }\end{array}$ & 14 months & 26 months & $\begin{array}{l}\text { CBD } 50 \mathrm{mg}(0.8 \mathrm{mg} / \mathrm{kg} / \text { day); PO } \\
\text { BID (+THC); CBD therapy started } \\
\text { at diagnosis }\end{array}$ \\
\hline UMPED18 & 9 & $\begin{array}{l}\text { DMG, } \\
\text { H3K27M } \\
\text { (brainstem, } \\
\text { DIPG) }\end{array}$ & $\begin{array}{l}\text { H3F3A } \\
\text { K27M; } \\
\text { PIK3CA } \\
\text { E545K; } \\
\text { TCF12 } \\
\text { V650D }\end{array}$ & $\begin{array}{l}\text { Radiation } \\
\text { (+AZD-1775); } \\
\text { panobinostat + } \\
\text { everolimus }\end{array}$ & 8 months & 10 months & $\begin{array}{l}\text { CBD } 300 \text { (13 mg/kg/day) + THC; } \\
\text { no toxicity; PO daily; therapy } \\
\text { started at radiation - taken until } \\
\text { passing }\end{array}$ \\
\hline UMPED22 & 5 yo & $\begin{array}{l}\text { DMG, } \\
\text { H3K27M } \\
\text { (brainstem, } \\
\text { DIPG) }\end{array}$ & $\begin{array}{l}\text { HIST1H3B } \\
\text { K27M; } \\
\text { ACVR1 } \\
\text { G328E }\end{array}$ & $\begin{array}{l}\text { Radiation; } \\
\text { hyper-baric O2; } \\
\text { Re-irradiation }\end{array}$ & 9 months & 12 months & $\begin{array}{l}\text { CBD } 45 \mathrm{mg}(2 \mathrm{mg} / \mathrm{kg} / \text { day })+\mathrm{THC} \text {; } \\
\text { PO BID or TID; therapy started at } \\
\text { radiation - taken until passing }\end{array}$ \\
\hline UMPED37 & 13 & $\begin{array}{l}\text { DMG, H3 WT } \\
\text { (bi-thalamic) }\end{array}$ & $\begin{array}{l}\text { H3 WT; EGFR } \\
\text { V292L; EGFR } \\
\text { in-frame } \\
\text { deletion; } \\
\text { deletion } \\
\text { CDKN2C }\end{array}$ & $\begin{array}{l}\text { Chemotherapy } \\
\text { (thioguanine, } \\
\text { procarbazine, } \\
\text { lomustine, and } \\
\text { vincristine); } \\
\text { Radiation; } \\
\text { osimertinib; } \\
\text { bevacizumab }\end{array}$ & 5 months & 17 months & $\begin{array}{l}\text { CBD } 150 \mathrm{mg} \text { ( } 3 \mathrm{mg} / \mathrm{kg} / \mathrm{day} \text { ) after } \\
\text { radiation -> } 50 \mathrm{mg} \text { ( } 1 \mathrm{mg} / \mathrm{kg} / \mathrm{day} \text { ), } \\
\text { until passing due to nausea; PO } \\
\text { daily; therapy started at radiation } \\
\text { - taken until passing }\end{array}$ \\
\hline UMPED56 & 8 yo & $\begin{array}{l}\text { DMG, } \\
\text { H3K27M } \\
\text { (brainstem, } \\
\text { DIPG) }\end{array}$ & $\begin{array}{l}\text { HIST1H3B } \\
\text { K27M; } \\
\text { ACVR1 } \\
\text { R206H }\end{array}$ & $\begin{array}{l}\text { Radiation; } \\
\text { ONC201; } \\
\text { bevacizumab }\end{array}$ & 13 months & 24 months & $\begin{array}{l}\mathrm{CBD}(0.6 \mathrm{mg} / \mathrm{kg} / \mathrm{day})+\mathrm{THC} ; \mathrm{PO} \\
\text { daily; therapy started at radiation } \\
\text { - taken until passing }\end{array}$ \\
\hline UMPED58 & 9 yo & $\begin{array}{l}\text { DMG, } \\
\text { H3K27M } \\
\text { (brainstem, } \\
\text { DIPG) }\end{array}$ & $\begin{array}{l}\text { H3F3A } \\
\text { K27M; ATRX } \\
\text { Q119*; } \\
\text { PPM1D } \\
\text { G463fs; } \\
\text { PDGFRA } \\
\text { amplification }\end{array}$ & $\begin{array}{l}\text { Radiation; } \\
\text { multi-agent } \\
\text { intra-arterial; } \\
\text { ONC201 }\end{array}$ & 18 months & 21 months & $\begin{array}{l}\text { CBD (? Dose) + THC; PO or per } \\
\text { rectum daily; therapy started at } \\
\text { radiation - taken until passing }\end{array}$ \\
\hline UMPED65 & $\begin{array}{l}16 \\
\text { yo }\end{array}$ & $\begin{array}{l}\text { DMG, } \\
\text { H3K27M } \\
\text { (brainstem, } \\
\text { DIPG) }\end{array}$ & $\begin{array}{l}\text { H3F3A } \\
\text { K27M; TP53; } \\
\text { PIK3CA }\end{array}$ & $\begin{array}{l}\text { Radiation; } \\
\text { ONC201; } \\
\text { panobinostat; } \\
\text { re-irradiation; } \\
\text { paxilisib }\end{array}$ & 16 months & 24 months & $\begin{array}{l}\mathrm{CBD}(0.3 \mathrm{mg} / \mathrm{kg} / \mathrm{day}) ; \mathrm{PO} \mathrm{BID} / \mathrm{TID} \text {, } \\
\text { intermittent early in therapy, } \\
\text { stopped } 7 \text { months prior to } \\
\text { passing }\end{array}$ \\
\hline UMPED67 & 7 yo & $\begin{array}{l}\text { DMG, } \\
\text { H3K27M } \\
\text { (thalamus) }\end{array}$ & $\begin{array}{l}\text { H3F3A } \\
\text { K27M; TP53 } \\
\text { C277F; NF1 } \\
\text { H2434fs }\end{array}$ & $\begin{array}{l}\text { Radiation; } \\
\text { ONC201; re- } \\
\text { irradiation; } \\
\text { bevacizumab }\end{array}$ & 10 months & 15 months & $\begin{array}{l}\mathrm{CBD}(0.7 \mathrm{mg} / \mathrm{kg} / \mathrm{day})+\mathrm{THC} ; \mathrm{PO} \\
\text { daily; therapy started at } \\
\text { radiation, stopped } 4-5 \text { months } \\
\text { prior to passing }\end{array}$ \\
\hline
\end{tabular}




\begin{tabular}{|c|c|c|c|c|c|c|c|}
\hline UMPED69 & 4 yo & $\begin{array}{l}\text { DMG, } \\
\text { H3K27M } \\
\text { (brainstem, } \\
\text { DIPG) }\end{array}$ & $\begin{array}{l}\text { HIST1H3B } \\
\text { K27M }\end{array}$ & $\begin{array}{l}\text { Radiation; } \\
\text { convection- } \\
\text { enhanced } \\
\text { delivery (CED) } \\
\text { trial; re- } \\
\text { irradiation; } \\
\text { ONC201; } \\
\text { paxalisib }\end{array}$ & 13 months & 28 months & $\begin{array}{l}\mathrm{CBD} 9 \mathrm{mg}(0.5 \mathrm{mg} / \mathrm{kg} / \mathrm{day})+\mathrm{THC} \text {; } \\
\mathrm{PO} \text { TID; therapy started at } \\
\text { radiation - taken until passing }\end{array}$ \\
\hline UMPED83 & $\begin{array}{l}11 \\
\text { yo }\end{array}$ & $\begin{array}{l}\text { DMG, } \\
\text { H3K27M } \\
\text { (thalamus) }\end{array}$ & $\begin{array}{l}\text { H3F3A } \\
\text { K27M; TP53 } \\
\text { S241C }\end{array}$ & $\begin{array}{l}\text { Chemotherapy } \\
\text { (temozolomide, } \\
\text { irinotecan, } \\
\text { bevacizumab); } \\
\text { Radiation; } \\
\text { ONC201 }\end{array}$ & 36 months & 60 months & $\begin{array}{l}\mathrm{CBD} 1500 \mathrm{mg}(25 \mathrm{mg} / \mathrm{kg} / \mathrm{day})+ \\
\mathrm{THC} \text {; PO TID; therapy started at } \\
\text { radiation, stopped one year prior } \\
\text { to passing }\end{array}$ \\
\hline UMPED86 & 7 yo & $\begin{array}{l}\text { DMG, } \\
\text { H3K27M } \\
\text { (brainstem, } \\
\text { DIPG) }\end{array}$ & $\begin{array}{l}\text { HIST1H3B } \\
\text { K27M; } \\
\text { ACVR1 } \\
\text { G328E; } \\
\text { PI3KCB; } \\
\text { PPM1D }\end{array}$ & $\begin{array}{l}\text { Radiation; } \\
\text { ONC201; Re- } \\
\text { irradiation }\end{array}$ & 6 months & 8 months & $\begin{array}{l}\text { CBD } 3 \mathrm{mg}(0.4 \mathrm{mg} / \mathrm{kg} / \text { day); PO } \\
\text { TID or QID; therapy started at } \\
\text { radiation - taken until passing }\end{array}$ \\
\hline UMPED97 & 16 & $\begin{array}{l}\text { Cortical } \\
\text { anaplastic } \\
\text { astrocytoma }\end{array}$ & $\begin{array}{l}\text { H3 WT; Tp53 } \\
\text { R342* } \\
\text { (+germline); } \\
\text { CDK4 gain; } \\
\text { KRAS gain }\end{array}$ & $\begin{array}{l}\text { Chemotherapy } \\
\text { (procarbazine, } \\
\text { CCNU, and } \\
\text { vincristine); } \\
\text { Radiation; } \\
\text { irinotecan and } \\
\text { bevacizumab }\end{array}$ & 5 months & 19 months & $\begin{array}{l}\mathrm{CBD} 400 \mathrm{mg}(6 \mathrm{mg} / \mathrm{kg} / \mathrm{day}) \text { after } \\
\text { radiation, until passing due to } \\
\text { nausea; } \mathrm{PO} \text { twice daily } \\
\text { (Epidiolex); therapy started at } \\
\text { radiation - taken until passing }\end{array}$ \\
\hline UMPED101 & 6 & $\begin{array}{l}\text { DMG, } \\
\text { H3K27M } \\
\text { (brainstem, }\end{array}$ & $\begin{array}{l}\text { H3F3A K27M } \\
\text { mutant }\end{array}$ & $\begin{array}{l}\text { Radiation; } \\
\text { ONC201; re- } \\
\text { irradiation; } \\
\text { bevacizumab }\end{array}$ & 10 months & 14 months & $\begin{array}{l}\text { CBD } 600 \mathrm{mg} \text { ( } 24 \mathrm{mg} / \mathrm{kg} / \mathrm{day}) \text { PO } \\
\text { TID; CBD therapy started after } \\
\text { radiation - taken until passing }\end{array}$ \\
\hline
\end{tabular}

